RT

511

\title{
RECRUITING AND SELECTION
}

THEIR PRACTICES IN BANKS

OPERATING IN LEBANON

\section{A RESEARCH TOPIC}

Presented to the Graduate Faculty

LEBANESE AMERICAN UNIVERSITY

In Partial Fulfillment

of the Requirements for the Degree

Master of Science

In

Buisness Management

BY

NADA JAMIL EL HAJJ

JUNE , 1995

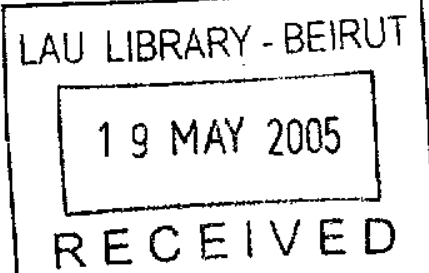




\title{
BEIRUT UNIVERSITY COLLEGE \\ P.O.BOX 98 13-5053 \\ BEIRUT, LEBANON
}

APPROVAL OF RESEARCH TOPIC

\begin{abstract}
CANDIDATE Nada H. KASSEM HAJJ

DATE June 28,1988

DEGREE MASTER OF SCIENCE BUSINESS MANAGEMENT ADVISOR Dr. HaMd1 F. ALI

TITLE OF RESEARCH TOPIC A DIscriminant Function Model for

Undergraduate Admissions at Beirut UnIversity College
\end{abstract}

The following professors nominated to serve as the advisors of the above candidate have approved her research work.

ADVISOR

SECOND READER
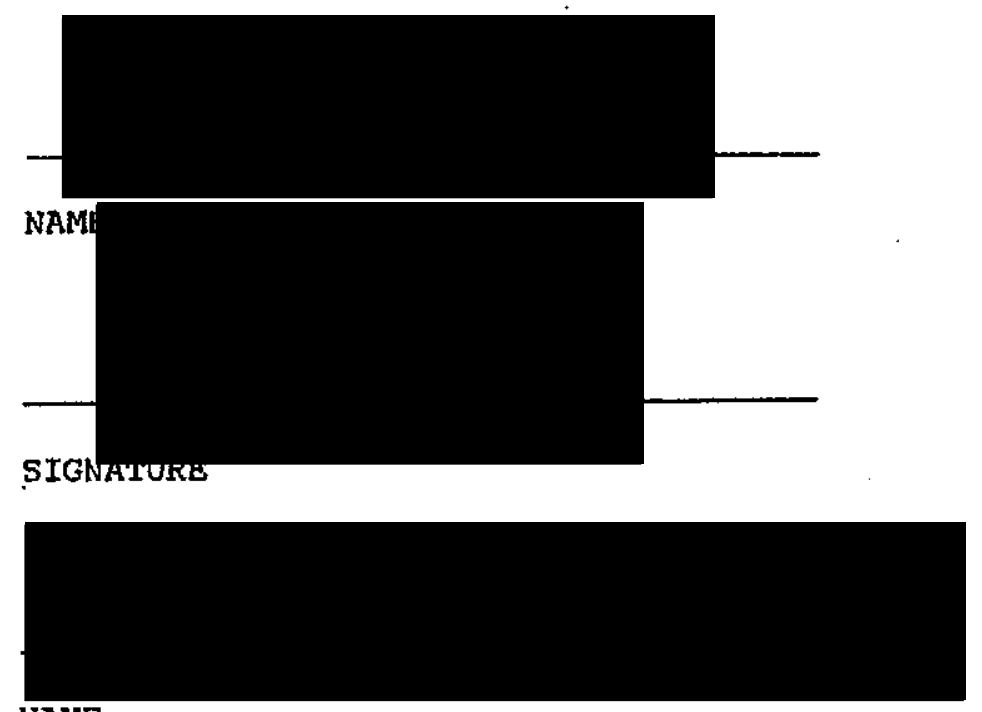

$$
\text { NAME }
$$

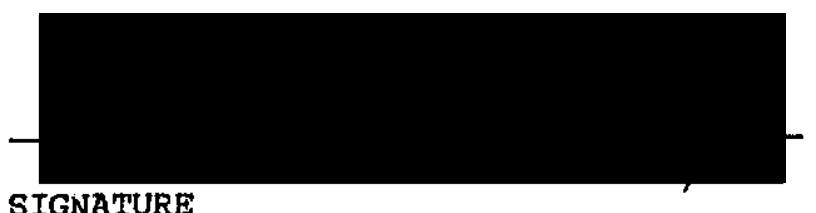

SIGNATURE 


\section{ABSTRACT}

The success of any organization depends largely on those called to carry out its operations and to achieve its goals, employees. Employees are then the most valuable assets in any organization, especially in labor intensive and service businesses such as Banks. Therefore, acquiring this new "Human Asset " should receive the same importance or even more importance than acquiring a new fixed asset.

The main purpose of this research is to assess the adequacy of recruiting and selection processes followed by banks operating in Lebanon. In addition, this research aims at studying the impact of recruiting an selection on employee satisfaction and turnover.

Based on the results obtained, it was found that the recruiting process is adequate but it needs some improvements. while it was found that the selection process in most of the banks contacted is below standard. It was also found that employee satisfaction and turnover are dependent on the adequacy of placement and recruiting policies.

Therefore, to secure the placement of the right person in the right place, to increase employee satisfaction, and to reduce employee turnover among new hires, it is recommended that the personnel managers should be personnel oriented, they should always update their knowledge through seminars and readings in personnel materials, they should assess the effectiveness of their recruiting and selection processes continuously to correct any mistakes in them, they should treat all recruits at all positions equally. Finally, they are recommended to try the use of recruitment software applications that facilitate their work and save a lot of their time. 


\section{TABLE OF CONTENTS}

\section{CHAPTER ONE}

INTTRODUCTION

1.1 Historical background

1.2 functions of the Personnel Department

1.3 Employment and the Human Resources Management System

1.4 Need for the Study

1.5 General statement of the Problem

1.6 Research questions and Hypotheses

1.7 Purpose of the Study

1.8 Limitations of the Study

1.9 Construction of the Study

\section{CHAPTER TWO}

LITERATURE REVIEW

\subsection{Introduction}

2.2 The Employment Process

2.2.1 Human Resources Planning

2.2.2 Determination of Position Requirements

2.2.2.1 Factors Affecting the Employment Process

2.2.2.1.A External Factors

2.2.2.1.A Internal Factors

\subsubsection{Recruiting}

2.2.3.A The Recruiting Process

2.2.3.B Internal Versus External Recruiting

2.2.3.C Methods of Internal Recruiting

2.2.3.D External Sources of Recruiting 


\subsubsection{Selection}

2.2.4.1 Basic principles of Selection

2.2.1.2 The Selection Process

2.2.4.3 Reliability \& Validity of Selection Tools

2.2.4.4 Selection Tools

2.2.4.4.A Application Blank

1- Content of the Application Blank

2- Limitations of Application Blanks

3- Weighted Application Blank

2.2.4.4.B Testing

1- Policies in Testing

2- Types of Tests

2.2.4.4.C Interviews

1- Preparation for the Interview

2- Types of Interviews

3- Guidelines for an Effective Interview

2.2.4.4.D Background Investigations

1- Sources \& Methods

2.3 Evaluation of the Employment Process

2.3.1 Job Satisfaction

2.3.2 Productivity

CHAPTER THREE

RESEARCH METHODOLOGY

3.1 The Population and the Sample

3.2 Methods Used in Data Collection

3.3 Measurements of the Independent Variables

3.4 Measurements of the Dependent Variables

3.5 Research Methodology 
CHAPTER FOUR

\section{FINDINGS OF THE STUDY}

4.1 Characteristics of the Respondents and the Banks

4.1.1 Characteristics of the Respondents

4.1.A Characteristics of the Personnel Managers

4.1.B Characteristics of the Employees

4.1.2 Characteristics of the Banks

4.2 Factors Affecting Employment

4.3 Assessment of the Recruiting Process

4.4 Assessment of the Selection Process

4.4.1 Selection Tests

4.4.2 Selection Interviews

4.4.3 Reference Checks

4.5 Correlation - Multiple Regression Analysis

4.6 Crosstabulations and Chi-Square Tests

CHAPTER FIVE

SUMMARY AND RECOMMENDATIONS

5.1 Introduction

5.2 Descriptive Analysis

5.3 Regression Analysis

5.4 Crosstabulations and chi-square Tests

5.5 Recommendations

5.6 Implications for Future Research 


\section{CHAPTER I \\ INTRODUCTION}

\subsection{Historical Background:}

In this age of increasing mechanization it is more than ever essential to spend a considerable amount of time in assessing the effectiveness of equipments available to ensure that these can be operated to the maximum advantage. Systems and procedures too must be examined frequently to ensure their effectiveness and their ability to lead to an orderly work flow.

Technical considerations are then a vital part of the management function; however, they can not achieve optimum results. No matter how effective the machines and systems are, the success of any organization depends on those called to use these machines and systems and to carry out the operations - the employees. Managing human resources must be equally considered if an organization is to survive and prosper.

Human resources management is a modern term that appeared during the 1970s. However, personnel departments first appeared in a significant number in the 1940s. With the creation of labor unions in 1935, organizations found themselves involved in collective bargaining and in resolving labor grievances. With the beginning of world war II, improved personnel procedures were developed to manage the recruitment of the large number of soldiers needed to serve in the military. The military then developed modern selection, training, and evaluation procedures which were subsequently used by organizations. Among these procedures one can cite tests which were used as a cost effective 
method of selecting pilots, and performance evaluations that were used to select officers for promotion'.

At that time, personnel departments were primarily responsible for employee selection, training and record keeping. Today, these activities are still core functions in human resources management along with other functions that were added to help the organization adapt to the ever changing environment.

Many factors have contributed to the growing importance of the personnel function:

1- Workers kept on demanding their organizations to accomodate their demands for better work schedules, more benefits, better work conditions etc.... This persuaded personnel departments to be involved in new personnel activities and labor relations ${ }^{2}$.

2- Competition, new technologies and the expanding scientific information turned management into a complex job demanding higher degrees of skills and expertise. This forced executives to seek personnel managers assistance in such matters as recruiting, selection, and compensation ${ }^{3}$.

3- The composition of employees has changed. In the past, organizations accepted women to work in their businesses and placed them in low positions since at that time the majority of married women used to leave their jobs once they get pregnant. However, nowadays mothers are still staying in their work and are asking to be placed in positions that match their skills and knowledge 4 .

4- The fourth and the highly important factor is the increased cost of personnel problems that pushed managers to direct their efforts to control them. The cost of personnel problems is considered the largest 
expense in an organization because of such problems as tardiness, absenteeism, and turnover. Besides, the main source of business bankruptcies is employees' mistakes resulting from poor selection and training programs. Now, managers are coming to recognize that the effectiveness of the human resources function has a substantial impact on the performance of the organization; Poor selection results in spurts of hirings followed by layoffs, poor performance evaluation leads to low compensation and high employee dissatisfaction etc ${ }^{5} \ldots$

\subsection{Functions of the Personnel Department:}

The ultimate responsibility of the personnel department is to maximize the use of human resources. This human resources utilization necessitates effective and careful selection, training and developing, appraising, and rewarding employees so that they contribute to the achievement of the organization's goals.

The basic personnel functions can be performed in any type of organizations; however, banks have specific needs and goals that make their application different from what it is in other organizations. A bank is composed of so many different departments; for instance, trust services have little relationship with lending services with each of them requiring varying skills and knowledge 6 .

The responsibility over the personnel functions varies with the size of the bank $^{7}$. A small bank with fewer than 80 employees usually does not have a human resources department or a human resources manager (a specific person for this responsibility); however personnel functions are performed by line 
managers. For example, the functions of recruiting, hiring, training and performance evaluation (if it is formally evaluated) are generally discharged by line managers directly responsible for the person being hired or evaluated; compensation decisions are also made by line managers and the payroll is handled by the finance officer. If the bank is larger, the coordination of personnel functions is handled by a specific full-time or part-time employee. As the bank becomes larger, separate positions are created and placed under the direction of a human resources manager. At this stage the personnel department generally includes supervisors in the areas of employment, compensation and benefits, and training and development. In large banks, the personnel officers have easier access to whatever type of information about employees; they usually rely on computerized personnel systems to make most of their decisions. In a small bank, on the other hand, personnel officers have to rely on first-hand information since the cost of search for information is not worth getting a computerized system ${ }^{8}$.

Whatever the size of a bank one can identify the five key personnel functions:

\section{1 - Compensation and Rewarding of Employees:}

An effective compensation and rewarding function is an important factor in attracting new employees, in preventing employee turnover and job dissatisfaction, in improving employee productivity, and increasing the bank profitability and competence. This function should be based on the coordination of the operating manager and the personnel manager. The role of the operating manager is to recommend salaries and rewards for his employees based on his knowledge of their performance and the role of the personnel manager is to set their salaries based on that information? 
A major mistake committed by personnel managers is their reliance on monetary rewards to compensate and motivate employees ${ }^{10}$. They ignore that nowadays employees needs are becoming more and more complex. Employees are no more satisfied by monetary rewards only; they have a wider range of non monetary needs to satisfy. They are looking for inner or psychological satisfactions through more opportunities to learn and grow and more possibilities to use their skills and talents. Personnel managers should be aware of these needs and must understand how to utilize both extrinsic and intrinsic rewards to motivate employees to perform better.

\section{2 - Training and Development:}

Training and Development $(T \& D)$ are important activities that must be performed in banks of all sizes. Every bank, regardless of its size, needs to have well trained employees to perform their jobs. A mistake of a non skilled employee may lead to bankruptcy especially if it is of a small size ${ }^{11}$.

Training plays a large part in determining the effectiveness and efficiency of a bank. The cost of a successful $\mathrm{T} \& \mathrm{D}$ program is negligent as compared to benefits that it produces; an effective T \& $\mathrm{D}$ program ${ }^{12}$ :

- $\quad$ Provides an effective cure for absenteeism, turnover and dissatisfaction with the work assigned to the employee.

- $\quad$ Improves the quality of employee work.

- Creates more favorable loyalty and cooperation.

- $\quad$ Reduces the number of mistakes.

- Reduces the learning time spent by employees when they are left to learn by themselves. 
However, to secure an effective T \& D program, banks should pay attention to two common mistakes. First, training should not stop once the person learns a job well. Learning should be a continuous process since there are always changes and new creations in bank services and a bank that is not up- to- date suffers losses of reputation and customers ${ }^{13}$.

Second, personnel departments should always avoid what normally happens in most banks. In these banks, the more a person knows and performs his task, the less his opportunity will be to learn another task. After a time the person's job becomes a routine and he will either become resistant to change or he will leave the bank to seek changes elsewhere. Training in more than one area reduces employees boredom, increases their knowledge, and provides a flexibility of staff that is an essential requirement of an efficient business. Learning how to perform more than one job results, in the long run, in a job done better by fewer employees and at a reduced cost. It also eliminates chaos and delay of work that usually occur when the only person who knows the job is absent ${ }^{14}$.

\section{3 - Performance Appraisal:}

Performance appraisal is the measurement of employee performance. It provides records on which managers rely in their decisions regarding salaries, promotions, demotions, and firing. These records help also in indentifying training needs; they inform managers which individuals need additional training. An effective performance evaluation program facilitates the establishment of skills and abilities to perform a job and in setting performance standards for each job. Besides, it provides individuals with a feedback on 
their performance for their own personal development. The feedback for employees acts as a motivator for better work and as a means of discovering personal weaknesses so that they can work to eliminate them and to improve their future performance ${ }^{15}$.

The responsibility for evaluating the performance of employees is generally shared between the human resources department (HRD) and the supervisor of the employee whose performance is being appraised. The HRD is responsible for the development of effective performance evaluation forms and of ensuring that performance evaluations are conducted uniformly and fairly throughout the bank. Immediate supervisors have the prime responsibility for evaluating their subordinates: They are the ones observing their performances, so they are best able to make accurate evaluations ${ }^{16}$.

\section{4 - Personnel Research:}

Personnel research is concerned with the gathering, analysis and interpretation of data. This function permeates all the other personnel functions. It provides information that may be used for improving $\mathrm{T} \& \mathrm{D}$, performance evaluation, recruiting and selection. For instance, research on the types of employees who have proven to be successful helps the organization in its recruiting and selection activities.

This function, as other personnel function is shared between the human research officer and line managers. The line manager's role is to provide the research officers with information about their employees, and the research officer's role is to gather additional information, analyse them and come up with conclusions ${ }^{17}$. 


\section{5 - Employment:}

Investing in human resources, especially in banks and service companies, is as important or even more important than investing in fixed assets. Banking is a labor intensive business where employees are banks most valuable assets. Therefore, as banks make elaborate studies and researches before acquiring a certain type of computers, they should also spend enough time in selecting the best prospects available for every level, from bookkeeper to officer.

The aim of selection is to match or align the abilities of the job candidate with the requirements of the vacancy. Selecting employees and placing them in positions for which they do not fit is very costly; time and efforts will be spent correcting placement mistakes through training, transfer, or firing. Therefore, banks are required to place a greater emphasis on this function. They must make sure that employment officers understand the bank in which they are working and the position to be filled, communicate and cooperate with the supervisors of the openings so that they come up with a clear definition of the skills and competences needed for a successful job performance ${ }^{18}$.

Finally, Employment is a multiple step process from assessing human resources needs, to establishing criteria, recruiting and finally selecting. Besides, this process is not set once and for ever; it should be always be modified as changes take place either internally or externally. For example, with the introduction of computers, banks have recently added "Computer Literacy" as a criterion for the selection of some candidates. 


\subsection{Employment and the Human Resources Management System:}

The Human resources management system is concerned with the process and activities concerned with the acquisition, utilization, developing and rewarding of employees in an organization; it consists of the five key human resources functions mentioned before. Employment is the function that sets the other functions in motion and is highly influenced by them ${ }^{19}$ :

A - Employment and compensation: An inadequate compensation program results in a constant recruiting and selection since employees leave the bank to find a better pay elsewhere. While an equitable compensation program increases the opportunity of attracting a sufficient number of employees and retaining well qualified ones ${ }^{20}$.

B - Employment and Training and Development: A bank which has gained a good reputation for developing an excellent T \& D program for their employees finds it easier to attract and retain qualified ones. Also employee turnover may decrease because employees are reluctant to leave a bank that provides the needed skills a knowledge for their personal development ${ }^{21}$.

C - Employment and Performance Appraisal: Working in a bank without periodic appraisal of performance is as attending a course without being graded. A bank that develops an effective performance evaluation program will secure a group of employees of high caliber, while a bank that does not make periodic performance appraisals will suffer the leave of its most efficient employees who will seek better salaries elsewhere and the retention of poor ones.

The lack of a performance appraisal program means that a bank applies a program of uniform salary increments for all employees making little difference between the star performer and the weaker employee. This will force the bank 
to spend on frequent selections to replace those who quit the bank to search for a new institution where they can be fairly treated ${ }^{22}$.

D - Employment and Personnel Research: Personnel research provides employment officers with valuable information to improve their recruiting and selection activities. Data of such kind as the source of employees who proved to be most successful and to have a permanent stay with the bank saves the employment officers money and time in searching in various recruiting sources. Also, information gathered through research may be used to make modifications in staffing practices, to revise procedures, or to develop new policies in an effort to render recruiting and selection more effective ${ }^{23}$.

Obviously all parts of the human resource management system should be integrated in order to function as a system. Employment is affected by everything that occurs in human resources management; when the other four personnel functions are effective, staffing is positively affected; while, when they are ineffective employment costs and efforts are triggered.

\subsection{Need for the study}

The introduction of new banking services has led to an intense competition between banks. In the coming few years, the banks that will succeed and increase their market shares are those banks that will succeed in providing the new competitive services. Even if banks are capable money wise and technical wise in providing these services, they can not excel in this domain unless they possess employees and officers of high caliber. Therefore, the effectiveness of 
employment procedures is the core of successful banking services ${ }^{24}$. Effective employment procedures insure the provision of effective services, the employment of highly skilled employees, the match of an individual's skills with the position requirements, and the reduction of employee dissatisfaction and turnover.

Since personnel managers control and direct employment activites and are those individuals generally responsible of employment decisions, it is important to study the effectiveness of the employment procedures they follow in acquiring new employees.

Also, since newly hired employees are those individuals who have actually passed the employment process, it is also important to study the effectiveness of this process and to compare employees answers to those of personnel managers.

\subsection{General Statement of the Problem}

With the maintenance of political stability, the government has succeeded in establishing a good basis for economic recovery and in the reconstruction of Lebanon. During the year 1993, money supply has increased by $21 \%$, the value of domestic currency appreciated by almost $7 \%$, the balance of payments witnessed a surplus of USD 1.14 billion in 1993 compared to 54 million in 1992 , and the government has set up a USD 1.8 billion property company known as "Solidere" to rebuild the devastated central district of Beirut ${ }^{25}$. This recovery has positively affected the banking sector. During the year 1993, total 
assets and total deposits of all banks operating in Lebanon have increased by $39 \%$ and $36.6 \%$ respectively, some banks have expanded their geographical coverage by opening new branches, and new foreign banking services were imported $^{26}$. These services represent the means by which banks compete with each other.

Banks should benefit from the opportunities now opened. They have to build a competitive advantage over competing banks that are introducing new banking facilities to attract their customers as well as against new foreign banks expected to start business in the future. In order to survive, a bank must be competitive not only in its technologies used, but also in its human resources who are expected to use these new technologies effectively and efficiently.

Employees represent an important asset for a bank; they can either make it or break it. Working in a bank is a very sensitive job. Bank officers and employees should avoid the temptation of money and must have a sense of difference between people's money and their $\mathrm{own}^{27}$. Consequently, banks should have adequate recruiting and selection programs that ensure the availability of honest and qualified employees who are able to apply modern theories and thoughts.

Personnel managers in banks are approached to show the effectiveness of employment procedures they apply in acquiring new employees. Also banks employees are called to show their reaction towards these procedures. 


\subsection{Research questions and hypotheses}

This piece of research intends to answer the following questions:

1- Do banks operating in Lebanon follow adequate recruiting and selection processes?

2- Does employee satisfaction increase with better recruiting and selection?

3- Is employee turnover affected by the adequacy of recruiting and selection?

In addition some hypotheses are tested to determine the following:

1- Whether the use of selection tests is dependent on the candidate's experience.

2- Whether turnover rate is dependent on whether tests are used as a selection tool.

3- Whether the type of the selection interview is dependent on the position to be filled.

4- Whether the-adequacy of the interview is dependent on the education of the candidate.

5- Whether job satisfaction is dependent on whether the employee's job matches his education and major.

6- Whether the adequacy of the placement on the job is dependent on the position to be filled. 


\subsection{Purpose of the study}

Employee turnover costs are very high. New employees usually enter a bank to get a one or two years experience and then quit. Employee turnover may be due to many reasons: Low pay, inadequate match of the individual's qualifications with the job requirements, lack of motivation and growth opportunities $\operatorname{etc}^{28}$...

This study aims to achieve three main purposes. First, it intends to give a descriptive research of effective recruiting and selection procedures. Second, it attempts to represent the effect of employment procedures on banks and employees. Finally, it is intended to describe and criticize the employment procedures followed in banks operating in Lebanon.

\subsection{Limitations of the study}

This study has two populations: banks personnel managers and newly hired employees. There are 78 banks operating in Lebanon. Since only 35 personnel managers have been included in this research, one can not generalize the results to all banks. also banks are of small sizes (number of employees is very small) and while introducing the topic to their personnel manager, they replied that in these banks recruiting and selection are not performed frequently. Therefore these banks were eliminated from the study. In addition, some personnel managers refused to fill the questionnaire even when they were informed that the results are confidential and that neither their name nor the bank's name will be presented in the research. Finally, some questionnaires of both populations were eliminated because they were not filled honestly and completely. 


\subsection{Construction of the study:}

This This chapter introduces the study. It includes a historical background of the appearance of the personnel department, a description of the various functions of the personnel department and how these functions affect employment This chapter also contains the need for the study, a general statement of the problem, the research questions to be answered, the purpose of the study, and finally, the limitations of the study.

Chapter two includes a deep litterature review of the recruiting and selection processes. Chapter three includes a description of the methodology used in this research, the population and the sample, and the coding of the questionnaires used. Chapter four contains a description and an anlysis of the research findings . Fianally, chapter five includes a summary of the results of this research and some recommendations. 


\section{CHAPTER TWO \\ LITTERATURE REVIEW}

\subsection{Introduction:}

The effectiveness of a bank depends upon the skills of its human resources. No matter how good the technology, efficient and economic the system, a bank can not achieve full potential if those employed to put plans into action are not fully committed and perform only the minimum expected.

Fortunately one can find today some organizations that have recognized the need for committed employees and have formed separate personnel departments headed by personnel specialists. The aim of these personnel departments is to ensure that the organization has continuously the right quality and quantity of employees, in the right place, and at the right time to perform successfully the work of their institution ${ }^{29}$.

Employment activities are important to banks of all sizes because of their effect on $^{30}$;

i. Banks goals: It is only by effective selection that a bank can expect to fulfill its mission and achieve its goals. Plans, programs, and systems are not "selfactuating"; it is the employees, the most important resources, that act as an activating force, making efficient use of all resources and enabling the bank to achieve its objectives.

ii. Employment Costs: Employment costs can be divided into direct and indirect costs. Direct employment costs encompass such costs as employment advertising, salaries of employment specialists, test, physical examinations 
and others. Indirect costs include such costs as the time operating managers spend interviewing prospective employees, the time supervisors or managers spend in training or orienting the new hires to the work place, and the amount of productivity lost while the new employee is in the process of learning how to perform the job. Employment costs may be ignored when a bank hires adequate employees. However, errors in hiring decisions may result either in the failure to employ a promising prospect or the hiring of an employee who fails to meet standards pushing the bank to make repetitive staffing; hence increasing direct employment costs. Therefore, it is important that employment should be performed as effectively as possible to make maximum benefit of their expenditures.

iii. Organizational impact: The performance of employment activities affects the bank in different ways. Some of these impacts are: Employee turnover, productivity, customer service, employee relations, morale, and the bank's image. Effective employment leads to low turnover, increased productivity, better customer service and high morale. Whereas, with ineffective employment, customer service will suffer, employee relations may be poor, and the bank's image will be down. 


\subsection{The employment process:}

Employment is a multiple step process whose desired outcome is a valid decision about hiring an applicant. (see Figure 1)

Although the four stages in this process are discussed individually; one should always keep in mind that they operate in conjunction with one another. Each of these stages builds on to the previous one (s). The results of one stage affect the other. For example, in determining performance crieteria, in stage 2 the personnel officer is influencing the recruiting and selection stages.

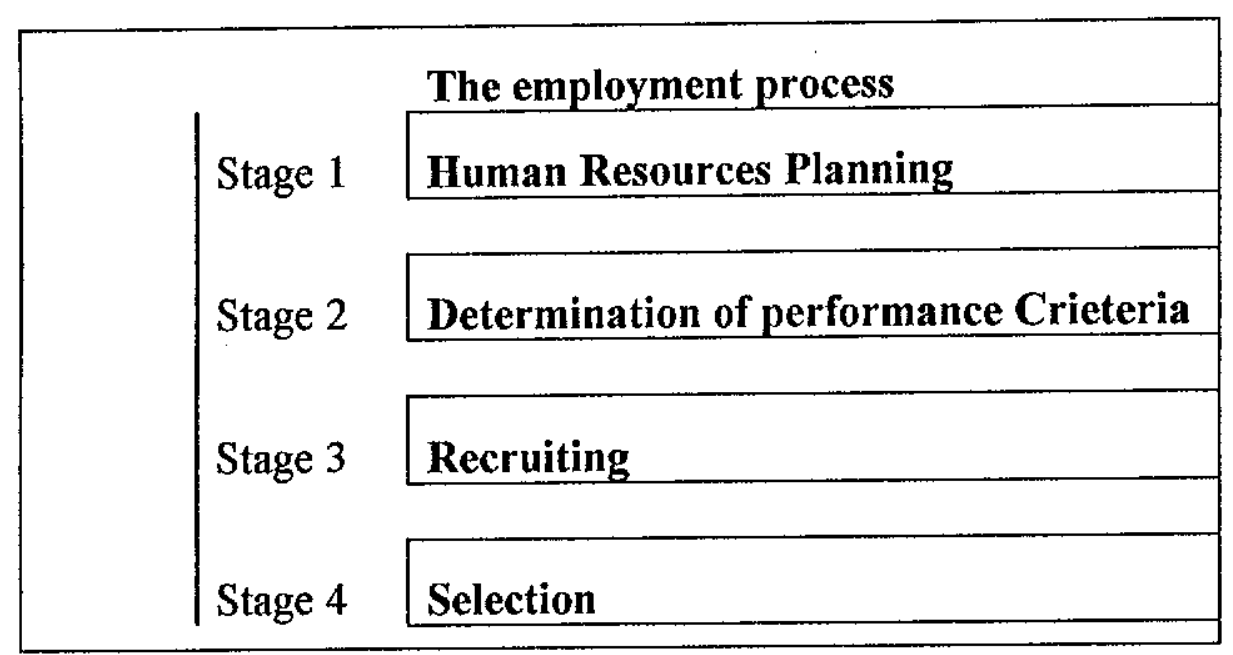

Fig. 1 - The employment process 


\subsubsection{A Assessing human resources needs or human resources planning:}

A bank operates most effectively when it determines well in advance what are the skills and the number of employees needed to accomplish its goals. It is hard for a bank to attract a sufficient number of employees with the required skills overnight. Before new employees are recruited or existing employees are transferred to new positions, someone needs to know how many of what kind of employees are needed. Having this information, the bank will have enough time to determine in advance the most appropriate sources of applicants as well as the most productive method of attracting individuals to apply for the job openings $^{31}$.

Human resources planning (HRP) is a continuous process that enables the bank to respond to the following factors ${ }^{32}$ :

\section{1 - New Services:}

Innovations always occur in the banking industry. A bank that does not provide new services, will suffer the loss of many of its customers. The introduction of new services requires the bank to make a thorough analysis of what kind of skills and employees currently needed are available and what new ones will be needed as services expand.

\section{2- Technological changes:}

As with services, technology is continuously changing. Technological changes should be analysed to determine their effect on the skills of existing employees and the need for new employees possessing new skills that current employees lack. 


\section{3- Changes in the bank's market share or its growth:}

In order to have a wider geographical coverage, some banks are opening additional branches. Here HRP reduces the impact of labor shortages. Through effective planning, identification of the need for additional skills and employees is made earlier and adequate recruiting and selection are performed before that need develops into a problem.

\subsubsection{B Stages of development of human resources planning:}

The development of a HRP system that fits the need of a bank and can be accepted by its responsibles can not take place all at once. As they develop, four stages of HRP can be identified ${ }^{33}$ :

Stage 1: This stage is highly informal and subjective. At this level, managers establish organizational goals and assess with every supervisor human resources requirements to achieve these goals in the short-run. The adequate quality and quantity of employees is then determined based in the discussion between managers and supervisors.

Stage 2: At this stage human resources needs are forecasted for the coming year. Here management succession and the readiness of successors are analysed a year in advance using usually simple methods such as following past trends. The forecast of quantity and quality of talents needed is then distributed to managers and in return, information is obtained identifying the talents of individuals and their interest in promotion. 
Stage 3: This stage involves forecasting human resources needs using sophisticated forecasting models with the help of computers. These computers can also be used to store current data on the skills and interests of employees and can easily suggest a list of individuals who best fit a particular position in few seconds.

Stage 4: This stage of HRP is a continuous process of developing future forecasts of employee needs. Computers here perform simulated human resources forecasts; they perform simulations of talents needed and costs in order to provide a continuous process of updated human resources needs. The career interests of employees and their talents are disseminated within the bank and among other organizations to aid employees in locating their ideal jobs.

In some banks, especially in small ones, and informal model of HRP may be adequate since for them an elaborate and sophisticated system may be costly. As the bank becomes larger, it needs a HRP system of higher sophistication ${ }^{34}$.

\subsubsection{Determination of position requirements:}

Having determined staffing requirements through planning, the next step is to establish the performance criteria required for the positions to be filled. Establishing performance criteria can be done through the review of the job description of the vacancy. If a bank does not have a job description for each position, performance criteria can be determined through the interaction between the employment officers, the employees doing the job, and the line manger or supervisor - the person normally making the final decision as to who will be hired. This interaction is the method that the personnel officer usually uses in making job descriptions. 
Establishing performance criteria is a two-step process: First, developing a list of skills and knowledge that candidates must possess; second, developing a corresponding list of behaviors and level of competencies required.

In the first step, the employment officer asks line managers about such matters as the skills and responsibilities that can be used to select applicants, job specifications that can be used by employment agencies and search firms, and criteria that can be used to write newspaper advertisements. Here, the position supervisor is usually in the best position to know what skills are needed to perform a job successfully ${ }^{35}$.

To determine the level of competencies, the employment officers translate what managers want from an employee into behavioral terms and levels of achievement that can be used in interviewing candidates. It involves translating the general statement about the criteria into a statement showing specific information about what is expected in the job ${ }^{36}$. For example, the performance criterion may be: "Educational achievement and experience"; the level of performance may be: "To hold a B.S. degree in business, to have a minimum average of 80 , and to have at least 5 years experience in a well known organization".

Experience shows that line managers alone can not be helpful in providing information concerning performance criteria. Usually, line managers have the tendency to overstate the importance of the job under their supervision. Therefore, the employment officer should also rely on the information gathered through their interaction with the employees currently working on the job ${ }^{37}$. 
The employment officer's interaction with the position direct supervisior and employees can be done either through questionnaires, interviews, or direct observations of the employees doing the job. Since each of these methods has its benefits and its drawbacks; a combination of questionnaires, interviews, and direct observations is probably the best method that maximizes the advantages and minimizes the disadvantages of any one approach used by itself. This method has the advantage of seeing the job from different perspectives resulting in a more complete and valid determination of performance criteria ${ }^{38}$.

\subsubsection{Factors affecting recruiting and selection:}

The entire human resources management (HRM) system, including recruiting and selection, is affected by a group of external and internal environmental forces. Although the basic recruiting and selection tasks remain the same; yet the manner in which these tasks are performed changes, depending on the effect of these environmental factors.

\subsubsection{A External factors:}

Banks are subject to and influenced by a set of external factors. The way in which they conduct their business is shaped or even affected by these outside influences. Recruiting and selection (R \& S), in particular, are affected by the following factors ${ }^{39}$ :

\section{1- Economy:}

The economic state of the country has a direct effect on the accomplishment of $R \& S$; it tends to increase or decrease the intensity of $R \& S$ activities. When 
the economy is growing and firms are expanding, competition for attracting and hiring qualified employees intensifies. Recruiting efforts are accelerated to fill in the new job vacancies and selection becomes more difficult because applicants are faced with a wider range of employment opportunities.

\section{2 - Labor market, work force:}

The work force represents the total number of individuals available to all employers within a country; it also encompasses the mix of skills available. The work force is usually dynamic, changing in number and characteristics over time; hence, affecting R \& S. A scarcity or abundance of skilled and experienced employees necessitates changes in $\mathrm{R} \& \mathrm{~S}$ practices making it more difficult or easier to attract and hold a sufficient number of employees to perform the work of a bank. For example, if there is a high demand for a scarce skill, an intensive and vigorous recruiting program may be required.

\section{3 - Competitors:}

Unless a bank is the only user of a labor market's particular skills, it will be forced to compete with other banks for these skills. The extent of competition influences the way the bank will perform its $R \& S$ activities. When competition is intense, the bank should follow a vigorous approach of $R \& S$; while if competition is moderate, a less intense approach should be followed. Besides, the method followed by a bank's competitors in attracting particular skills suggests that the employer should modify its $\mathrm{R} \& \mathrm{~S}$ practices in order to remain competitive in these skills.

\section{4 - Customers:}

Customers are the people who actually use and profit from a bank's services; they represent an important external environmental force. Customers always 
demand efficient and quick services. Banks may, therefore, lose their customers or gain additional ones depending on the quality of their employees.

\section{5 - Technology:}

Computers and automation have drastically changed the kind of employees that a bank must have to provide its services. Masses of old employees are replaced by fewer skilled ones and new skills are needed today to meet the demand of new technology. Nowadays, any position, even a record keeping one, requires computer literacy. Therefore, selection practices have to be modified to ensure that a bank has and will continue to have the right kind of employees whenever needed.

\section{6 - Society:}

A bank should convey a positive image for the members of its society. The bank's image can positively or negatively affect the effectiveness of $R \& S$. If a bank has a reputation of fairness and integrity in dealing with employees, it can find more and better qualified applicants seeking work in it.

These external environmental factors exert high pressure on employment. There are expectations to be satisfied, demands to be met, and challenges to be faced. These pressures should be identified and employment activities should be carried out and modified accordingly to meet these external demands, expectations, pressures, and changes in a productive way.

\subsubsection{B Internal environmental forces:}

The internal environmental factors or forces within the boundaries of a bank have a considerable influences on the manner in which the bank performs its 
$R$ \& $S$ activities. These forces influence the importance attached to each employment activity and determines the effectiveness with which these activities will be performed ${ }^{40}$ :

\section{1 - Mission and objectives:}

Mission and objectives define what a bank does and how it acts to do what it aims to achieve. They provide a direction for the bank hence shaping its activities including $\mathrm{R} \& \mathrm{~S}$. A bank that has the objective to grow and to provide new services usually requires a larger number of highly skilled and imaginative employees than a bank that has a conservative growth and follow the market strategies.

\section{2 - Policies:}

Organizational policies establish patterns that guide managers and employees in accomplishing their jobs. Personnel policies influence the effectiveness of $R$ \& S. A bank with a rigid compensation policy, for example, will lose most of its employees and will have a hard time in recruiting qualified ones.

\section{3 - Organizational climate:}

The organizational climate can be referred to the psychological atmosphere prevailing at work. This atmosphere has a considerable impact on $\mathrm{R} \& \mathrm{~S}$. A positive climate improves work quality, motivates employees, reduces job dissatisfaction, employee turnover, and absenteeism, making $R$ \& $S$ tasks easier; while a negative climate has the opposite effect.

\section{4 - Management Philosophy - Corporate Culture:}

The prevailing values of management affect every individual and everything in a bank. If management has a genuine interest and concern for employees, 
employee dissatisfaction and turnover will decrease leading to less frequent $\mathrm{R} \& \mathrm{~S}$.

\subsubsection{Recruiting:}

Recruiting refers to the process of attracting potential job candidates from the external labor force to apply for the job openings. An effective recruiting process enables the bank to attract a sufficient number of candidates who have the ability and aptitude to achieve its goals. Selection depends on the effectiveness of the recruiting process; unless a bank has a sufficient pool of appropriate recruits, it can not select outstanding job seekers ${ }^{41}$.

Recruiting activities start when employee requisitions are sent to the HRD. The preparation of employee requisitions is the responsibility of line managers and is the final step of the human resources planning process. The employee requisition should include a job description and a job specification for the opening. The responsibility of the HRD lies in the analysis of the job description and the job specification to determine the skills and abilities required from job applicants ${ }^{42}$. 


\subsubsection{A The recruiting process:}

The recruiting process basically consists of recruitment planning, the development of recruiting strategy, applicant search, screening, applicant pool, and evaluation of the recruiting process ${ }^{42}$.

\section{1 - Recruitment planning:}

In planning recruiting activities, a bank determines how many applicants should be recruited. A bank must recruit more that it needs to hire since some applicants may not be accepted and others may not accept job offers. In determining how many applicants it should attract, a bank can rely on yield ratios based on its past recruiting activities. For examples, a $6: 1$ yield ratio of interviews to hires means that six candidates should be interviewed to hire one person and to fill 6 positions, 36 individuals should be attracted.

\section{2 - Recruiting strategy:}

After a bank has determined the number of applicants to be recruited, it should develop a specific strategy to identify how, when, and where employees should be recruited. Numerous methods are available for a bank to decide how to find recruits, such as: private employment agencies, employee referrals, advertising, and the bank's recruiters.

\section{2.a - Where to recruit:}

A bank should recruit applicants who have the highest probability of succeeding on the job. In deciding where to recruit, a bank needs to consider two important factors: First, it should determine the prime labor market from which to recruit. Second, it should analyse its current employees and 
determine the source of its most successful ones. Only those who satisfy these factors should be recruited.

\section{$2 . b$ - When to recruit:}

Recruiting should start in advance of anticipated openings to avoid problems of rush selection. Here HRP helps in determining the adequate date for recruiting.

\section{2.c- How to recruit:}

In order to attract candidates a bank should determine what enticements to offer. An important consideration here is whether to convey a realistic image of the job and the bank to applicants or not. An unrealistic image conveys a positive image and attracts a large number of recruits. However, most of new hires quit the bank early when they discover that what was written in advertisement is different from what is found at work. On the other hand, a realistic image will have reverse effects.

\section{3 - Applicant search:}

At this stage, actual recruiting activities start. An important issue here is whether a particular position should be filled internally or externally. If positions are to be filled from outside, the bank must first identify where people are likely to be found - sources of recruiting - before it decides how to attract people - methods of recruiting.

Therefore, to match methods to sources effectively, a bank should conduct a research to determine the best method to be used for each specific job. Also, it can simply review statistics on present and past employees to identify the best sources and methods of recruiting. 


\section{4 - Screening:}

Not all applicants can go through the selection process. As applicants apply for the job openings, the bank should screen them to eliminate those who are obviously unqualified. A comparison of job requirements and skills should be made with each applicant's skills and abilities. Sometimes a screening interview is conducted to select the applicants that should be included in the applicant pool.

The purpose of the screening stage is to save a great deal of the bank time and effort that can be wasted in processing the applications of unqualified applicants. Also, screening helps individuals know immediately that they are unqualified so that they can apply for other jobs.

\section{5 - Applicant pool:}

The applicant pool consists of those individuals who have passed the screening stage and have expressed an interest in the bank. There are two important things that most of the banks disregard: First, they should keep the applicant informed about the status of his / her application. Second, they should ask the applicant to give them a notice in case he / she gets a job elsewhere so that they remove his / her application from the applicant pool.

Applicants of this pool will later go through a long selection process to determine whether they will be employed or not. 


\section{6 - Evaluation of the recruiting process:}

Banks must periodically evaluate their recruiting process to determine whether it can be rendered more effective and less costly. In this evaluation the following issues can be examined:

1 - Whether the yield ratios can be improved and optimized to reduce recruiting and selection costs ${ }^{44}$.

2 - Whether advertisements are effective in attracting recruits ${ }^{45}$.

3 - Whether the criteria used in screening applicants are carefully examined to ensure that only unqualified individuals are eliminated and whether the crieteria are too high or too $10 \mathrm{w}^{46}$.

4 - Whether the bank has difficulties in attracting recruits. If a difficulty exists, the bank should evaluate both its image and the opportunities and benefits offered to prospective employees ${ }^{47}$.

5 - Whether internal candidates were considered sufficiently ${ }^{48}$.

The HRD is largely responsible for most recruiting activities. It recommends the recruiting policy to top management, develops the strategy and procedures for advertising job openings, gathers information from applicants, screens this information to form an applicant pool, and evaluates the whole recruiting process. 


\subsubsection{B Internal versus external recruiting:}

When job vacancies exist in a bank, the first place it has to look for replacement is within itself. Internal recruiting is the best way for a bank to fill a vacancy; it has many advantages over external recruiting for both the bank and its employees. The following advantages are observed:

1- It provides the bank's present employees with the opportunity to be promoted to higher level positions because of their service and commitment. Therefore, a promotion from within policy enhances motivation, helps in building employee morale, and keeps employees from leaving the bank ${ }^{49}$.

2- It enables the bank to save considerable amount of time and money in selecting and training new employees. Current employees are already familiar with the bank and do not need any orientation ${ }^{50}$.

3- It enables the bank to make more accurate decisions. The bank already knows its employee capabilities; it can rely on the person's established track record with it and select the person best suited for the new position $^{51}$.

However, internal recruiting leads eventually to "inbreeding", a lack of new ideas and creativity in addition to the ripple effect: When a current employee moves to a different post, someone else must be found to replace him/her. If this replacement is already an employee, then the now-vacant job must also be filled. Finally, replacing the promoted person from outside the bank entails recruiting, selection, and training costs. That is why it is unlikely to find a bank or any other organization that rigidly sticks to internal recruiting ${ }^{52}$. 
On the other hand, external recruiting, although more expensive than internal recruiting, has the advantage of bringing new blood, new ideas, and new management thoughts which are increasingly needed in our time.

\subsubsection{Methods of internal recruiting:}

\section{1 - Management and skills inventories:}

This is the commonly used method of internal recruiting. It consists of having the personnel department examining the records and files of its existing employees to determine which one possesses the appropriate qualifications for the vacancy. This device has proven to be extremely successful provided that skill inventories are maintained on an up-to-date basis. This method is accompanied by improvement in employee morale and the discovery of hidden talents provided that the personnel specialist is fair enough and not biased ${ }^{53}$.

\section{2 - Job posting and job bidding:}

In a job posting system, the bank notifies its employees about openings through the use of its publications or bulletin boards. The purpose of this system is to communicate to employees the fact that a job opening exists. Job bidding allows employees with the required skills to apply for the vacancies ${ }^{54}$.

An effective job posting and bidding system necessitates that a job specification should be included with the listing of the openings so that employees can judge whether they possess the required skills and abilities ${ }^{55}$. It also requires that job vacancies be known to every employee so that complaints commonly heard that insiders never hear about an opening until it has been filled by an outsider are minimized ${ }^{56}$. 
One major problem in this method is that it prompts employees to apply for positions for which they may not be fit and affects their morale if the bank refuses to offer them the job ${ }^{57}$.

\section{3 - Employees contacts and referrals:}

Before banks go outside to recruit new employees, many of them ask their employees to encourage friends and relatives to apply for job openings. Some banks follow the practice of allowing employees to invite their friends and relatives to visit them at work so that they can see the challenges of working in the bank. In order to encourage them to refer qualified candidates, some banks give awards and bonuses to the employee who refers good recruits ${ }^{58}$.

Employee referrals are relatively inexpensive and usually produce quick responses and stability. However, banks should be concerned about problems resulting from hiring relatives of present employees. Such as the increase of the likelyhood of nepotism and fanatism to friends and relatives ${ }^{59}$.

\subsubsection{External sources of recruiting:}

Inevitably banks should not mainly depend on internal sources of recruiting. They should, however, look to outside sources for additional employees especially when they are expanding their work on a permanent basis as when opening new branches. The following circumstances necessitate the need for external recruiting ${ }^{60}$ :

- The creation of new jobs resulting from expansion into new services requiring special skills not currently available. As when banks have recently introduced computers and new banking services. 
- Vacancies in jobs resulting from internal promotions, death, resignation or retirement of existing employees.

- Expansion into new geographic areas.

- The need for new ideas.

Some of the most common sources of new employees are colleges and universities, high schools, competitors and other organizations, unsolicited applicants, and former employees.

\section{1 - Colleges and Universities ${ }^{61}$ :}

It requires the development of close working relationships between placement directors or professors at colleges or universities and the bank recruiters. Some banks have improved this practice by developing close working relationships with business professors asking them to propose some students for summer internships to allow these students to see the challenges of bank careers and to permit the personnel specialist to select the best students.

\section{2 - Competitors and other organizations ${ }^{62}$ :}

They represent the most important sources of applicants for positions requiring experience. Small banks in particular, look for employees of other or larger banks which have the resources needed to support an extensive T \& D program.

In some banks, it is also common to recruit the professionals and managers of other organizations that are providing them with their services. 


\section{3 - Unsolicited applicants ${ }^{63}$ :}

This is a valuable and the least expensive source of employees for positions ranging from entry level to top level managers. If a bank is well known and has the reputation for being a good place to work in, it will be able to attract prospective employees without engaging in extensive recruiting. However, it may end up having a large pool of applications to study the majority of which may not fit the position to be filled.

\section{4 - Former employees ${ }^{64}$ :}

The pool of former employees who have quit or have been laid off represents an important source of recruits. Former employees are already trained and familiar with the bank policies. From a financial perspective, this source permits the bank to recoup its original investment made in training previous employees.

\subsubsection{E Recruitment methods:}

Recruitment methods are used to encourage potential candidates to apply for the job openings. The analysis of these methods helps the bank determine where potential applicants are likely to be found. Each source of external recruiting can be attracted using a special method; for example, internships can be used to attract nonexperienced recruits.

\section{1 - Private employment agencies ${ }^{65}$ :}

Private employment agencies provide their services to both, the job seekers and the bank seeking recruits. They assist banks in locating employees and aid job seekers in their search for jobs. Some agencies are specialized in one field while others locate individuals in all fields. 
Private employment agencies are best used when a bank wants to recruit a small number of employees. Here it can list the job openings with several agencies or with one agency. Several agencies enable the bank to broaden its scope of recruiting. Whereas using one agency allows it to build good relationships with the agency which may lead to better referrals since the agency tends to know more about the bank and the type of employees it hires.

\section{2 - Company recruiters ${ }^{66}$ :}

Bank recruiters usually make close contacts with placement directors at colleges or universities or with the students' direct professors. They play an important role in providing job seekers with information about the bank's attitudes and philosophy. The reason is that the attitudes of the recruiters reflect those of the bank.

The role of the bank recruiters is to determine which individuals are suited to work and to encourage them to apply for the job. In doing this, the recruiter is involved in a two way communication process: He gets information about job seekers by reviewing their files in the university and provides information about the bank, its policies, and the duties and responsibilities of the position to be filled.

\section{3 - Executive search firms ${ }^{67}$ :}

These are specialized form of private employment agencies whose job is to locate top level executives and experienced professionals. Since candidates are existing managers working with competitors, the use of these firms helps the bank avoiding being accused of stealing competitor's managers. 


\section{4 - Applications - walk ins and write ins $\mathbf{s}^{68}:$}

If a bank enjoys a favorable reputation, it may be able to obtain a large applicant pool from individuals who submit applications for employment. Walk ins and write ins are closely related and do not cost anything. Walk ins are automatically informed by the receptionist that there are no openings at the present time and if they are permitted to fill in an application the application is quickly filed away even without a screening interview. Call ins are also told there are no job openings and are told to apply in person.

These methods work well when the receptionist in the HRD has an up-to-date list of job openings with a job description for each opening. If a match is found between the the application received and the job specification, the recruit is asked either to conduct an immediate interview or an arrangement is made with him for an interview at a later date.

\section{5 - Customers $^{69}$ :}

In many cases customers suggest certain individuals as potential employees of a bank. This approach may be of value in building goodwill with significant customers whether persons or organizations and a way in which the personnel department can contribute to the profitability of a bank.

However, sometimes the bank may be under pressure when an important customer enforces an unqualified person and informs the bank that he will close his accounts with it in case the person was rejected. In this situation, the bank has to weight the outcome of the resulting two situations: whether to accept an unqualified person and retain the customer or to lose the customer and maintain a group of qualified employees. 


\section{6 - Advertising $^{70}$ :}

Advertising in printed media, primarily in newspapers, is often the most productive and most commonly used method of recruitment. An effective employment advertising should avoid generalities and provide concise information about the job, the skills needed, the bank, the way of responding and the possibilities for career development.

In planning for successful advertising, the following issues should be considered:

- The type of employees the bank wants to hire.

- The adequate number of employees needed to form a sufficient applicant pool.

- The time when additional employees will be needed.

- The message the advertising should convey.

- The advertising medium to be used and the advertising costs.

\subsubsection{Selection:}

Having formed the applicant pool, the next step consists of the process of choosing from this pool the individual or individuals deemed to be best qualified for the job opening, that is, selection. It is a difficult process because it involves making judgements about people and any mistake in selecting can be costly and damaging to both the bank and its employees ${ }^{n}$.

The personnel department (P.D) holds the major responsibility for personnel selection; but this responsibility is also shared with line managers. The P.D usually reduces the number of applicants to three or four candidates to be interviewed by line managers who make the final selection choice. The P.D is then responsible of the quality of selection tools that provide line managers with the information needed to make their selection decision ${ }^{72}$. 


\subsubsection{Basic principles of selection:}

The selection process depends largely on 2 basic principles. The first principle is that "Past behavior is the best predictor of future behavior" ${ }^{173}$. Knowing what an individual had done in the past is a best predictor of what he is likely to do in the future. The second basic principle is that "the organization should collect as much reliable and valid data as is economically feasible and then use it to select the best applicants ${ }^{74}$. Reliable data refers to information that is consistent and repeatable; valid data refer to information that indicates how well employees will perform their job. The amount of valid and reliable data varies with the degree of importance and difficulty of the job.

\subsubsection{The selection process:}

Job specifications and descriptions describe the qualifications required for a successful job performance; however, the selection process is designed to identify or select individuals who best meet these qualifications. This process is frequently described as a "succession of hurdles" that an applicant must clear in order to survive the process and becomes an employee ${ }^{75}$. Most organizations reject undesirable applicants at each step of the process to reduce time and efforts. Others, however, have applicants go through the entire process waiting until the end and select the candidate with the best overall score on all the steps $^{76}$. This section briefly states the major steps in the selection process. An elaborate description of each step will be presented in later sections of this chapter.

\section{1- Preliminary or screening interviews"}

A preliminary interview is the first step in the selection process; it typically occurs as a part of the recruiting process. It involves asking candidates direct 
questions to determine whether they possess the basic skills and abilities required for the opening. The rule is that individuals who are obviously not qualified should be immediately eliminated from the applicant pool.

The preliminary interview is of a very short duration; if the first questions prove that an individual lacks the required criteria, the interview may be closed in three to five minutes and the individual is immediately told that he is not qualified for the job.

\section{2 - Application blanks:}

The submission or completion of an application blank is a basic part of the selection process. The primary purpose of the application blank is to provide meaningful employment information that helps employers make accurate decisions $^{78}$.

Some banks require applicants to fill an application blank that can be used as a basis for selection and once hired, they ask them to fill a new elaborate application blank to be kept in their personal files. In other banks, the completion of an application blank is considered the final step in the selection process $^{79}$.

\section{3 - Interviews:}

Employment interviews are used almost by every bank to hire employees at all levels. They enable the interviewer to extract information that can not be found neither in application blanks nor in tests; through them, the interviewers can read applicants face and gestures. 
Although interviews are an important step in the selection process, research shows that interview data are generally neither valid nor reliable. Interviews are usually conducted by interviewers having different orientations, different perceptual biases, different levels of competence. Also, interview results are subjective no matter how structured the interview ${ }^{80}$.

\section{4 - Employment testing:}

Employment tests are a valuable tool to measure individual characteristics. They can measure intelligence, knowledge, interest in the job and other characteristics. Tests have two major advantages over interviews: First, some tests can be made more objective; second, they can be rendered more valid and reliable than interviews ${ }^{81}$.

\section{5 - Reference checks:}

An investigation of the background of employees should be made before making a selection decision. These background investigations may include an investigation of previous employment, educational credentials, and criminal activities.

\section{6 - Physical examinations:}

Some banks require applicants to obtain a physical examination. They require this examination not for selection purposes; but as a protection from excessive worker compensation claims, to reduce medical absenteeism, and to safeguard the health of present employees through the detection of contagious diseases ${ }^{82}$. 


\section{7 - Final interview ${ }^{83}$ :}

The purpose of this interview is to gather all information collected in the previous steps and to clarify missing or ambiguous information. It is typically held with the supervisor to whom the ultimate hiring decision is left although the human resources officer may indicate his choice of an applicant. It usually comprises a personality contest since the supervisor will choose the person he likes the most and enjoys working with.

While this generalized selection model shows the series of logical steps that are usually followed in choosing employees; specific procedures vary from one bank to another or even from one job to another. In some banks, for example, the candidate must be interviewed by the line manager before being tested and interviewed by the personnel officer. Additionally, there are other factors that affect the selection process:

$i$ - The bank's hierarchy $y^{84}$ : Banks usually put a standardized selection procedure to be followed for all applicants. Deviation from the predetermined steps is usual especially when filling positions at different levels in the organizational hierarchy. Generally, the higher the position, the more complicated the selection process will be and the lower the position, the less likely the steps specified by the model will be followed.

ii - The applicant pool ${ }^{55}$ : The number of applicants from which to select potential employees is an important factor. If there are many applicants for a particular position, the selection officer can be highly selective; whereas, if few applicants are available, selection becomes a matter of choosing whomever is available. 
iii - The speed of decision making ${ }^{86}$ : The time available for making a selection decision is an important variable that exerts a major influence on the selection process. A sudden resignation of an important decision maker necessitates filling the position immediately. Under these conditions the steps in the selections process are likely to be ignored; very few telephone calls, and short interviews may constitute the entire process.

iv - Probationary period ${ }^{87}$ : Many banks use a probationary period that provides them with the knowledge of an employee's ability to perform the job before his permanent employment is assured. Probationary period can be used as a substitute or supplement to the use of other selection procedures. The use of a probationary period enables the personnel officer to evaluate an individual actual performance in different areas and under various circumstances and to make accurate placement decisions.

\subsubsection{Reliability and validity of selection tools:}

For an effective employment decision, selection information should be both reliable and valid.

Reliability refers to the repeatability of measurement. The higher the selection instrument reliability, the greater the confidence that can be placed in it. A reliable selection instrument is that on which an individual score does not vary when it is administered several times ${ }^{88}$. These are some of the major causes of obtaining unreliable selection information ${ }^{89}$ :

- The person using the measuring instrument does not have a clear perception of the behavior being measured or a well defined standard to be used in making evaluations. 
- The selection tool may be unclear; for instance, questions in a interview or a test or items on an application blank may be ambiguous and lead to random inconsistent answers.

- The selection tool may be used at different locations or occasions leading to different results.

Validity refers to the extent to which an instrument can be used as a predictor of the likelihood that an applicant will perform his job well. In personnel testing, it refers "to the extent to which a predictor variable is correlated with a criterion variable" ${ }^{190}$. Predictor variables refer to the information obtained as a part of the employment process such as test scores, interview data, personnel references, and data from application blanks. Criterion data refers to a measure of job performance that indicates the degree of success in the job such as retardiness, degree of productivity, absenteeism, etc... ${ }^{91}$.

The validity of predictor can be evaluated by computing a correlation coefficient between the predictor and the criterion. A correlation coefficient is a number between -1 and +1 that indicates the degree of relation between 2 variables. A correlation of 0.3 is considered quite acceptable since research showed that validity coefficients rarely exceed $0.5^{92}$.

Worth mentioning is that reliability is an important issue in selection because it is a limiting constraint on validity; an unreliable measuring can not be valid ${ }^{93}$. 


\subsubsection{Selection Tools:}

\subsubsection{A Application Blank:}

For almost all positions, the selection process begins with the review of the application blanks that prospective employees have submitted. The primary purpose of the application blank is to provide valid and reliable selection information. However, they are not very valid because they are not designed to identify outstanding performers. To be a valid selection tool, the application blank must request information about an applicant's previous background that can be used to predict future performance; yet most application blanks request only little information that needs additional investigation and elaboration ${ }^{94}$. Application blanks have many uses. They can be used to eliminate applicants who are obviously unqualified. They also serve as the basis for interviews; they introduce the applicant to the interviewers and provide them with the information that requires further investigation such as time lapses, reasons for leaving previous jobs, level of skills etc... ${ }^{95}$.

\section{1 - Content of an application blank:}

Application blanks are typically designed to provide four kinds of information ${ }^{96}$ :

a - Vital statistics: Name, address, phone number, marital status, date of birth.

b - Educational background: Schools attended, degrees obtained and dates of enrollment.

c - Work history: Jobs held and former employers during the last 5 to 10 years, salaries, responsibilities, and the reason for leaving previous jobs.

d - Background experience: Professional associations, hobbies, interests. 
In addition, applicants are required to sign the application blank in order to certify that all the provided information is correct and to acknowledge that wrong information is grounds for dismissal.

\section{2 - Limitations of the application blank:}

Although an application blank can be considered a very reliable selection tool, it does have some limitations:

a - It is usually difficult to compare duties and responsibilities of previously held positions with those of the position the applicant is seeking; job titles can be misleading. For instance, a managerial position in one bank may involve only few managerial tasks; while the same position in another bank may require excessive managerial responsibility ${ }^{97}$.

b - The application blank is an impersonal selection procedure and no mater how much information it provides, it can never be a substitute for the direct personal contact of a company representative ${ }^{98}$.

c - The application blank asks for a limited amount of information; individuals who have outstanding performance may not have the opportunity to explain it in a limited space ${ }^{99}$.

d - The application blank provides biased information; it provides the personnel officer with the information that the applicant wants to give and omits unfavorable information ${ }^{100}$.

e - The application blank is objective and fails to provide the motives of an individual. They tell the "what" of a person but not the "why" and "how" which are more important in assessing the individual's growth potential $^{101}$. 


\section{3 - Weighted application blanks ${ }^{102}$ :}

This selection tool is aimed at eliminating biases in selection procedures. It enables the recruiter to score an applicant's information rapidly.

In the weighted application blank individual items are reduced to a quantitative score. Items which are determined to predict success more than others are given more statistical weights. Based on past experience, a cutting score is established for the total. The individual scoring above this standard is the person who deserves further consideration.

\subsubsection{B Testing:}

Employment testing refers to written or oral procedures for determining job suitability. Testing is accomplished by examining the skills, knowledges, and capabilities of candidates according to a predetermined set of guidelines. Test results are assessed in relation to the requirements of a given position and finally, conclusions are drawn as to the suitability of the applicants.

Selection tests, when used as a supplement to other selection devices, provide selection officers with valuable information for better hiring decisions. They have several advantages over other selection tools of which we can cite ${ }^{103}$ :

- Objectivity: Tests results are not influenced by those evaluating them.

- Cost effectiveness: Selection tests are usually less expensive as compared to the time and effort spent in interviews.

- Quality of information: Tests have the advantage of their ability to uncover what an individual can do and whether he has the necessary qualifications for the opening. Such information is not always clearly presented in other selection tools as application blanks. 
However one should not use test alone and neglect other selection devices for there are definite disadvantages of using selection tests ${ }^{104}$ :

- Tests do not measure the candidate's willingness to perform successfully: Successful job performance depends on two variables, the "can do ability" and "the will do ability". Tests can measure the "can do" or the skills necessary to perform the job; but they can not measure the "will do" ability or the applicant's willingness to exert the motivation required to get the job done successfully. - Tests are more accurate at predicting failure than success: Tests assess the individual's current skills and abilities; but can not predict who will actually fail or succeed in the future. A person who gets a score above the minimum acceptable one will not necessarily be an outperformer.

- Tests create anxiety on the part of the test taker: Individuals seeking employment may become nervous and answer incorrectly when they know that they are going to face another hurdle that could eliminate them from further employment consideration. Consequently even the best qualified candidates may not be able to reflect their actual abilities accurately and may be rejected.

\section{1 - Policies in testing:}

The general theory behind testing is that human behavior can be forecasted by sampling it. Banks administering tests must have a written policy which states that the primary objective of their selection tests is to select qualified candidates. The policy should also describe how various tests are administered, evaluated, and interpreted. Policy information should be made 
available to all those involved in the testing process ${ }^{105}$. Here are some of the general guidelines for administering tests:

1.a- Job analysis should be the first step in a test program. Data on successful job performance can not be secured except through analyzing, examining, and carefully studying the job. Job analysis results in a direct correlation between test results and job performance $^{106}$.

1.b- The bank should make every effort to eliminate anxiety producing factors. Candidates, for example, should not wait long before the test is given ${ }^{107}$.

1.c- The number of people who have access to test questions and answers and scoring sheets should be very limited ${ }^{108}$.

1.d- Tests should be given under uniform conditions. The testing environment should be the same each time the test is given. Besides, the same amount of instructions and time should be given each time the test is administered ${ }^{109}$.

1.e- Selection officers should be objective in scoring. A test is considered objective if all individuals scoring it give nearly, the same grade. To secure objectivity in correcting test, a preestablished answer list should be used as a standard ${ }^{110}$.

1.f- Normative data should be used in evaluating test scores. Normative data provides a frame of reference for comparing an applicant's performance on a test with that of a group of previously tested individuals. The test result of the representative group - normative data is then the standard by which the scores of candidates are evaluated and interpreted ${ }^{111}$. 


\section{2 - Types of tests:}

Tests can be grouped into categories including achievement and aptitude tests, interest tests, and personality tests.

\section{2.a - Achievement and aptitude tests:}

Achievement tests are the most used tests. They measure the candidate's current skills and indicate his existing abilities. Aptitude tests are designed to measure a person's potential ability to perform a task. This distinction is in terms only; professional testers prefer to categorize achievement and aptitude tests together since both tests are aimed to measure developed ability ${ }^{112}$. They are divided into the following subcategories:

$i$ - Job knowledge tests: They are also known as trade tests; they require applicants to show the degree of knowledge they have concerning how to perform a given job by answering questions on "how to perform a task" either orally or in writing ${ }^{113}$.

ii - Work samples: They require the job applicant to demonstrate the level of skills he possesses for a given job. They can be used with actual job equipments such as typing or performed on simulated situations such as inbasket tests for managers in testing their ability to write business letters ${ }^{114}$.

Since work samples test an existing level of achievement, they can be best used to select experienced employees who already possess a degree of proficiency in a given area. Their purpose is to measure proficiency rather than capacity and they are used by banks that do not have training facilities and want to hire people who are already proficient ${ }^{115}$. 


\section{$2 . b$ - Intelligence tests ${ }^{16}$ :}

They are used to measure an individual's general learning ability. A high score means that the individual has the capacity to learn a certain job; but it does not mean that he already has the ability to perform the job.

Personnel officers use intelligence tests in measuring a person's ability to perform cognitive and thinking tasks. They use general intelligence tests that concentrate on abstract functions involving the use of numerical or verbal reasoning such as words meaning and definitions and arithmetic reasoning used in business.

\section{2.c - Interest tests:}

These tests are designed to discover patterns of individual interest that help the selection officer determining what types of work may be statisfying to employees. The higher the degree of interest in a job, the higher the probability that the individual will succeed on $\mathrm{it}^{177}$. Interest tests are highly associated with the decrease in employee turnover resulting from dissatisfaction with the job.

Interest should not be confused with aptitude. A person may have the interest to work in a given field; but lacks the basic abilities to succeed in it. Consequently, interest tests should always be used in conjunction with aptitude tests $^{118}$. 


\subsubsection{C Interviews:}

The employment interview is a vital part of the whole selection process, it is a "human link between the applicant and the bank"119. The employment interview has many purposes:

- To collect and analyse information for making a selection decision ${ }^{120}$. This information is a supplement for previously collected information.

- To clarify and verify any ambiguity in previously gathered information $^{121}$.

- To "sell the bank". It provides the interviewer the opportunity to give a realistic picture about the bank and to convince the candidate that the bank is a good place to work ${ }^{122}$.

- To establish friendship between the candidate and the selection officer. The interviewer usually represents the bank; if he is friendly and cooperative, these characteristics are likely to be attributed to the bank $^{123}$.

\section{1 - Preparation for the interview:}

There is a commonly held belief that interviewing does not require any preparation. The perception of an interview is that it is an effortless conversation between two people sitting together-the interviewer asking questions and the applicant answering - and how well the applicant responds determines whether or not the job offer is extended. This belief is wrong and is one of the reasons why most interviews do not achieve their purpose ${ }^{124}$.

In order to conduct an effective interview a number of preparatory steps should be completed well before meeting the applicant. This process of interview preparation involves learning as much as possible about the job to be filled, the 
bank and its policies as well as the applicant. It also involves determining the method for carrying the interview and the main topics to be discussed.

\section{1.a - Familiarization: (1)}

i- The job ${ }^{125}$ :

The process of interview preparation starts with familiarization with the details of a job every time it becomes available. The more the interviewer knows about the job to be filled, the more accurate he can be in assessing the candidate's suitability to it. Familiarization with the job includes reviewing the following items:

- The job duties and responsibilities.

- The education and prior experience needed.

- $\quad$ Reporting relationships.

- Work environment and time schedule.

- $\quad$ Salaries and benefits.

Familiarization with all this information helps the employer in answering the candidate's questions by giving the needed information concerning the job. Such information enables the applicant to decide well in advance whether he is interested to work in the bank or not.

\section{ii - The bank ${ }^{126}$ :}

The interviewer should know the bank thoroughly to be able to answer the candidate's questions accurately. The more the interviewer knows about the bank, the more he will be in a position to represent it fully. 


\section{iii - The applicant's background:}

The interviewer must review any material that is available about the applicant before the interview begins. He can study the application form, test scores, and the screening interview information in order to get a preliminary understanding of the applicant and his background. A review of the application blank may reveal some unclear or missed information that may be needed for the employment decision ${ }^{127}$.

An important reminder here is that the interviewer should read and analyse the application thoroughly not just scanning it in one or two minutes during their way from the secretary's office to the office where the interview is held. Also, interviewers should not stick to the application blank during the interview and repeat the same questions found in it instead of asking new clarifying questions.

\section{1.b - Interview strategy:}

The interviewer should formulate the strategy of information gathering or the method for carrying the interview. There are various methods of conducting an interview depending on the amount of control or structure that will be exercised by the interviewer. In classifying interviews according to the degree of the interviewer's control, we can identify three types:

\section{i - Patterned interview ${ }^{128}$ :}

This is the most structured type of interviews where the interviewer has a direct control over the interview and prepares a list of questions in advance from which he does not deviate. Here, the interviewer prepares a direct question and a list of possible answers from which he checks the interviewee's response. 
However, this interview strategy rarely elicits information about the applicant's traits and habit patterns that are important for hiring decision. Besides, it allows little opportunity or freedom for the interviewer and the interviewee to elaborate questions and answers. That is why very few employment interviews are structured.

\section{ii - Semistructured interview ${ }^{129}$ :}

This approach combines freedom to develop insights and structure to facilitate the collection of factual information. In a semistructured interview, only the general questions are prepared in advance and then the interviewer asks additional probing questions depending on the interviewee's answers. There are two popular interviewing programs that use semistructured interviews; situational interviewing and targeted interviewing.

Under situational interviewing the interviewer asks the candidate to decide what actions he does under a hypothetical situation. The response is then evaluated against preset criteria derived usually from a detailed job analysis that identifies essential characteristics and skills.

On the other hand, the targeted selection interview is based on the assumption that past behavior is a good indicator of future behavior. Questions asked focus on what the person has done in a pervious situation. 


\section{iii - Non directive interview ${ }^{130}$ :}

In non directive interviews or non structured interviews, the interviewer does not plan advance what questions to ask. However, the interviewer gives the candidate a great amount of freedom to speak and give valuable information that can not be uncovered through a patterned interview. The interviewer may only prepare general few questions to get the interview started; but the interviewee will determine the course of the interview:

\section{1.c - Structure of the interview:}

To secure the collection of all needed information the interviewer should determine the topics to be explored and the questions to be asked that will help the interviewer in gathering a considerable amount of information about the candidate's ability to succeed on the job.

A tool that helps in determining which data to gather is the technique of "factor analysis". This technique devides the factors that account for success or failure at work $^{131}$ :

1 - Knowledge / experience.

2 - Intellectual ability.

3 - Personality strength and limitations.

4 - Motivational characteristics and interests.

Acquiring information about these factors enables the interviewer to write a descriptive paragraph about each of these factors including the relevance of the candidate's knowledge and work experience on the job, his relationship and interaction with people, his thought and problem solving processes, his aspirations, interests and energy level. 


\section{2 - Types of interviews:}

There is wide range of selection interview types or formats. In addition to the screening, the patterned, semistructured, and non structured interview types, the selection officer can also use one or more of the following types of interviews in selecting new hires:

\section{2.a - The one-to-one interview ${ }^{132}$ :}

As the name suggests, the one-to-one interview involves the interviewee and only one selection officer. This interview format is normally used by employers when hiring low level employees rather than hiring for high managerial positions.

\section{2.b - The stress interview ${ }^{133}$ :}

Although interviews involve a certain amount of stress, the interviewer intentionally creates additional stress. The rational in this approach is the belief that the environment at work is a stressful one and that it is important to see how the applicant responds and reacts under pressure. Typically, the stress interview is conducted in the form of a board interview where interviewers rapidly fire questions on the applicant allowing little time if any time to gain composure. However, since the stress created in this interview type is not similar to that found at work and leads to abnormal behavior, stress interviews are rarely followed in effective selection.

\section{2.c - The board interview ${ }^{134}$ :}

This is the most widely used approach in interviewing candidates for managerial positions where a panel of interviewers question and observe a single candidate. The acceptance of the candidate depends on the approval of 
the panel. This approach saves the interviewee time; instead of rushing from one office to another, all interviewers can be brought together so that the interviewee can respond to all their questions.

\section{2.d - The group interview ${ }^{135}$ :}

It consists of having a group of candidates being interviewed by one more interviewers. This approach allows, the interviewer(s) to collect information from a group of applicants simultaneously and avoids having to repeat the same question and the same information about the bank to each individual. Sometimes the group interview takes the form of an assessment center involving the group to solve and discuss a certain issue.

\section{3 - Guidelines for an effective interview:}

Although employment interviews are used extensively as a selection tool and most employment officers rely heavily on information collected through them, the reliability and validity of interviews are highly questionable ${ }^{136}$. To render interviews an affective selection device, the interviewer must follow the following guidelines:

The interviewer should not be influenced by the results of previous interviewees ${ }^{137}$.

- The interviewer should avoid generalization or stereotyping. candidates coming from a certain university should not be rated outstanding if it happens that most of the company's outstanding employees are graduates of that university ${ }^{138}$.

- The interviewer should avoid making quick decisions based on the first impressions. Most interviewers make their decision during the first few 
minutes of the interview and do not take into consideration what the candidate says during the remaining interview time ${ }^{139}$.

The interviewer should avoid searching for only negative information during the interview. Interviewers are usually more influenced by small negative information than by large positive information which may change the selection decision that was made. This may cause the dissmissal of many good candidates ${ }^{140}$.

- The interviewer should not dominate the interview. During the selection interview the candidates should talk $75 \%$ of the time; but the opposite occurs. The effective interviewer must learn "how to lead the discussion rather than how to dominate $\mathrm{it}^{\text {"141. }}$.

- The interviewer must avoid telegraphing the desired answer or asking questions that reveal what he wants from the candidate ${ }^{142}$.

- The interviewer should not wait too long after the interview is over to write notes about the candidate. Notes should be taken during the interview and then developed short after the interview is over in order not to forget some remarks. However, taking notes does not mean that the interviewer should always be writing and not watching the candidate. Writing during the whole time prevents the interviewer from observing the candidate's behavior and may render the candidate nervous and anxious when he knows that the interviewer is writing all what he is saying ${ }^{143}$.

The interview should take place in a secluded place, the surrounding should be comfortable, and the interview should not be interrupted whatsoever. Such a climate contributes to a feeling on the part of the candidate that he matters the bank and that the interview is very important ${ }^{144}$. 
- The interviewer should know how to get the interview started and how to close it. He should start the interview with a neutral question such as "tell me about your hobby" to reduce the candidate's stress and then starts the selection interview after two to three minutes depending on the amount of stress. The interview should also have a sense of closure. To close an interview, the interviewer may ask whether the candidate wants to ask any question, he may tell the candidate how he will get informed about the result or just to close the interview with a polite statement showing respect to the applicant ${ }^{145}$.

- The interviewer should always encourage the applicant to talk more whether in smiling and nodding his head, paraphrasing what the applicant was saying to encourage him talk more about the topic, repeating the question or asking for further clarifications ${ }^{146}$.

\subsubsection{D Background investigations:}

Checking a candidate's background has become an important part of the selection process for candidates have the tendency to supply inaccurate information on application blanks and during selection interviews. Although checking references involves spending a good deal of time and money, they are necessary in banking because working in banks is a sensitive job.

\section{1- Source and methods of background investigations:}

Background references are usually drawn from three main sources: schools, former employers, and personal references. Generally, personal references are not very valuable since references that are likely to be selected by the candidate are those who will speak or write well of him. Schools or former employers, however, are generally more dependable because information obtained from 
these sources are based on the candidate's actual performance at school or on his previous job ${ }^{147}$.

There are three main methods that the employment officer can use in conducting background investigations ${ }^{148}$ :

1.a - Personal visits: This is the most effective method for conducting background checking for in a face to face meeting the investigator is in a position to ask more questions and to probe areas of major disccrepancies. However, this method is rarely used because of the time and money it requires. It is normally restricted to unusual and highly important positions.

1.b - Telephone calls: Calling references on telephone is the least time and money consuming method. References that an applicant provides on the application blank are called and approached to verify some of the information that the selection officer feals it requires additional investigation.

This method is very effective when conducted with the candidate's previous employer who usually provides only little information in his written recommendation - the time when the candidate started and stopped working in the organization and the position held. Information concerning previous performance, behavior, and the reason behind leaving the job that former employers are reluctant to provide in writing can be easily revealed in telephone calls. 
1.c- Letters: This is the most time consuming method of reference checking. It consists of sending uniform letters to former employers or to colleges and universities. Its advantage is that it provides a copy directly fromthe sources. however, care should be taken here not to make the letter too long so that the respondent will not spend an inordinate amount of time answering questions.

However one problem with this method is that former employers are reluctant to provide any but only minimal information about the candidate. This will put the selection officer at a disadvantage since his employment decision must be based on non verified information. 


\subsection{Evaluating the employment process:}

An effective recruiting and selection program results in satisfied employees, reduced absentism and turnover, increased productivity and employees desire to learn.

\subsection{1 - Job satisfaction:}

Monitoring job satisfaction is very important to ensure maximum use of human resources, a dissatisfied employee does not produce at full potential.

An effective selection program generally matches the skills of an individual with the requirements of the job and results in high job satisfaction. Employees, especially those working in banks, must show high satisfaction at work since a dissatisfied employee performs his job carelessly and may commit mistakes and frauds that affect the bank profitability and sometimes, its reputation $^{149}$.

Absenteeism and turnover, resistance or desire to learn more about the job are indirect measure of job satisfaction ${ }^{150}$.

2.3.1.A- Absenteeism and turnover: These two factors are highly correlated; when absenteeism rates are high, turnover rates are also high. They represent the usual way to express dissatisfaction at work ${ }^{151}$.

Studies showed that the highest turnover rates are found in companies whose employees are dissatisfied whether with pay, with the work environment, or with the job itself. Most explanations for turnover showed that dissatisfied employees usually quit the organization whenever they find alternative jobs that satisfy their needs ${ }^{152}$. 
Studies also show that absenteeism and especially turnover rates are higher with young and new hires than with old employees because younger people are more aggressive than older ones ${ }^{153}$.

It is worth mentioning that turnover and absenteeism costs are high. Turnover cost consist of hiring, training, and developing costs that should be incurred every time a new employee is hired to replace the one who left the organization. Absenteeism costs include service revenues lost during the absenteeism period as well as the reduced quality of services that should be provided with fewer employees. Consequently, organizations should enhance their recruiting and selection activities in order to minimize these $\operatorname{cost}^{154}$.

2.3.1.B- Resistance to learn: A poor selection program usually results in placing an individual on a job that does not fit him. If selection data shows that an individual is best fit to work in the personnel department but was placed in the accounting department simply because there is a vacancy in that department, the employee is likely to be dissatisfied with the job and will show resistance to learn more about it ${ }^{155}$.

\subsection{2 - Productivity:}

A fair hiring program that places the right person the right place results in longterm gains to the bank from the standpoint of both productivity and longitivity. This is based on the assumption that a work force which enjoys a high morale will be more productive than a work force that suffers from poor placement and low morale ${ }^{156}$. 
This chapter includes a detailed literature review of the employment process. It contains a detailed description of effective recruiting methods and sources and of effective selection tools and policies.

The next chapter is going to describe the methodology used in this research, the population and the sample, and the coding of the questionnaires used. Chapter four includes a presentation and an analysis of the research findings. Finally, chapter five includes a summary of the research findings and the recommendations . 


\section{CHAPTER III \\ RESEARCH METHODOLOGY}

This chapter includes a discussion about the population and the sample selected, the methods used in data collection, the measurements of the variables, and the research methodology.

\subsection{The population and the sample:}

As mentioned in chapter one, the effectiveness of recruiting and selection is going to be assessed from the point of view of both personnel managers and employees who were hired recently (Within maximum 3 years).

Personnel managers are directly involved in the employment process, they are asked to fill a questionnaire to determine what are the employment tools they depend on in hiring new employees and whether these tools are effective or not. The number of banks contacted was 35 .

Employees who are hired recently are those individuals who have actually passed the employment process. They are asked to fill a questionnaire which is approximately similar to that distributed to personnel managers in order to determine whether there is any difference between the personnel managers' answers and those of employees. The number of questionnaires collected was 116. 


\subsection{Methods used in data collection:}

Questionnaires and interviews are the main methods of data collection in this research. For each of the banks that were selected, a questionnaire was filled by the personnel manager and three or four questionnaires were filled by newly hired employees at different levels. The purpose of questionnaire distribution is to collect as much data as possible because of time limitations and the need of a representative sample.

Besides questionnaires, few managers suggested to fill the questionnaire through interviews. Although this method was time consuming it was very effective since it has many advantages over simple filling of questionnaires :

Personnel interviews provide the opportunity to give a feedback to the respondent whether in clarifying the questions or in reassuring the respondent who is reluctant to provide information that his or her answers will be strictly confidential. Also, interviews provide some flexibility in probing for clearer explanations of their answers and in expanding questions to determine indirectly whether what he or she was pretending was exactly what was meant.

Appendix (A) shows the questionnaires used in this research. The variables studied in these questionnaires are divided into two types: The dependent and the independent variables. The following sections include the discussion of the measurement of the variables of the questionnaires. 


\subsection{Measurement of the independent variables:}

The independent variables are those related to the personal characteristics of the respondents whether personnel managers or newly hired employees.

3.3A The coding system used for the independent variables in the questionnaire directed to personnel managers in presented below:

A1- Position currently occupied: Personnel manager is coded one, assistant personnel manager is coded 2 , administrative manager or others (performing personnel functions) is coded 3 .

A2- Education: B.S. is coded 1, M.S. is coded 2, and Ph.Dd is coded 3 .

A3- Major: If the manager's major is related to his job then the answer is coded 1 , if no the answer is coded 2 .

A4- Age : The age is input as it is and then receded depending on its frequency distribution.

A5- Sex: Male is coded 1 , female is coded 2.

A6- Marital status: Married is coded 1, single or engaged is coded 2.

A7- A8 - A9- The number of years of experience, the number of employees, and the number of branches: These questions are also coded like question A7; the answer was input as it is and then recoded according to the frequency distribution. 
A10- Whether the bank has a personnel department or not: Yes is coded 1 , No is coded 2 .

A11- The year of formation of the personnel department: The purpose of this question is to determine after how many years of the banks foundation the personnel department was formed. "Formation" also means the formation of the personnel department in its current status. This answer was input as it is and then recoded while analyzing the data.

A12- Whether there are personnel policies in the bank: Yes is coded 1, No is coded 2 .

A13- Whether personnel policies are known to all employees: Yes is coded 1 , No is coded 2 .

A14- This question is divided into 3 questions:A14a- A14b, and A14c: How personnel policies are made known to employees. These questions are coded in the same way. If the option is chosen then the question is coded 1 and 2 if otherwise.

A15- The performance of personnel functions: This question has 3 options and is coded as follows: 1 for choice a, 2 for choice b, and 3 for choice c. 
3.3.B The coding system used for the independent variables in the questionnaire directed to newly hired employees is presented below:

The first 7 questions and questions A11 and B4 of the personnel managers questionnaires were also used in the analysis of the questionnaire directed to employees to be used as independent variables. They are coded in the same way and they are labeled $\mathrm{X} 1$ to $\mathrm{X} 9$.

The coding used for the remaining independent variables is as follows:

A1, and A2- The number of employees and branches: Answers to these questions were input as they are in order to be recoded later in the analysis.

A3- Education: School education is coded 1

B.S is coded 2.

Masters and higher are coded 3.

A4- Major: Business is coded 1, Computer Science is coded 2, Banking is coded 3, and others (literature, political studies etc...) is coded 4 .

A5- The university from where the employee graduated:

AUB is coded 1.

BUC is coded 2.

USJ is coded 3.

Lebanese university is coded 4.

Arabic University is coded 4

Others (Schools, foreign universities etc ...) is coded 6. 
A6- This question is coded as questions $\mathrm{A} 1$ and $\mathrm{A} 2$ were coded. The answers were input as they are and then recoded while analyzing the data.

A7- Sex: Male is coded 1 , female is coded 2.

A8- Marital status: Married is coded 1, single or engaged is coded 2.

A9- Age: This question was input as it is to be recoded while analyzing the data.

A10- The department where employee works: if the employee's major is related to his work, than the answer is coded 1 and 2 if otherwise.

A11- Position: - Officer of first and second category, or assistant head of section are coded 1 .

- Head of section, or controller are coded 2.

- Higher levels are coded 3.

A12- A13 and A14- They are coded in the same way: Yes is coded 1, No is coded 2.

A15- This question is divided into 3 questions:A15a, A15b, and A15c: are coded in the same way. If the option is chosen then the answer is coded 1 and 2 if not chosen. 


\subsection{Measurement of the dependent variables:}

The dependent variables measure turnover, factors affecting the employment decision, recruiting methods and recruiting sources, selection tests, interviews, references checking methods, and the evaluation of the recruiting and selection processes. The coding system of these variables is presented below:

\subsection{A- Questionnaire directed to personnel managers:}

The coding of the various sections is as follows:

Turnover section: The questions of this section are coded in 3 different ways:

- Questions B1 and B2 were input as they are to be recoded later.

- A new question B3 was inserted to determine the turnover rate of newly hired employees (Number of leaves among new hires divided by the number of newly hired employees). The rate was input as it is to be recoded later.

- B4 to B8: These questions have all the same 3 choices and are coded uniformly: 1 for choice a, 2 for $b$, and 3 for $c$.

Factors affecting employment section: Questions $\mathrm{C} 1$ to $\mathrm{C} 9$ of this section have the same 3 choices (strong, medium or No effect). Strong effect is coded 1 , Medium effect is coded 2, and No effect is coded 3.

Sections D, E, F, G and $H$ (Recruiting methods and sources, and selection tools): Questions D1 to D7, E1 to E6, F1 to F6, G1 to G7, H1 to H13, and I1 to $\mathrm{I} 3$ of these sections have all 4 choices and hence they are coded as follows:

Always is coded 1.

Most of the times is coded 2.

Sometimes is coded 3.

Never is coded 4. 
A question (G0) was inserted in section $\mathrm{G}$ to determine whether tests are used in selection. If tests are used then $\mathrm{G} 0$ is coded 1 and 2 if not.

Employee performance section: Questions $\mathrm{J} 1$, to $\mathrm{J} 4$ are aimed to relate the effectiveness of the employment process to employee performance. All these questions have 3 options $a, b$, and $c$ and are coded with 1,2 , and 3 respectively .

\subsection{B- The questionnaire directed to new employees:}

The coding system of the various sections of independent variables is presented as follows:

Turnovers section: Questions B1, B2 and B3 are coded in the same way since they have the same 3 choices:

Choice A is coded 1.

Choice B is coded 2.

Choice $\mathrm{C}$ is coded 3 .

Factors affecting employment section: Questions $\mathrm{C} 1$ to $\mathrm{C} 10$ of this section have the same 3 choices and are coded in the same manner:

Strong effect is coded 1.

Medium effect is coded 2.

No effect is coded 3.

Recruiting methods section:

Question D1- This question is to determine how the new employee was informed about the existence of the job vacancy. Since this question has 8 choices (from a to e) these choices are coded from 1 to 8 respectively. 
Question D2 - This question is to determine whether screening interviews are used in selection. If the respondent was subject to a short screening interview then the answer is coded 1 and 2 if not.

Selection tests section: Questions E1 to E6 of this section have the same choices (Agree, Disagree, Undecided) and are all coded as follows:

Agree is coded 1.

Disagree is coded 2.

Undecided is coded 3.

\begin{abstract}
A question (E0) was inserted in this section to determine whether the respondent was tested when employed. If the respondent was tested, the answer is then coded 1 and 2 if not.
\end{abstract}

Selection interviews section:- The questions of this section are of 3 types and are coded in 3 different ways:

- Questions F1, F2, F3 and F4 have two choices a and b:

$$
\begin{aligned}
& a \text { is coded } 1 . \\
& b \text { is coded } 2 .
\end{aligned}
$$

- Question F5 has 3 choices $a, b$, and $c$ and is coded 1,2 and 3 respectively .

- Questions F6 to F13 have the same 3 choices (Agree, Disagree, Undecided) and are coded as follows:

Agree is coded 1.

Disagree is coded 2.

Undecided is coded 3. 
General evaluation of the employment process section:Questions G1 to G9 of this section have 5 choices and are all coded uniformly:

Strongly agree is coded 1 .

Agree is coded 2.

Undecided is coded 3.

Disagree is coded 4.

Strongly disagree is coded 5.

\subsection{Research Methodology:}

The descriptive analysis approach will be used in order to answer the research questions stated in chapter one. Descriptive analysis entails the transformation of raw data into meaningful statistical information thus facilitating the understanding and interpretation of results. In addition, statistical analysis through SPSS will be used to answer the research question and to test the hypotheses stated in chapter one .

This chapter includes a discussion about the population and the sample selected, the data gathering methods, the measurement of the variables and the research methodology. The next chapter will include a presentation of the research findings and an analysis of these findings . The last chapter (chapter5) will include a summary of the research findings and some recommendations for more effective recruiting and selection. 


\section{CHAPTER IV \\ FINDINGS OF THE STUDY}

This research is concerned with the assessment of the effectiveness of recuriting and slection methods followed by banks operating in Lebanon. Therefore, to achieve the prupose of this research two questionnaires were designed; one questionnaire was directed to personnel managers and one to newly hired employees. These questionnaires are almost similar and consist of seven sections:

1- Demographic and business section: it deals with the characteristics of the respondents and the bank they work in .

2- Turnover section: it measures the turnover rate among new hires and it deals with the assessment of turnover among males and females .

3- Recruiting section: It shows the major recruiting methods and sources used by personnel managers.

4- Selection tests section: It measures the adequacy of selection tests used in selection.

5- Selection interviews section: It measures the adequacy of selection interviews used in selection.

6- Reference check section: It shows the references that banks depend on in verifying the information provided by the candidates.

7- The evaluation of the recruiting and selection process: It measures the employee's satisfaction to determine whether it improves with better recruiting and selection. 
This chapter answers, the research questions presented in chapter one. These questions are:

1- Do banks operating in Lebanon follow adequate recruiting and selection processes?

2- Does employee satisfaction increase with better recruiting and selection?

3- Is employee turnover affected by the adequacy of recruiting and selection.

In addition some hypotheses are tested to determine the following:

1- Whether the use $\mathrm{f}$ selection tests is dependent on the candidate's experience.

2- Whether turnover rate is dependent on whether tests are used as a selection tool.

3- Whether the type of the selection interview is dependent on the position to be filled.

4- Whether the adequacy of the interview is dependent on the candidate's education.

5- Whether job safisfaction is dependent on whether the employee's job matches his education and major.

6- Whether the adequacy of the placement on the job is dependent on the position to be filled.

To answer the research questions and to test the hypotheses stated above the descriptive analysis approach will be used as well as the statistical analysis through the use of SPSS. Therefore, frequency distributions, percentage distributions, graphs, cross tabulations, and linear regressions will be presented in this chapter. 


\subsection{Characteristics of the respondents and the banks:}

In this section an analysis of the answers of demographic and business section will be presented. Those questions deal with the position, education, major, age, sex, marital status, and experience of the respondent. In addition, few questions are related to the bank such as the number of employees in it, whether the bank has a personnel department and when was it formed, whether there are personnel policies in the bank and how these policies are known to employees. Finally, a question was asked to determine by whom personnel functions are performed.

\subsection{Characteristics of respondents:}

4.1.1A. Each demographic question will be presented separately for both types of respondents. We will first start by the analysis of demographic data of personnel managers

\section{Table 1}

The positon currently occupied (Question A1)

\begin{tabular}{|l|c|c|c|}
\hline \multicolumn{1}{|c|}{ Position } & Freq & Percent & Cum. Percent \\
\hline Personal manager & 24 & 68.60 & 68.60 \\
\hline Assistant personel manager & 6 & 17.10 & 85.70 \\
\hline General or administrative manager & 5 & 14.30 & 100.00 \\
\hline Total & 35 & 100.00 & \\
\hline
\end{tabular}

Table1 indicates that the majority of respondents are only holding the position of personnel manager while $14.3 \%$ are general or administrative managers who are also responsible of personnel work. 
Table 2

The education of respondent (Question A2)

\begin{tabular}{|l|c|c|c|}
\hline \multicolumn{1}{|c|}{ Education } & Frequency & Percent & Cumulative perecent \\
\hline Bachelor degree & 19 & 54.30 & 54.30 \\
\hline Master degree & 14 & 40.00 & 94.30 \\
\hline P h.D & 2 & 5.70 & 100.00 \\
\hline Total & 35 & 100.00 & \\
\hline
\end{tabular}

The education of the personnel manager

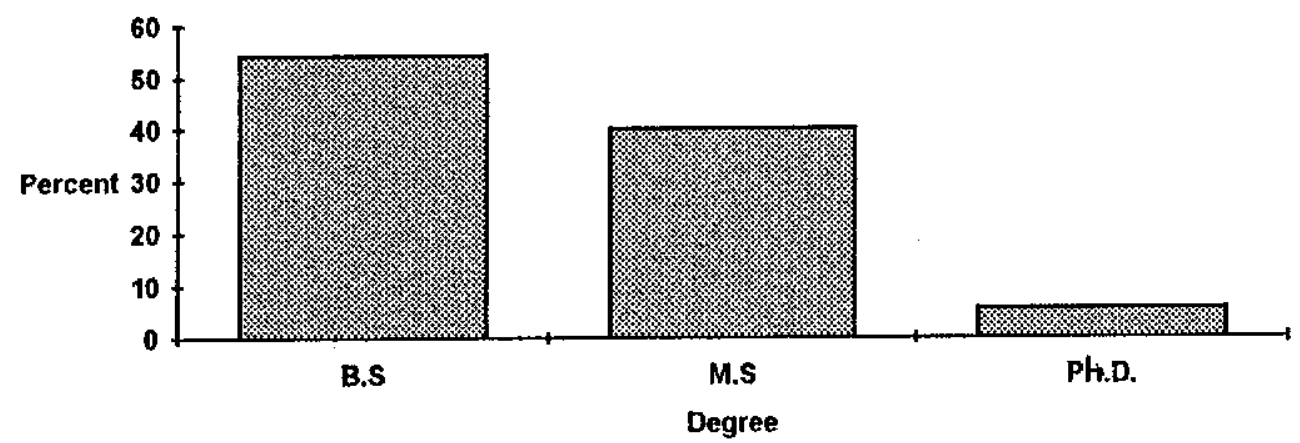

Question A2 indicates that $54.3 \%$ of the personnel managers are holders of at least a B.S degree, $40.0 \%$ of them 0 are holders of a Master degree; while very few (5.7\%) are holders of $\mathrm{PhD}$. 
Table 3

Whether the major of the personnel manager is related to personnel (Question A3)

\begin{tabular}{|l|c|c|c|}
\hline \multicolumn{1}{|c|}{ Major } & Frequency & Percent & Cumulative perecent \\
\hline Related & 13 & 37.10 & 37.10 \\
\hline Not Related & 22 & 62.90 & 100.00 \\
\hline Total & 35 & 100.00 & \\
\hline
\end{tabular}

Major : related or not

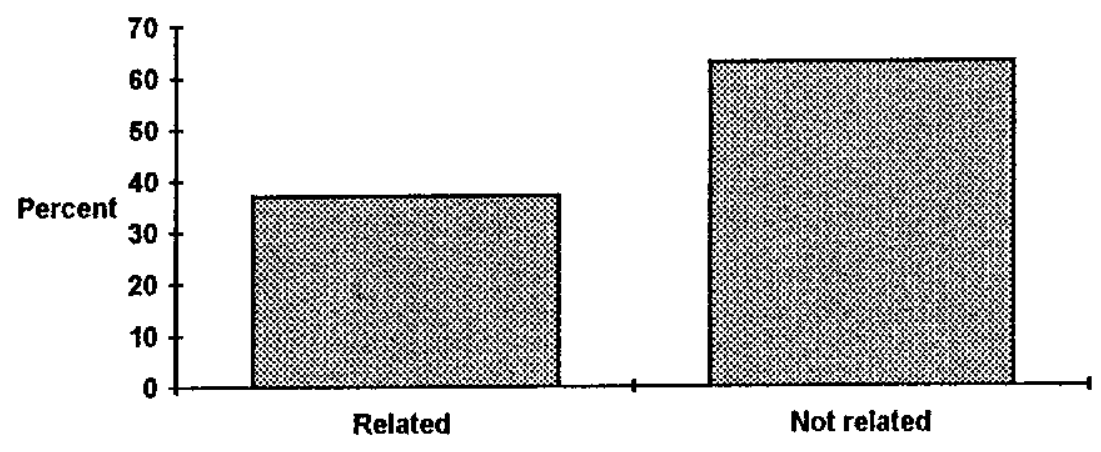

Related major means that the respondent's major is related to his work. This question indicates that $62.9 \%(22 / 35)$ of the personnel manager's major is not related to personnel; their major is either finance, or economics, or computer science, etc....... 
Table 4

The age of the respondent (Question A4)

\begin{tabular}{|l|c|c|c|}
\hline \multicolumn{1}{|c|}{ Age } & Frequency & Percent & Cum. perecent \\
\hline below 35 years & 7 & 20.00 & 20.00 \\
\hline between 36 and 45 years & 15 & 43.00 & 63.00 \\
\hline above 45 years & 13 & 37.00 & 100.00 \\
\hline Total & 35 & 100.00 & \\
\hline
\end{tabular}

Age is divided into three categories from young to old. Most of the personnel managers are between 36 and 45 years (43\%), 13 over 35 of them (37\%) can be considered old (above 45 years ). The mean age is 41.7 years and the mode is 52 years.

Table 5

The sex of the respondent (Question A5)

\begin{tabular}{|l|c|c|c|}
\hline \multicolumn{1}{|c|}{ Sex } & Frequency & Percent & Cum. perecent \\
\hline Male & 24 & 68.60 & 68.60 \\
\hline Female & 11 & 31.40 & 100.00 \\
\hline Total & 35 & 100.00 & \\
\hline
\end{tabular}

The majority of personnel managers $(68.6 \%)$ are males while $31.4 \%$ are female. This might be because it takes a long time for a person to reach the position of "Head of personnel department" and most of the females , especially married women, leave their job at a certain age. 
Table 6

The marital status of the respondent (Question A6)

\begin{tabular}{|l|c|c|c|}
\hline \multicolumn{1}{|c|}{ Marital Status } & Frequency & Percent & Cum. perecent \\
\hline Married & 27 & 77.10 & 77.10 \\
\hline Not married & 8 & 22.90 & 100.00 \\
\hline Total & 35 & 100.00 & \\
\hline
\end{tabular}

Question A6 indicates that most of the respondents are married while $22.90 \%$ of them are either engaged or still not married.

\section{Table 7}

The experience of the respondent (question $A 7$ ):

\begin{tabular}{|l|c|c|c|}
\hline \multicolumn{1}{|c|}{ Experience } & Frequency & Percent & Cum. perecent \\
\hline From 0 to 9 years & 14 & 40.00 & 40.00 \\
\hline From 10 to 19 yèars & 16 & 45.70 & 85.70 \\
\hline 20 years and above & 5 & 14.30 & 100.00 \\
\hline Total & 35 & 100.00 & \\
\hline
\end{tabular}

The experience of the personnel manager

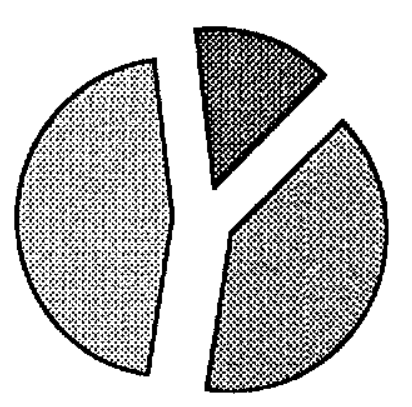


Experience is divided into 3 groups to determine the degree of experience of the respondents from low to high. It was found that the majority of them $(45.7 \%)$ are in the range of those having 10 to 19 years of experience in the personnel work. The mean is 11.4 years. 


\subsubsection{B Demographic data of newly hired employees:}

\section{Table 8}

The position of the employee (Question A11)

\begin{tabular}{|l|c|c|c|}
\hline \multicolumn{1}{|c|}{ Position } & Frequency & Percent & Cum. perecent \\
\hline Low & 56 & 48.30 & 48.30 \\
\hline Medium & 37 & 31.90 & 80.20 \\
\hline High & 23 & 19.80 & 100.00 \\
\hline Total & 116 & 100.00 & \\
\hline
\end{tabular}

The experience of the respondent

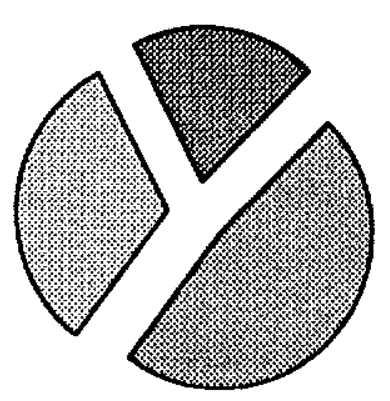

$48.3 \%$ of the respondents are those in low positions while $19.8 \%$ are in high positions. This low response among employees of high positions is due to their reluctance to provide information and to their excuse for not having enough time to answer the questionnaire. Another reason might be the scarcity of new employees at high level since the individual becomes reluctant to leave his job to go to a new one in another bank. 
Table 9

The experience of the respondent (Question A6).

\begin{tabular}{|l|c|c|c|}
\hline \multicolumn{1}{|c|}{ Experience } & Frequency & Percent & Cum. Percent \\
\hline No experience & 48 & 41.38 & 41.38 \\
\hline From to 10 years & 41 & 35.34 & 76.72 \\
\hline 11 years and more total & 27 & 23.28 & 100.00 \\
\hline Total & 116 & 100.00 & \\
\hline
\end{tabular}

Table 9 shows that most of the respondents of this questionnaire are fresh graduates. That is why most of them are in low positions. $23.28 \%$ have 11 years of experience and above since as mentioned before old employees are reluctant to leave their jobs and take the risk of whether the new job is more satisfactory than the old one or not.

\section{Table 10}

The education of the respondents (Question A3)

\begin{tabular}{|l|c|c|c|}
\hline \multicolumn{1}{|c|}{ Education } & Frequency & Percent & Cum. perecent \\
\hline High school & 30 & 25.90 & 25.90 \\
\hline B.S & 72 & 62.10 & 88.00 \\
\hline M.S. or higher & 14 & 12.00 & 100.00 \\
\hline Total & 116 & 100.00 & \\
\hline
\end{tabular}

The majority of new hires are holders of a leat a B.S degree. This is a good indicator since in the past the trend was to choose holders of Baccaloriat while nowadays banks are asking for at least a university degree for an employee of first degree (low positon) 


\section{Table 11}

Whether the major is related or not (Question A10):

\begin{tabular}{|l|c|c|c|}
\hline \multicolumn{1}{|c|}{ Major } & Frequency & Percent & Cum. perecent \\
\hline Related & 64 & 55.20 & 55.20 \\
\hline Not Related & 52 & 44.80 & 100.00 \\
\hline Total & 116 & 100.00 & \\
\hline
\end{tabular}

\section{Whether the employees major is related to job}

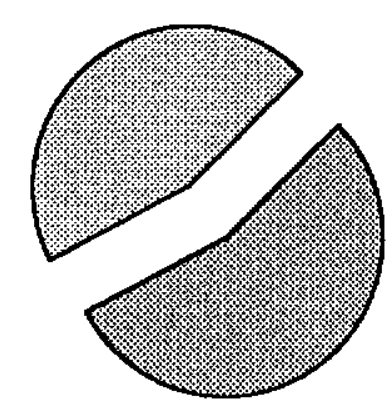

The purpose of question A10 is to determine whether there is a fit between the empolyee's major and his/her work. $55.2 \%$ of respondents have their major related to their job while $44.8 \%$ of them- which is a large percentage- are on jobs which are not related to their major. 
Table 12

The major of the respondents (Question A4)

\begin{tabular}{|l|c|c|c|}
\hline \multicolumn{1}{|c|}{ Major } & Frequency & Percent & Cum. perecent \\
\hline Business & 50 & 43.10 & 43.10 \\
\hline Computer Science & 15 & 12.90 & 56.00 \\
\hline Banking & 12 & 10.40 & 66.40 \\
\hline others & 39 & 33.60 & 100.00 \\
\hline Total & 116 & 100.00 & \\
\hline
\end{tabular}

Major of employees

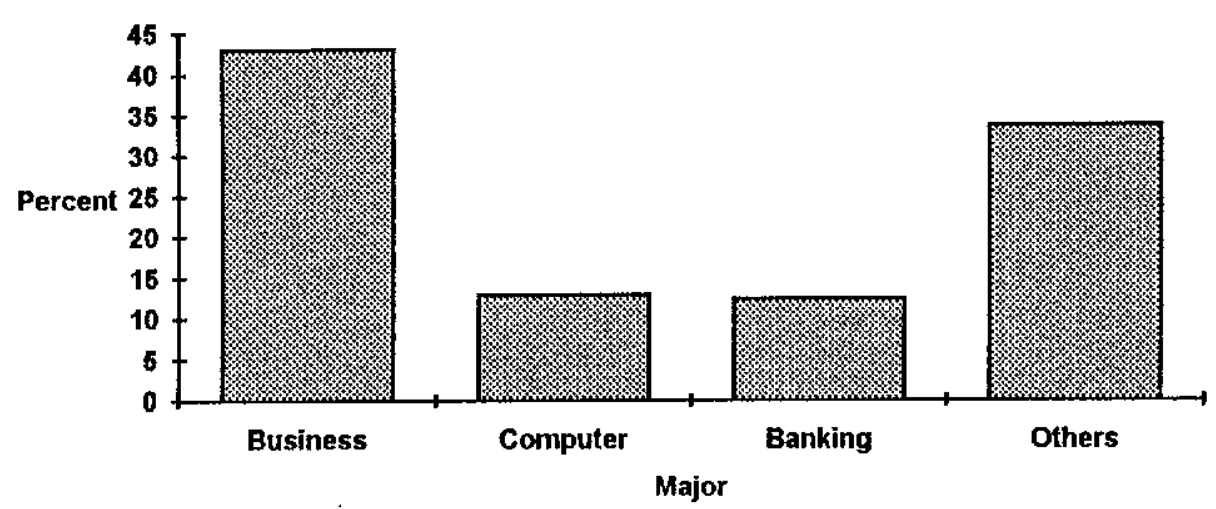

Table 13

The univesity from where the applicant graduated (Question A5):

\begin{tabular}{|l|c|c|}
\hline \multicolumn{1}{|c|}{ University } & Frequency & Percent \\
\hline A.U.B & 26 & 22.40 \\
\hline B.U.C & 22 & 19.00 \\
\hline U S J & 15 & 12.90 \\
\hline Lebanese. University & 18 & 15.50 \\
\hline Arab University & 9 & 7.80 \\
\hline Others & 26 & 22.40 \\
\hline Total & 116 & 100.00 \\
\hline
\end{tabular}


Universities or schools from where employees graduated

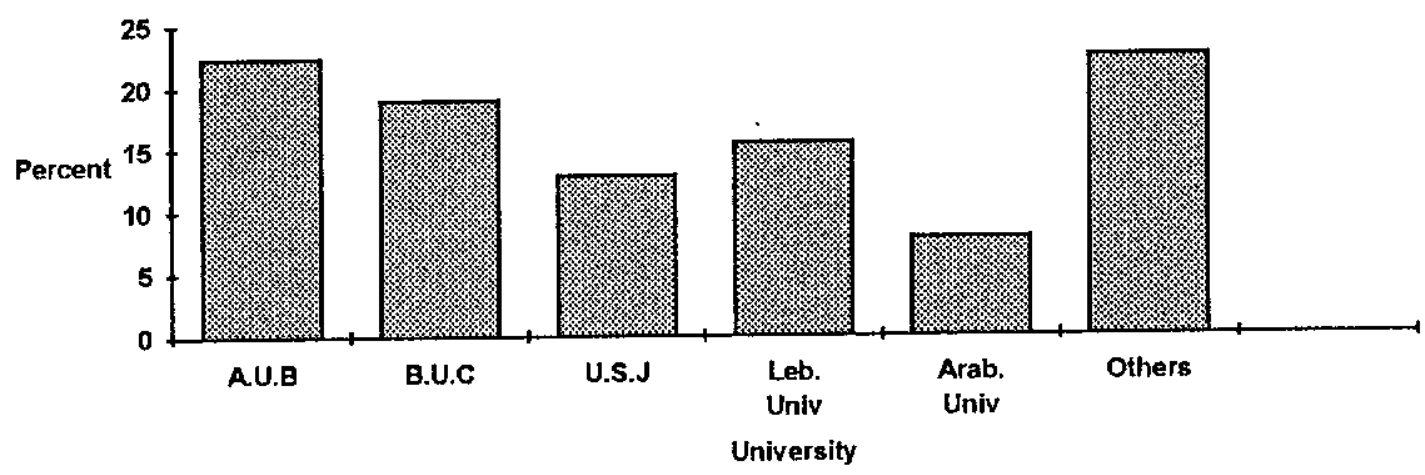

$41.40 \%$ respondents are AUB and BUC graduates. This indicates that there may be a trend to accept more graduates of these two universities than among others..

\section{Table 14}

The age of the respondent (Question A9):

\begin{tabular}{|l|c|c|c|}
\hline \multicolumn{1}{|c|}{ Age } & Frequency & Percent & Cum. perecent \\
\hline between 20 and 30 years & 76 & 65.50 & 65.50 \\
\hline between·31 and 40 years & 30 & 25.90 & 91.40 \\
\hline above 41 years & 10 & 8.60 & 100.00 \\
\hline Total & 116 & 100.00 & \\
\hline
\end{tabular}

The majority of new hires are young employees. This might be explained by the fear of old employees to leave their job and find a new one which might not be as satisfactory as the old one. 
Table 15

The sex of the respondent (Question $A 5)$ :

\begin{tabular}{|l|c|c|c|}
\hline \multicolumn{1}{|c|}{ Sex } & Frequency & Percent & Cum. perecent \\
\hline Male & 58 & 50.00 & 50.00 \\
\hline Female & 58 & 50.00 & 100.00 \\
\hline Total & 116 & 100.00 & \\
\hline
\end{tabular}

The respondents are equally divided into 2 groups: $50 \%$ are males and $50 \%$ are females.

\section{Table 16}

The marital status of the respondent (Question A8):

\begin{tabular}{|l|c|c|c|}
\hline \multicolumn{1}{|c|}{ Marital Status } & Frequency & Percent & Cum. perecent \\
\hline Married & 45 & 38.80 & 38.80 \\
\hline Not married & 71 & 61.20 & 100.00 \\
\hline Total & 116 & 100.00 & \\
\hline
\end{tabular}

Question A8 indicates that the majority of respondents are not married (61.2\%) this might be because most of them are under 30 years old.

\section{Summary:}

Most of the personnel managers are holders of a B.S degree and most of them have a major not related to personnel. The majority of them are males, married, and between 36 and 45 years old. 
As for newly hired employees most of them are young, single, and holders of a B.S degree; but only $55.20 \%$ of them have their work related to what they have studied. The majority of them are graduates of American style universities and their major is mainly in Business, Computer Science and Banking .

\subsubsection{Business characteristics of the bank:}

The analysis of the business section will be presented based on personnel managers answers since no major differences appeared between their answers and those of new employees.

\section{Table 17}

The number of employees in the bank (Question A1):

\begin{tabular}{|l|c|c|c|}
\hline \multicolumn{1}{|c|}{ No. of employees } & Frequency & Percent & Cum. perecent \\
\hline Below 150 employess & 14 & 40.00 & 40.00 \\
\hline between 151 and 350 & 10 & 28.57 & 68.57 \\
\hline Above 351 & 11 & 31.43 & 100.00 \\
\hline Total & 35 & 100.00 & \\
\hline
\end{tabular}

For further tabulations, banks were classified into 3 categories depending on the number of their employees. The mean number of employees was 290 employed while the mode was 110 . Worth mentioning here is that most of the banks in Lebanon are those which have below 350 employees and almost all the banks that have more than 350 employees were contacted since in these banks recruiting and selection occur more frequently than in smaller banks. 
Table 18

Personnel department formation: (Question A11)

\begin{tabular}{|l|c|c|c|}
\hline \multicolumn{1}{|c|}{ Formation } & Frequency & Percent & Cum. perecent \\
\hline With the bank's foundation & 11 & 31.43 & 31.43 \\
\hline Between 1 and 10 years & 16 & 45.71 & 77.14 \\
\hline After 10 years & 8 & 22.86 & 100.00 \\
\hline Totoal & 35 & 100.00 & \\
\hline
\end{tabular}

All the managers contacted stated that the bank in which they are working had a personnel department. As for the question when the personnel department was formed ( in its current form) the results were as follows: 11/35 of the banks had their personnel department formed with the bank's foundation, 16/35 of the banks had it formed between 1 and 10 years, while 8/35 of them had it after 10 years of the bank's foundation. The mean is 6.1 years, the mode is just with the foundation of the bank.

\section{Table 19}

whether personnel policies are known to all employees (Question A13):

\begin{tabular}{|l|c|c|c|}
\hline Known to employees & Frequency & Percent & Cum. perecent \\
\hline Yes & 27 & 77.10 & 77.10 \\
\hline No & 8 & 22.90 & 100.00 \\
\hline Total & 116 & 100.00 & \\
\hline
\end{tabular}

All personnel managers stated that they have personnel polices in their bank. As to the dissemination of these policies among employees 27 or $(77.1 \%)$ of the personnel manager answered "Yes", while only 8 of them (22.9\%)answered "No". 
Table 20

How personnel policies are disseminated in the bank:

(Questions A14a-A14b-A14 C).

\begin{tabular}{|l|c|c|}
\hline \multicolumn{1}{|c|}{ Method } & $\begin{array}{c}\text { Frequency } \\
\text { out of 35 }\end{array}$ & $\begin{array}{c}\text { Percent } \\
\text { out of 35 }\end{array}$ \\
\hline Internal Bulletins & 24 & 68.60 \\
\hline Bulletin Boards & 7 & 20.00 \\
\hline Meetings & 10 & 28.60 \\
\hline
\end{tabular}

Table 20 shows that the most common used method in distributing personnel polices among employees is by internal bulletins.

It is worth mentioning here that meetings represent an important method for discussing and clarifying not only personnel policies but other policies related to the work. This can be an indicator that very few banks conduct periodic meetings to discuss current issues.

Table 21

How personnel functions are performed (Question A15).

\begin{tabular}{|l|c|c|c|}
\hline & Frequency & Percent & Cum. perecent \\
\hline Centralized in the P.D & 26 & 74.30 & 74.30 \\
\hline Decentralized & 1 & 2.90 & 77.10 \\
\hline By a single individual & 8 & 22.90 & 100.00 \\
\hline Total & 35 & 100.00 & \\
\hline
\end{tabular}

In most of the banks (26/35) personnel functions are preformed in the personnel department under the control of the personnel manager. In $22.9 \%(8 / 35)$ of the 
banks personnel functions are performed by a single individual; this is mainly in small banks (those having less than 100 employees).

Wherever these functions are performed their approval is made at higher levels and through committees.

\section{Summary:}

In most of the banks the personnel department was formed either with the bank's foundation or within 10 years of its foundation. All banks have personnel policies of which $77.1 \%$ disseminate them among all employees. The most used method of promoting personnel policies among employees is through internal bulletins. Finally, the majority of banks have the personnel functions centralized on the personnel department while in $22.9 \%$ of them- mainly small banks- personnel functions are performed by a single person. 


\section{4-2 Factors affecting empolyment:}

The purpose of this section is to determine the factors that affect the employment decision in banks. Ten factors that seem to affect the employment decision are analized based on their effect (strong, medium, no effect). Since this section showed differences between personnel managers and employees' answers, results of both respondents will be presented.

\section{Table 22}

The religion of the candidate (C1):

\begin{tabular}{|l|c|c|c|c|}
\multicolumn{1}{c}{ Personnel Managers } & \multicolumn{2}{c|}{ Employees } \\
\hline \multicolumn{1}{|c|}{ Effect } & Frequency & Percent & Frequecny & Percent \\
\hline Strong & 1 & 2.90 & 19 & 16.40 \\
\hline Medium & 12 & 34.00 & 56 & 48.30 \\
\hline No & 21 & 60.00 & 56 & 35.30 \\
\hline No answer & 1 & 2.90 & & \\
\hline Total & 35 & 100.00 & 116 & 100.00 \\
\hline
\end{tabular}

$60.0 \%$ of managers stated that religion has no effect while most of the employees (64.7\%) stated the opposite that religion has an effect and this effect is mostly medium. 
Table 23

The age of the candidate (C2)

Personnel Managers

\begin{tabular}{|l|c|c|c|c|}
\hline \multicolumn{1}{|c|}{ Effect } & Frequency & Percent & Frequency & Percent \\
\hline Strong & 18 & 51.40 & 49 & 42.20 \\
\hline Medium & 11 & 31.40 & 39 & 33.60 \\
\hline No & 6 & 17.10 & 28 & 24.10 \\
\hline Total & 35 & 100.00 & 116 & 100.00 \\
\hline
\end{tabular}

The majority of both personnel managers and employees answered that the candidate's age has a strong effect on employment. This might be because in their opinion for each position there is a suitable age. A branch manager for example, can not be a young person.

Table 24

The marital status of the candidate (C3)

\begin{tabular}{|l|c|c|c|c|}
\multicolumn{1}{|c|}{ Personnel Managers } & \multicolumn{2}{c|}{ Employees } \\
\hline Strong & Freq & Percent & Freq & Percent \\
\hline Medium & 11 & 31.40 & 41 & 35.30 \\
\hline No & 12 & 34.30 & 31 & 26.70 \\
\hline Total & 12 & 34.30 & 44 & 37.90 \\
\hline
\end{tabular}

The opinion of both personnel managers and employees is approximately evenly distributed among the three choices. However, adding the first two choices, one can find that more than $60 \%$ of respondents stated that the candidate's marital status does have an effect on the employment decision. 
When faced with two candidates of the same qualifications one is married and the other is not, the single person has the higher apportunity to be selected. Since this reduces many costs:children education, the cost of retardiness and urgent absences because of children problems, especially with women, etc...

\section{Table 25}

The sex of the candidate (C4):

Personnel Managers Employees

\begin{tabular}{|l|c|c|c|c|}
\hline \multicolumn{1}{|c|}{ Effect } & Freq & Percent & Freq & Percent \\
\hline Strong & 11 & 31.40 & 28 & 24.10 \\
\hline Medium & 11 & 31.40 & 38 & 32.80 \\
\hline No & 13 & 37.40 & 50 & 43.10 \\
\hline Total & 35 & 100.00 & 116 & 100.00 \\
\hline
\end{tabular}

As with sex, the opinion of both respondents is approximately evenly distributed among the three choices. Adding the first two choices together, one can find that more than $55 \%$ of the respondents agree that sex has an effect on the employment decision. This might be explained by the preference of banks to hire males more than females.

Table 26

The education of the candidate(C5)

\begin{tabular}{|l|c|c|c|c|}
\hline \multicolumn{1}{|c|}{ Effect } & Frequecny & Percent & Frequecny & Percent \\
\hline Strong & 34 & 97.10 & 78 & 67.20 \\
\hline Medium & 1 & 2.90 & 33 & 28.40 \\
\hline No & 0 & 0.00 & 5 & 4.30 \\
\hline Total & 35 & 100.00 & 116 & 100.00 \\
\hline
\end{tabular}


Question C5 indicates that the majority of respondents (97\% of personnel managers and $67.20 \%$ of employees ) answered that the education of the candidate has a strong effect on the employment decision. This result was expected and does not need much more explanation.

Table 27

The position to be filled (C6)

\begin{tabular}{|l|c|c|c|c|}
\multicolumn{1}{|c|}{ Personnel Managers } & Employees \\
\hline Etrong & Frequecny & Percent & Frequency & Percent \\
\hline Medium & 30 & 85.00 & 83 & 71.60 \\
\hline No & 40 & 11.00 & 31 & 26.70 \\
\hline Total & 1 & 2.90 & 2 & 1.70 \\
\hline
\end{tabular}

This question also indicates that the majority of respondents $(85 \%$ of personnel managers and $71.60 \%$ of employees ) agreed that the importance of the position to be filled has a strong effect on the employment decisions with only $2.90 \%$ of personnel managers and $1.70 \%$ of employees stating that this factor does not have any effect at all. 
Table 28

The organization where the candidate has previously worked (C7)

\begin{tabular}{|l|c|c|c|c|}
\multicolumn{1}{c}{ Personnel Managers } & \multicolumn{2}{c|}{ Employees } \\
\hline \multicolumn{1}{|c|}{ Effect } & Frequency & Percent & Frequecny & Percent \\
\hline Strong & 14 & 40.00 & 40 & 34.48 \\
\hline Medium & 17 & 48.57 & 60 & 51.72 \\
\hline No & 4 & 11.43 & 16 & 13.00 \\
\hline Total & 35 & 100.00 & 116 & 100.00 \\
\hline
\end{tabular}

The organization where the candidate had previously worked seems to have an effect and mostly a medium effect. By adding the first two options, it was found that $88.57 \%$ of personnel managers and $85 \%$ of employees answered that the organization from where the candidate got his experience has an effect on the employment decision.

\section{Table 29}

The university from where the applicant graduated (C8)

\begin{tabular}{|l|c|c|c|c|}
\multicolumn{4}{c}{ Personnel Managers } & \multicolumn{2}{c|}{ Employees } \\
\hline \multicolumn{1}{|c|}{ Effect } & Frequecny & Percent & Frequency & Percent \\
\hline strong & 12 & 34.30 & 44 & 37.93 \\
\hline Medium & 13 & 37.10 & 44 & 37.93 \\
\hline No & 10 & 28.60 & 28 & 24.14 \\
\hline Total & 35 & 100.00 & 116 & 100.00 \\
\hline
\end{tabular}

$0.40 \%$ of personnel managers and 75.86 of employees answered that the university from where the candidate graduated has an effect on the employment decision. This indicates that there is discrimination in this domain where some banks prefer to hire graduates of specific universities. 
Table 30

The Bank customers (C9)

\begin{tabular}{|l|c|c|c|c|}
\multicolumn{1}{c|}{ Personnel Managers } & Employees \\
\hline Effect & Frequecny & Percent & Frequecny & Percent \\
\hline strong & 5 & 14.30 & 37 & 31.90 \\
\hline Medium & 21 & 60.00 & 54 & 46.55 \\
\hline No & 9 & 25.70 & 25 & 21.55 \\
\hline Total & 35 & 100.00 & 116 & 100.00 \\
\hline
\end{tabular}

Customers, especially important ones, may sometimes impose some individuals as employees whose refusal may lead to the lossof these important customers.

In analyzing question $\mathrm{C} 9$, it was found that about one fourth of managers stated that the bank customers have no effect on the employment decision and $60 \%$ of them stated that this factor had rather a medium effect. This might be because the education and the qualifications of the candicate are ranked in the first place.

Looking at employees answers one can give the same interpretation.

Table 31

Political interference (C10)

\begin{tabular}{|l|c|c|}
\hline \multicolumn{1}{|c|}{ Effect } & Frequecny & Percent \\
\hline Strong & 28 & 24.10 \\
\hline Medium & 43 & 37.10 \\
\hline No & 45 & 38.80 \\
\hline Total & 116 & 100.00 \\
\hline
\end{tabular}


Question C10 was directed only to employees since most of the personnel managers interviewed first suggested to eliminate this question and did not answer it:

Table 31 indicates that more than $60 \%$ of employees answered that political interference does have an effect on the employment decision and mostly a medium effect because here also the qualifications and the education of the candidates might be considered first. However, this indicates that there is an effect beyond the personnel managers' control that may negatively affect the adequacy of selection.

Putting the above factors on a scale, they can be ranked from first to last according to their effect from highest to lowest.

Highest

Lorvest

effect

Effect $_{x}$

Education

position Age

Organization:

University Marital

Sex

Customers

Religion

Experience

Status 


\section{Descriptive Analysis}

The descriptive analysis approach will be used to answer the first research question. " Do banks operating in Lebanon follow adequate recruiting and selection processes?".

To answer this question, the assessment of recruiting and selection processes must be analyzed.

\subsection{Assessment of the recruiting process:}

This section is concerned with the assessment of the adequacy of the recruiting process followed by banks. The questions of sections $D, E$, and $F$ of the questionnaire directed to personnel managers are analyzed.

\section{Table 32}

Human Resources planning

\begin{tabular}{|c|c|c|c|c|}
\hline & Always & Most of times & Sometimes & Never \\
\hline $\begin{array}{l}\text { Identification of performance } \\
\text { crieteria (D1) }\end{array}$ & $\begin{array}{c}13 \\
(37.1 \%) \\
\end{array}$ & $\begin{array}{c}14 \\
(40.0 \%) \\
\end{array}$ & $\begin{array}{c}8 \\
(22.9 \%) \\
\end{array}$ & $\begin{array}{c}0 \\
(0.0 \%)\end{array}$ \\
\hline $\begin{array}{l}\text { Existence of jobs descriptions } \\
\text { for all Jobs (D2) }\end{array}$ & $\begin{array}{c}13 \\
(37.1 \%) \\
\end{array}$ & $\begin{array}{c}11 \\
(31.4 \%) \\
\end{array}$ & $\begin{array}{c}9 \\
(25.7 \%) \\
\end{array}$ & $\begin{array}{c}2 \\
(5.7 \%) \\
\end{array}$ \\
\hline $\begin{array}{l}\text { Readiness with a pool of } \\
\text { recruits (D3) }\end{array}$ & $\begin{array}{c}13 \\
(37.1 \%) \\
\end{array}$ & $\begin{array}{c}16 \\
(45.7 \%) \\
\end{array}$ & $\begin{array}{c}6 \\
(17.1 \%) \\
\end{array}$ & $\begin{array}{c}0 \\
(0.0 \%)\end{array}$ \\
\hline Human resource planning (D4) & $\begin{array}{c}15 \\
(42.9 \%) \\
\end{array}$ & $\begin{array}{c}13 \\
(37.1 \%) \\
\end{array}$ & $\begin{array}{c}6 \\
(17.1 \%)\end{array}$ & $\begin{array}{c}1 \\
(2.9 \%) \\
\end{array}$ \\
\hline
\end{tabular}

The above questions indicate that effective assessment of human resource needs methods are followed by banks. All the banks selected ( $100.0 \%$ of them) identify performance criteria at different occasions, $94.3 \%$ have job 
descriptions for all employees, $100.0 \%$ of them are ready with a pool of appropriate recruits whenever these is a need for new employees, and $97.1 \%$ of the banks selected anticipate human resources needs ahead of time before that need develops into a problem.

Table 32 indicates that the answers are in the first three options (the "yes" option) while only 2 banks do not have job descriptions for all jobs and only in 1 bank human resources needs are not anticipated in advance.

Table 33

Analysis of Question D5

\begin{tabular}{|l|c|c|c|c|}
\hline & Always & Most of times & Sometimes & Never \\
\hline $\begin{array}{l}\text { we depend on graduates of } \\
\text { specific universities (D5) }\end{array}$ & $\begin{array}{c}7 \\
(20.0 \%)\end{array}$ & $\begin{array}{c}8 \\
(22.9 \%)\end{array}$ & $\begin{array}{c}10 \\
(28.6 \%)\end{array}$ & $\begin{array}{c}10 \\
(28.6 \%)\end{array}$ \\
\hline
\end{tabular}

Question D5 indicates that only $28.6 \%$ of the banks selected answered the question positively; while $71.4 \%$ of them prefer to hire graduates of specific universities.

It is preferable for a bank not to have all its new employees from a single source "specific university". Bringing employees from different backgrounds and universities brings new methods and new ideas to perform the work in a better way instead of having a dominance of a single style of thinking and planning whenever appropriate preparation is practiced by the different universities. 
Table 34

Sources of Recruits

\begin{tabular}{|l|c|c|c|c|}
\hline Source of recruits: & Always & Most of times & Sometimes & Never \\
\hline $\begin{array}{l}\text { Transfers \& promotions } \\
\text { (E1) }\end{array}$ & $\begin{array}{c}2 \\
(5.7 \%)\end{array}$ & $\begin{array}{c}17 \\
(48.6 \%)\end{array}$ & $\begin{array}{c}15 \\
(42.9 \%)\end{array}$ & $\begin{array}{c}1 \\
(2.9 \%)\end{array}$ \\
\hline $\begin{array}{l}\text { Specfic University(ies) } \\
\text { graduates (E2) }\end{array}$ & $\begin{array}{c}2 \\
(5.7 \%)\end{array}$ & $\begin{array}{c}(22.9 \%) \\
(54.3 \%)\end{array}$ & $\begin{array}{c}6 \\
(17.1 \%)\end{array}$ \\
\hline Other banks employees (E3) & 4 & 6 & 19 & 6 \\
$(11.4 \%)$ & $(17.1 \%)$ & $(54.3 \%)$ & $(17.1 \%)$ \\
\hline Relatives \& friends of & 4 & 5 & 17 & 9 \\
current employees (E4) & $(11.4 \%)$ & $(14.3 \%)$ & $(48.6 \%)$ & $(25.7 \%)$ \\
\hline $\begin{array}{l}\text { Employees of companies } \\
\text { serving the bank (E5) }\end{array}$ & $\begin{array}{c}2 \\
(5.8 \%)\end{array}$ & $(2.9 \%)$ & $\begin{array}{c}10 \\
(28.6 \%)\end{array}$ & $\begin{array}{c}22 \\
(62.9 \%)\end{array}$ \\
\hline $\begin{array}{l}\text { Pass by candidates (E6) } \\
(17.1 \%)\end{array}$ & $(40.0 \%)$ & $(37.1 \%)$ & $(5.7 \%)$ \\
\hline
\end{tabular}

Selecting employees from various sources is a good recruiting policy since as with universities, employees from different sources tend to have different styles and methods in thinking and working. In scanning the questionnaires one by one, it was found that almost all the banks use more than three sources at the same time. This indicates that there is a variability in the sources of recruits. This can also be assured by looking at the results of the questionnaires in the above table, (Table 34).

Table 34 indicates that most of the banks have variability in the sources of recruits although the highest percentage is in "Sometimes" and "Most of times" options. 
Question (E5) indicates that $62.9 \%$ of the banks do not depend on employees of the companies providing them with their services as a source of recruits. However, on the contrary, employees of the companies serving the bank represent a good source since those employees got familiar with the bank and its policies and in return the bank personnel manager tends to know those people after a period of work and cooperation with them.

Question (E2) indicates that $83.9 \%$ of banks choose specific university graduates which is a negative trend since what is preferable, as mentioned before, is not to select all new hires from a specific university (ies) or source . This question then reassures the results of the previous question (D5).

Table 35

\section{Recruitng methods}

\begin{tabular}{|l|c|c|c|c|}
\hline Recriting Methods & Always & Most of times & Sometimes & Never \\
\hline Advertising (F1) & 0 & 3 & 13 & 19 \\
$(0.0 \%)$ & $(8.6 \%)$ & $(37.1 \%)$ & $(54.3 \%)$ \\
\hline $\begin{array}{l}\text { Private employment } \\
\text { firms (F2) }\end{array}$ & $\begin{array}{c}1 \\
(2.9 \%)\end{array}$ & $\begin{array}{c}(8.6 \%) \\
(20.0 \%)\end{array}$ & $\begin{array}{c}24 \\
(68.6 \%)\end{array}$ \\
\hline Internships (F3) & 2 & 2 & 22 & 10 \\
\hline University & 1 & $(5.7 \%)$ & $(62.9 \%)$ & $(28.6 \%)$ \\
professors (F4) & $(2.9 \%)$ & $(8.6 \%)$ & $(45.7 \%)$ & $(42.9 \%)$ \\
\hline Pass-by candidates & 14 & 10 & 11 & 0 \\
(F5) & $(40.0 \%)$ & $(28.6 \%)$ & $(31.4 \%)$ & $(0.0 \%)$ \\
\hline $\begin{array}{l}\text { Current employees } \\
\text { (F6) }\end{array}$ & $\begin{array}{c}5 \\
(14.3 \%)\end{array}$ & $(20.0 \%)$ & $(60.0 \%)$ & $(5.7 \%)$ \\
\hline
\end{tabular}


In Grouping the first three options of the questions together " Always, Most of times, and Sometimes " as "yes" one can conclude the following:

- About half of the banks (54.3\%) do not depend on advertsising in attracting recruits and the majority of those using advertisements- although not always do not mention the name of the bank in the add ; they put only the qualifications required and the telephone number and P.O.Box of the bank only.

- $68.6 \%$ of the banks do not depend on private employment firms and most of them say that they do not deal with these firms on purpose.

- 71.4\% of the banks depend on internships and mainly "Sometimes". Interships represent an excellent method of recruiting for the bank and the candidate at the same time. It provides the bank with accurate information about the candidade's performance after the training period he was subject to. In return, it provides the candidate with valuable information about the bank whether it is a good place for him to work.

- $57.1 \%$ of the banks depend on their relations with university professors in suggesting adequate recruits. This method is usually the most effective and the least expensive method of recruiting. By this method, the personnel officer can rely on the university professor who suggests adequate recruits based on their university track records.

- All Banks depend on their reputation in attracting recruits for their job vacancies.

- $94.31 \%$ of the banks depend on their current employees in suggesting adequate recruits. It is through employees that the positions and the challenges of working in the bank are disseminated among friends and relatives of employees. 
Table 36

Whether screening interviews are used in selection

\begin{tabular}{|l|c|c|c|c|}
\multicolumn{2}{c}{ Personnel Managers (D6) } & \multicolumn{2}{c|}{ New Employees (D2) } \\
\hline & Frequencies & Percent & Frequencies & Percent \\
\hline Yes & 30 & 86.40 & 57 & 49.10 \\
\hline No & 5 & 14.30 & 59 & 50.90 \\
\hline Total & 35 & 100.00 & 116 & 100.00 \\
\hline
\end{tabular}

In assessing whether the candidate was subject of a short screening interview before the selection process started (question D6), wide differencies appeared between the answers of personnel managers and employees as shown in Table 36.

The screening interview is of great importance. Its name indicates that its purpose is to screen out immediately those who seem not to possess the minimum requirements of the job. The performance of this interview facilitates the personnel manager's work and reduces the time, money, and effort that might be spent in further testing and interviewing an individual who can be eliminated at earlier stages of the selection process.

Table 36 shows the differences in the answers of respondents. Personnel managers stated that $86.4 \%$ of them use the screening interview as a first step in the selection process while only $49.1 \%$ of employees stated that they were subject to a short screening interview.

Since employees are those individuals who have actually passed the selection process and who do not have any benefit from giving misleading answers, one 
can conclude that the last step in the recruiting process or the first step in th selection process is not effective.

\section{Summary:}

Effective assessment of human resources needs are followed by banks. Human resources needs are anticipated ahead of time in $97.1 \%$ of the banks. All banks are ready with a pool of appropriate recruits from which to select when a sudden need for new employees arises, they identify performance criteria for every position to be filled.

Almost all the banks have variability in their sources of recruits. This is good since different sources bring different and new ideas to the job.

Most of the banks depend on advertising, internships, current employees, and on their reputation in attracting recruits. About $57 \%$ of them depend on university professors; $41.4 \%$ of them only depend on private employment firms because of their reluctance to cooperate with them.

Two negative responses were found in this section: The first is the preference of banks to hire employees from specific universities. The second negative answer is that about half of the employees stated that they were not subject to a screening interview when they were selected.

Therefore, the answers of this section proved that, on average, effective human resources planning and recruiting methods are adopted by banks operating in Lebanon except in two important points that need improvement: 1- Short screening interviews must always precede the selection process. 2- Banks should hire their employees from a variety of universities. 


\section{4-4 Assessment of the Selection Process:}

This section is concerned with the assessment of the selection tools used by banks operating in Lebanon. Three selection tools: -tests, interviews, and reference cheeks- are used. The assessment of each of these tools will be presented in the following sections.

\subsubsection{Selection Tests:}

Questions of section "G" in the questionnaire directed to personnel managers and questions of section "E" in the questionnaire directed to newly hired employees are analyzed in this section.

This section includes a description and an assessment of selection tests and selection polices followed by banks.

Question (G0) shows the percentage use of tests in selection; it also shows discrepancies between personnel managers and employees' answers.

\section{Table 37}

Use of selection tests

\begin{tabular}{|l|c|c|c|c|}
\multicolumn{4}{c}{ Personnel Managers } & \multicolumn{2}{c|}{ Employees } \\
\hline Use tests & Frequencies & Percent & Frequencies & Percent \\
\hline yes & 30 & 85.70 & 60 & 51.70 \\
\hline No & 5 & 14.30 & 56 & 48.30 \\
\hline Total & 35 & 100.00 & 116 & 100.00 \\
\hline
\end{tabular}

Question (G0) indicates that $85.7 \%$ of the personnel managers answered that they use tests as a selection tool while only $51.7 \%$ of the employees who answered the questionnaire stated that they were subject to tests and most of those who were tested are employees at low level. Most of the personnel 
managers who answered that they do not use tests during selection said that they depend on examining the employee performance during the probation period which they call " A long term test" and it is used as a substitute to tests. This can be convincing; but why to bring a new employee and incurr training and salaries expenses, let him know the internal policies and procedures of the bank and later tell him that he is not up to the standard required? This hurts the employee and the bank as well.

Table 38

Testing policies : Personnel managers answers

\begin{tabular}{|l|c|c|c|c|}
\hline Testing Polices & Always & Most of times & $\begin{array}{c}\text { Sometime } \\
\mathbf{s}\end{array}$ & Never \\
\hline $\begin{array}{l}\text { Tests are given under } \\
\text { unifrom conditions (G1) }\end{array}$ & $\begin{array}{c}12 \\
(40.0 \%)\end{array}$ & $\begin{array}{c}9 \\
(30.0 \%)\end{array}$ & $\begin{array}{c}7 \\
(23.3 \%)\end{array}$ & $\begin{array}{c}2 \\
(6.7 \%)\end{array}$ \\
\hline $\begin{array}{l}\text { Tests results are compared } \\
\text { to a score (G2) }\end{array}$ & 9 & 9 & 10 & 2 \\
$(30.0 \%)$ & $(30.0 \%)$ & $(33.3 \%)$ & $(6.7 \%)$ \\
\hline $\begin{array}{l}\text { Test materials are related } \\
\text { to the job (G3) }\end{array}$ & $\begin{array}{c}5 \\
(17.70 \%)\end{array}$ & $\begin{array}{c}6 \\
(60.0 \%)\end{array}$ & $\begin{array}{c}1 \\
(20.0 \%)\end{array}$ & $(3.30 \%)$ \\
\hline
\end{tabular}

Missing cases $=5$ (The banks where tests are not used in selection).

Table 38 indicates that effective testing policies are adopted by banks that use tests in their selection process. It was found that $93.30 \%$ of them use tests under uniform conditions; $93.30 \%$ compare tests results to a standard score, and in $96.70 \%$ of the banks test materials are related to the job to be filled. 
In comparing personnel managers and employees answers it was found that a huge difference exists between the results:

\section{Table 39}

Testing policies: Employees Answers

\begin{tabular}{|l|c|c|c|}
\hline \multicolumn{1}{|c|}{ Testing policies } & Yes & No & Undecided \\
\hline $\begin{array}{l}\text { Tests are given in a calm } \\
\text { place (E1) }\end{array}$ & $\begin{array}{c}18 \\
(30.0 \%)\end{array}$ & $\begin{array}{c}34 \\
(56.7 \%)\end{array}$ & $\begin{array}{c}8 \\
(13.3 \%)\end{array}$ \\
\hline $\begin{array}{l}\text { Test materials are related } \\
\text { to the job (E2). }\end{array}$ & $\begin{array}{c}41 \\
(68.3 \%)\end{array}$ & $\begin{array}{c}11 \\
(18.3 \%)\end{array}$ & $\begin{array}{c}8 \\
(13.3 \%)\end{array}$ \\
\hline
\end{tabular}

Missing cases $=56$ (those who were not subject to selection tests).

Only $30 \%$ of those tested answered that the test was held in a suitable calm place. $68.6 \%$ answered that test materials were related to their job compared to $96.70 \%$ of managers who stated that test materials are related to the job to be filled.

This indicates that testing policies are unfavorable, based on employees answers. 
Table 40

Types of Tests: Personnel managers answers

\begin{tabular}{|l|c|c|c|c|}
\hline \multicolumn{1}{|c|}{ Type } & Always & Most of times & Sometimes & Never \\
\hline $\begin{array}{l}\text { Intelligence } \\
\text { tests }\end{array}$ & $\begin{array}{c}11 \\
(36.7 \%)\end{array}$ & $\begin{array}{c}12 \\
(40.0 \%)\end{array}$ & $\begin{array}{c}4 \\
(13.3 \%)\end{array}$ & $\begin{array}{c}3 \\
(10.0 \%)\end{array}$ \\
\hline Interest tests & 5 & 9 & 8 & 8 \\
$(16.7 \%)$ & $(30.0 \%)$ & $(26.7 \%)$ & $(26.7 \%)$ \\
\hline Knowledge & 9 & 9 & 9 & 3 \\
tests & $(30.0 \%)$ & $(30.0 \%)$ & $(30.0 \%)$ & $(10.0 \%)$ \\
\hline Skills tests & $\begin{array}{c}14 \\
(46.7 \%)\end{array}$ & $\begin{array}{c}9 \\
(30.0 \%)\end{array}$ & $\begin{array}{c}4 \\
(13.3 \%)\end{array}$ & \begin{tabular}{c}
$6.7 \%)$ \\
\hline
\end{tabular}
\end{tabular}

Missing cases $=5$ (Those who do not use tests)

Table 41

Types of tests: Employess answers

\begin{tabular}{|l|c|c|c|}
\hline \multicolumn{1}{|c|}{ Type } & Yes & No & Undecided \\
\hline Intelligence tests & $\begin{array}{c}19 \\
(31.7 \%)\end{array}$ & $\begin{array}{c}28 \\
(46.7 \%)\end{array}$ & $\begin{array}{c}13 \\
(21.7 \%)\end{array}$ \\
\hline Interest tests & $\begin{array}{c}40 \\
(66.7 \%)\end{array}$ & $\begin{array}{c}16 \\
(26.7 \%)\end{array}$ & $\begin{array}{c}4 \\
(6.7 \%)\end{array}$ \\
\hline Knowledge tests & 14 & 33 & 13 \\
& $(23.3 \%)$ & $(55.0 \%)$ & $(21.7 \%)$ \\
\hline Skills tests & $\begin{array}{c}33 \\
(55.0 \%)\end{array}$ & $\begin{array}{c}18 \\
(30.0 \%)\end{array}$ & $\begin{array}{c}9 \\
(15.0 \%)\end{array}$ \\
\hline
\end{tabular}


Missing cases $=56$ (Those who were not tested).

The above questions in the Table 40 and 41 also show great divergence between personnel managers answers and employees answers:

- About $90 \%$ of managers stated that they use intelligence tests while only $31.7 \%$ of employees were subject to this type of tests.

- Personnel managers results indicate that about $73.3 \%$ of them use interest tests at different occasions while only 66.75 of those employees who were subject to tests stated that they were subject to interest test. It is worth mentioning here that interest tests are important; through these test managers can determine where the individual can be more satisfied and can produce at maximum.

- $90 \%$ of personnel managers use knowledge tests (at different occasions) while only $23.3 \%$ of employees were subject to this type of tests. This indicates that what managers pretend that test materials are related to the job is doubtful. Job knowledge tests are very important since they do not only indicate whether the individual can be accepted or not, but they also indicate the amount of training that the candidate needs if he is employed.

- $93.3 \%$ of personnel managers give skills tests during selection while only $55.0 \%$ of employees were subject to these tests. Skill tests are also very important especially case solving tests since the work that the employee is going to perform represents real cases. Testing the employee's logic and ability to analyse and solve cases is a good indicator of his ability to deal with real cases at work. 


\section{Summary:}

This section has shown differences between personnel managers and employees' answers concerning the use of tests. Personnel managers answered that the majority of them use tests, test materials are related to the job, tests are held under uniform conditions. Also, the majority of them also stated that they use the four types of tests and mainly the skills tests - (93.3\%) of them.

However, employees gave different answers : about half of them were tested and very few $(30.0 \%)$ answered that the tests were held in a suitable place and $68.0 \%$ of them answered that test materials are related to their jobs. Very few of them were subject to intelligence and job knowledge tests $(31.7 \%$ and $23.3 \%$ respectively) $55.0 \%$ of them were subject to skills tests and $66.7 \%$ were subject to interest tests. The last two percentages indicate that these results are a little bit favorable; however, on the average, the testing policies are not as adequate as they must be; they need more improvement.

\subsubsection{Selection Interviews:}

This section is concerned with the assessment of the effectiveness of selection interviews. As with the previous section, this section shows discripancies between the answers of personnel managers and employees. Therefore, in each part of this section the results of the two types of respondents are going to be presented and compared. 
Table 42

Personnel managers answers

\begin{tabular}{|l|c|c|c|c|}
\hline An interview is held with & Always & Most of times & Sometimes & Never \\
\hline $\begin{array}{l}\text { The personnel manager } \\
\text { (H1) }\end{array}$ & $\begin{array}{c}30 \\
(85.7 \%)\end{array}$ & $\begin{array}{c}5 \\
(14.3 \%)\end{array}$ & $\begin{array}{c}0 \\
(0.0 \%)\end{array}$ & $\begin{array}{c}0 \\
(0.0 \%)\end{array}$ \\
\hline $\begin{array}{l}\text { The department manager } \\
\text { (H2) }\end{array}$ & $\begin{array}{c}5 \\
(14.3 \%)\end{array}$ & $\begin{array}{c}(37.1 \%) \\
(14.3 \%)\end{array}$ & $\begin{array}{c}12 \\
(34.3 \%)\end{array}$ \\
\hline
\end{tabular}

Table 43

Employees answers

\begin{tabular}{|l|c|c|}
\hline An interviews held with: & Yes & No \\
\hline The personnel manager (F2) & $\begin{array}{c}91 \\
(78.4 \%)\end{array}$ & $\begin{array}{c}25 \\
(21.6 \%)\end{array}$ \\
\hline The department manager (F1) & $\begin{array}{c}59 \\
(50.9 \%)\end{array}$ & $\begin{array}{c}57 \\
(49.1 \%)\end{array}$ \\
\hline
\end{tabular}

Question $\mathrm{H} 1$ indicates that in all banks the candidate should be subject to an interview with the personnel manager while $78.4 \%$ of employees stated that they were interviewed by the personnel manager.

In $65.7 \%$ of banks an interview is held with the position supervisor while $50.9 \%$ of employees answered that they were interviewed with their supervisor at work. Whomever is accurate, this percentage should be higher since the interview with the candidate's expected supervisor is very important for both 
the candidate and the manager. As for the manager, this interview enables him to discuss with the candidate and to get an idea about the person of whom he will be responsible. As for the candidate, it enables him to get an idea about the person to whom he will report at work.

\section{Table 44}

Preparation for the interview:Personnel managers answers

\begin{tabular}{|l|c|c|c|c|}
\hline The interviewer knows & Always & Most of times & Sometimes & Never \\
\hline The bank (H4) & $\begin{array}{c}25 \\
(71.4 \%)\end{array}$ & $\begin{array}{c}7 \\
(20.0 \%)\end{array}$ & $\begin{array}{c}1 \\
(2.9 \%)\end{array}$ & $\begin{array}{c}2 \\
(5.7 \%)\end{array}$ \\
\hline The job (H5) & $\begin{array}{c}22 \\
(62.9 \%)\end{array}$ & $\begin{array}{c}6 \\
(17.1 \%)\end{array}$ & $\begin{array}{c}5 \\
(14.3 \%)\end{array}$ & $\begin{array}{c}2 \\
(5.7 \%)\end{array}$ \\
\hline The candidate's credentials & $\begin{array}{c}15 \\
(42.9 \%)\end{array}$ & $\begin{array}{c}7 \\
(20.0 \%)\end{array}$ & $\begin{array}{c}12 \\
(34.3 \%)\end{array}$ & $\begin{array}{c}1 \\
(\mathrm{H} 6)\end{array}$
\end{tabular}

Table 45

Preparation for the interview: Employees answers

\begin{tabular}{|l|c|c|c|}
\hline The interviewer knows & Yes & No & Undecided \\
\hline The bank (F10) & $\begin{array}{c}93 \\
(80.2 \%)\end{array}$ & $\begin{array}{c}9 \\
(7.8 \%)\end{array}$ & $\begin{array}{c}14 \\
(12.0 \%)\end{array}$ \\
\hline The job (F11) & $\begin{array}{c}64 \\
(55.2 \%)\end{array}$ & $\begin{array}{c}21 \\
(18.1 \%)\end{array}$ & $\begin{array}{c}30 \\
(25.9 \%)\end{array}$ \\
\hline $\begin{array}{l}\text { The candidate's } \\
\text { credentials (F12) }\end{array}$ & $\begin{array}{c}60 \\
(51.7 \%)\end{array}$ & $\begin{array}{c}31 \\
(26.7 \%)\end{array}$ & $(21.6 \%)$ \\
\hline
\end{tabular}


The preparation for the interview" questions indicate quite favorable results:

- In most of the banks the interviewer can market the bank and is able to inform the interviewee about all types of information he wants to explore about the bank.

- The majority of personnel managers (94.3\%) stated that they know everything about the job (its responsibilities, duties, reporting relationship, etc ...) before the interview started while only $18.1 \%$ of employees answered "no". This is also a good sign since the interviewer is in a better position to present the job to the candidate and to answer job related questions directed by the candidate. From this information the interviewee can then determine whether he is interested in the job or not .

- $97.1 \%$ of managers answered that they review the previously gathered information about the candidate before they meet him while only $51.7 \%$ of employees felt that the interviewer had already got an idea about them (their education, experience, qualifications etc....). Proving to the interviewer that the interviewer had already reviewed any information about him is very important since it indicates to the candidate that he matterrs the bank. It also prevents the interviewer from repeating the same information already gathered in the preceeding stages of the selection process, hence preventing the interview from being boring. 
Table 46

Interviewing policies: Personnel manager answers

\begin{tabular}{|l|c|c|c|c|}
\hline \multicolumn{1}{|c|}{ Policies } & Always & Most of times & Sometimes & Never \\
\hline $\begin{array}{l}\text { Interviewer talks most of } \\
\text { the time (H7) }\end{array}$ & $\begin{array}{c}8 \\
(22.9 \%)\end{array}$ & $\begin{array}{c}8 \\
(22.9 \%)\end{array}$ & $\begin{array}{c}11 \\
(31.4 \%)\end{array}$ & $\begin{array}{c}8 \\
(22.9 \%)\end{array}$ \\
\hline $\begin{array}{l}\text { Interviewer do not ask job } \\
\text { related questions (H8) }\end{array}$ & $\begin{array}{c}(22.9 \%) \\
(8.6 \%)\end{array}$ & $\begin{array}{c}8 \\
(22.9 \%)\end{array}$ & $\begin{array}{c}16 \\
(45.7 \%)\end{array}$ \\
\hline $\begin{array}{l}\text { Interruptions are allowed } \\
\text { during the interview (H9) }\end{array}$ & $\begin{array}{c}3 \\
(8.6 \%)\end{array}$ & $\begin{array}{c}(11.4 \%) \\
(24.3 \%)\end{array}$ & $\begin{array}{c}16 \\
(45.7 \%)\end{array}$ \\
\hline
\end{tabular}

Table 47

Interviewing policies : Employees answers

\begin{tabular}{|l|c|c|c|}
\hline \multicolumn{1}{|c|}{ Policies } & Yes & No & undecided \\
\hline $\begin{array}{l}\text { Interviewer talks most of the } \\
\text { time (F6) }\end{array}$ & $\begin{array}{c}49 \\
(42.2 \%)\end{array}$ & $\begin{array}{c}52 \\
(44.8 \%)\end{array}$ & $\begin{array}{c}15 \\
(12.9 \%)\end{array}$ \\
\hline $\begin{array}{l}\text { Interviewer did not ask job } \\
\text { related questions (F7) }\end{array}$ & $\begin{array}{c}59 \\
(50.9 \%)\end{array}$ & $\begin{array}{c}42 \\
(36.2 \%)\end{array}$ & $\begin{array}{c}15 \\
(12.9 \%)\end{array}$ \\
\hline Interruptions are allowed (F8) & $\begin{array}{c}53 \\
(45.7 \%)\end{array}$ & $\begin{array}{c}52 \\
(44.8 \%)\end{array}$ & $\begin{array}{c}11 \\
(9.5 \%)\end{array}$ \\
\hline
\end{tabular}


The above questions indicate that ineffective interview techniques are followed by personnel managers:

- $42.2 \%$ of employees and about $67.1 \%$ of personnel managers stated that during the interview, the interviewer talks more than the interviewee; however, the interviewer should not dominate the interview. It is the candidate who is tested and not the interviewer.

- $54.3 \%$ of personnel managers and $50.9 \%$ of employees answered that the interviewer does not ask job related questions during the interview. This also indicates negative results since the purpose of the interview is not only to gather personal information about the candidate but to assess his suitability to the job through testing his knowledge and experience.

- $54.3 \%$ of personnel managers and $45.7 \%$ of employees answered that the interview is subject to outside interruptions. However, interviews should be held in a suitable and comfortable place. Interruptions should never take place during the interview - even telephone calls should not be accepted - since this may annoy both the interviewer and the interviewee. Also, this may indicate to the candidate that he is not important and he does not matter the bank which may, in return, affects the bank's image.

In analyzing the question of whether during the interview the interviewer was sticking to the application and verifying the information in it, the following results were found: 
Table 48

Question (H3) : Personnel managers answers

\begin{tabular}{|l|c|c|c|c|}
\hline & Always & Most of times & Sometimes & Never \\
\hline $\begin{array}{l}\text { The interviewer sticks } \\
\text { to the application blank }(\mathrm{H} 3)\end{array}$ & $\begin{array}{c}13 \\
(37.1 \%)\end{array}$ & $\begin{array}{c}9 \\
(25.7 \%)\end{array}$ & $\begin{array}{c}7 \\
(20.0 \%)\end{array}$ & $\begin{array}{c}6 \\
(17.1 \%)\end{array}$ \\
\hline
\end{tabular}

Table 49

Question (F9) : Employees answers

\begin{tabular}{|c|c|c|c|}
\hline & Yes & No & Undecided \\
\hline $\begin{array}{l}\text { The interviewer sticks } \\
\text { to the application blank }\end{array}$ & $\begin{array}{c}73 \\
(62.9 \%)\end{array}$ & $\begin{array}{c}30 \\
(25.9 \%)\end{array}$ & $\begin{array}{c}13 \\
(11.2 \%)\end{array}$ \\
\hline
\end{tabular}

$82.9 \%$ of personnel managers and $62.9 \%$ of employees answered that during the interview, the interviewer had the applicant's application blank and was verifying the information that was found in it. This indicates unfavorable results since in this way interviews are used to get personal information instead of job related information. Since such information is already available, why to waste the interview time in repeating the same questions already answered in the application ? Interview time must be devoted for the collection of only missing personal information about the candidate and for the gathering of any type of information regarding the candidate's experience and knowledge about the job. 
Table 50

Preparation of interview questions: Personnel managers answers

\begin{tabular}{|c|c|c|c|c|}
\hline The interviewer prepares & Always & Most of time & Sometimes & Never \\
\hline All questions & $\begin{array}{c}4 \\
(11.4 \%) \\
\end{array}$ & $\begin{array}{c}5 \\
(14.3 \%) \\
\end{array}$ & $\begin{array}{c}8 \\
(22.9 \%) \\
\end{array}$ & $\begin{array}{c}18 \\
(51.4 \%) \\
\end{array}$ \\
\hline Main questions & $\begin{array}{c}4 \\
(11.4 \%) \\
\end{array}$ & $\begin{array}{c}11 \\
(31.4 \%)\end{array}$ & $\begin{array}{c}7 \\
(20.0 \%) \\
\end{array}$ & $\begin{array}{c}13 \\
(37.1 \%) \\
\end{array}$ \\
\hline No questions & $\begin{array}{c}8 \\
(22.9 \%)\end{array}$ & $\begin{array}{c}1 \\
(2.9 \%)\end{array}$ & $\begin{array}{c}9 \\
(25.7 \%)\end{array}$ & $\begin{array}{c}17 \\
(48.6 \%)\end{array}$ \\
\hline
\end{tabular}

The above questions in Table 52 aindicate that in more than $50 \%$ of the banks the interviewer prepares the questions to be asked during the interview especially main question (62.9\%) . Worth mentioning here is that preparing interview questions and listing them in front of the interviewer or just in his mind is very important. This enables the interviewer to cover all the subjects he wants to discuss rather than closing the interview and then discovering that some topics were not discussed. 


\section{Summary:}

In analyzing the questions of "selection Interviews" section, a wide difference appeared between the answers of personnel managers and employees. Personnel manager's answers indicate that interview techniques are adequate; while reading employees' results one can discover that most of the questions indicate that there are some deficiencies in the selection interviews:

- only $50.9 \%$ of the newly hired employees were subject to an interview with their supervisor and $78.4 \%$ of them were interviewed with the personnel manager.

- only $55.2 \%$ of the employees stated that the interviewer had a knowledge about the job to be filled (its duties, responsibilities, reporting relationships, salary....) . Also, only $51.7 \%$ of employees answered that during the interview they found that the interviewer had already reviewed any infromation about them.

- $42.2 \%$ of employees answered that the interviewer was talking most of the interview time; $50.9 \%$ of them only stated that the interviewer did not asked job related questions during the interview and $45.7 \%$ of them answered that the interview was subject to outside interruptions.

- $62.9 \%$ of employees stated that during the interview the interviewer had their applications form in front of him and was verifying the information already put in it.

All these results indicate that interviews are not held adequately to reach their aim which is to assess the candidate's knowledge and ability to work on a certain job. In most of the questions of this section, negative results were obtained: job related questions are not asked during the interview, the interviewer dominates the interview, interruptions are allowed during the interview ,etc..... . 


\subsubsection{Reference check:}

This section is concerned with the description and assessment of reference checking sources that personnel managers depend on in verifying the information provided by the candidate. The questions analyzed in this section are those of section I in the personnel managers' questionnarie and they are concerned with determining the sources of references:

\section{Table 51}

\section{Sources of references}

\begin{tabular}{|l|c|c|c|c|}
\hline \multicolumn{1}{|c|}{ Sources of references } & Always & Most of times & Sometimes & Never \\
\hline Personal references & 10 & 12 & 12 & 1 \\
$(28.6 \%)$ & $(34.6 \%)$ & $(34.3 \%)$ & $(2.9 \%)$ \\
\hline Previous employers & 15 & 15 & 4 & 1 \\
$(42.9 \%)$ & $(42.9 \%)$ & $(11.4 \%)$ & $(2.9 \%)$ \\
\hline Universities & 12 & 13 & 19 & 1 \\
$(34.3 \%)$ & $(37.1 \%)$ & $(25.7 \%)$ & $(2.9 \%)$ \\
\hline
\end{tabular}

Reference checking questions indicate that $97.1 \%$ of the banks verify the information provided by the applicant. These banks depend mainly on recommendations provided by the candidate's previous employers $(42.90 \%$ always , and $42.9 \%$ most of times).

During the interviews held in collecting the research data some personnel managers said that they use three sources listed in Table 51; but they have more confidence in the last two ones, especially in recommendations of universities and in grade reports. They think these are the most dependable and accurate sources. As for personel references, they sometimes do not take them into consideration since in their opinion references chosen by the individuals are those who will speak well of them and won't give any negative point about them. 
As mentioned before, most of the personnel manager's answers indicated that they follow adequate recruiting and selection processes while the employees answers proved that there is wide differences between their answers and those of the personnel managers. In addition, since employees have no intention to provide inaccurate answers and since all, the questionnaires which include inconsistent or random answers were eliminated from the sample, our further criticisms and analysis will be based on employees' answers.

\section{Conclusion:}

The analysis of the recruiting and selection processes indicated that the recruiting process is adequate, but it needs more improvement. However, the selection tools and policies in most of the banks are below standard. 


\subsection{Correlation - Multiple regression Analysis :}

Multiple regression analysis can be defined as the analysis of association that simultaneously investigates the effect of two or more independent variables on a single dependent variable. The dependent variable is the variable whose variation is likely to be explained by the independent variable(s). The independent variable is the variable used to explain the variation in the dependent variable.

Multiple regression involves the study of the following measurements :

1- The coefficient of partial regression $(\beta)$ : It shows the effects on the dependent variable of one unit increases in any of the independent variables . Simply it is the percentage of the variance in the dependent variable that is explained by a single independent variable, holding other independent variables constant. It is called coefficient of partial regression because the independent variables are usually correlated with the other dependent variables . It can be either positive or negative; a positive coefficient of partial regression indicates a positive relationship between the dependent variable and the independent variable while a negative coefficient of partial regression indicates a negative relationship.

2 - The coefficient of multiple determination or the multiple index of determination ( $R$ square) : It indicates the percentage of variance in the dependent variable explained by the variation in the independent variables . For instance, if $R^{2}$ is 0.75 , one can say that the variation in the independent variables accounted for $75 \%$ of the variance in the dependent variable . 
3 - $F$ test : To test the significance of the regression equation the, $F$ test can be used. The tests of the regression equations in this research will be done at 0.05 significance level. If the significant $F$ is less than 0.05 , it can be concluded that the estimated functional relationship (or regression ) is not due to chance or random variation .

4 - T Test : To test the significance of the independent variables the $T$ test can be done for each independent variable in the regression equation. The $T$ tests will be done also at 0.05 level of statistical significance. If the variable's significant $\mathrm{T}$ is less than 0.05 , it can be concluded that an association existed between the dependent variable and the independent variables other than random variation in the data .

\subsubsection{Regression equations Built in the study:}

The regression equations were built to answer the research questions stated in chapter one. They are built based on the results of the questionnaires directed to banks' newly hired employees. Each of the three equations will be presented and analyzed in the following sections .

Worth mentioning here is that two averages of the questions were computed. The first average was FINTER where questions E6 to E13 of the selection interview section were grouped as one question. The second average was GASTISF where questions G2 to G9 of the questionnaire were grouped as one question. 


\subsubsection{A The regression equation With the effectiveness of interviewing techniques(FINTER) being the dependent variable:}

The purpose of building this equation is to determine what makes effective interviews . A set of variables was chosen from which only the strongest variables remained in the equation. The independent variables are $:$ whether the employee was subject to an interview with his supervisor $(\mathrm{F} 1)$, with the personnel manager (F2), whether there is a personnel department in the bank (A12), whether there are personnel policies in the bank (A13), whether these polices are known to all employees (A14), the education of the personnel manager (X1), his major $(\mathrm{X} 2), \operatorname{sex}(\mathrm{X} 3)$, age $(\mathrm{X} 4)$, marital status $(\mathrm{X} 5)$ and experience $(\mathrm{X} 6)$.

The first step in developing the regression model was to examine the correlation between the dependent variable and the independent variables chosen the resulting correlation matrix is shown in appendix (B).

A stepwise regression analysis was used to build the regression equation, The independent variables are ranked in order of their importance as potential predictors of FINTER. Two variables have entered the equation. The first one is the education of the personnel manager (X1), the second one is the experience of the personnel manager (X6).

Table 58 shows the result of the regression output at 0.05 level of statistical significance . 


\section{Table 58}

Regression output with FINTER being the

\section{Dependent Variable}

\begin{tabular}{|lccccc|}
\hline Multiple R & & 0.39882 & & & \\
R Square & & 0.15906 & & & \\
Adjusted R Square & & 0.14418 & & & \\
Standard Error & & 0.40587 & & & \\
$\quad$ Variable & $\underline{\text { B }}$ & $\underline{\text { SE B }}$ & $\underline{\text { Beta }}$ & $\underline{\mathbf{T}}$ & $\underline{\text { Sig T }}$ \\
$\quad$ X1 & 0.25708 & 0.5952 & 0.37374 & 4.319 & 0.0000 \\
$\quad$ X2 & 0.11022 & 0.5560 & 0.17153 & 1.982 & 0.0499 \\
Constant & 1.12327 & 0.18463 & & 6.084 & 0.0000 \\
& & & & & \\
F $=10.6868$ & & Signif F $=$ & 0.0001 & & \\
& & & & & \\
\hline
\end{tabular}

In this output $R$ square is 0.15906 which means that $15.906 \%$ of the variation in FINTER could be explained by the education and experience of the personnel manager. Hence, as the experience and education of the personnel manager increases, he can seek better and effective ways in conducting selection interviews. 
The coefficient of the first independent variable $\beta(X 1)$ is 0.25708 which means that for each added value in X1, FINTER would directly vary by 0.25708 , holding other variables constant. The coefficient of the second independent variable $\beta(\mathrm{X} 6)$ is 0.11022 which means that the FINTER increases by 0.11022 for each added value in X6 holding other variables constant . $\beta$ (X1) and $\beta(\mathrm{X} 6)$ are both positive meaning that the linear relationship between FINTER and each independent variable is positive .

The regression equation that can be built in predicting the effectiveness of interview techniques is then :

$$
\begin{aligned}
& \text { FINTER }=1.12327+0.25708 \times 1+0.11022 \times 6 \\
& \begin{array}{lll}
(0.0000) & (0.0000) & 0.0499
\end{array}
\end{aligned}
$$

In testing the significance of the overall regression model using $\mathrm{F}$ test , it was found that significant $F$ is 0.0001 which is much less than the level of significance used (0.05). Hence the regression model is significant and one can conclude that there does appear to be an association between FINTER and X1 and $\mathrm{X} 2$ other than by random variation .

In testing the significance of the independent variables using $\mathrm{T}$ test, the significant $\mathrm{T}$ for $\mathrm{X} 1$ and $\mathrm{X} 2$ were less than the level of significance adopted in the tests (0.05). Therefore, $\mathrm{X} 1$ and $\mathrm{X} 6$ are significant or the relation between each of the independent variables and the dependent variable is not due to mere chance.

* The significant $\mathrm{T}$ for the constant and each dependent variable is put in parentheses under the relevant independent variables in the equation . 


\section{Interpretation of the equation:}

The resulting equation is self - explanatory. As for X1 ( $\beta$ eta $=0.25708)$, for each added value in X1, FINTER would directly vary by the value of 0.25708 and the relation between FINTER and $\mathrm{X} 1$ is positive. As for X6 ( $\beta$ eta $=0.11022$ ), for each added value in X6, FINTER would directly vary by 0.11022 . Therefore, the effectiveness of interview techniques and policies increases as the education and experience of the personnel manager in the personnel domain increase. As $\mathrm{X} 1$ and $\mathrm{X} 2$ increase, interviews will achieve their goal which is to assess the individual's education, knowledge, and ability to work on the vacant job rather than just seeking personal and irrelevant data from the candidate.

\subsection{B_Regression Built with GSATISF being the dependent variable:}

To answer the second research question " Does satisfaction increase with better recruiting and selection?", a regression equation was built to determine what affects job satisfaction. Therefore, the dependent variable in this equation is GSATISF and the selected independent variables are: Whether interviews were effective (FINTER), whether tests were used in selection (E0), whether tests materials were related to the job (E1), whether tests were held is a calm place (E2), whether the various types of tests were used (E3), (E4), (E5) and (E6), the number of employees in the bank (A1), the number of branches of the bank (A2), the education of the employee(A3), his age (A6) $\operatorname{sex}(\mathrm{A} 7)$, marital status (A8), experience (A6), whether his job is related to his major (A10), his position (A11), whether the employee was put on the job just because it was vacant (G7), whether the bank has a personnel department (A12). whether there are personnel policies in the bank (A13), and whether these policies are known to all employees(A14). 
Table 60 shows the regression output at 0.05 significance level. The independent variables that have entered the equation are four and they are presented in Table 60 in order of their importance as potential predictors of GSATISF .

Table 60

Regression Output with GSATISF being the

Dependent Variable

\begin{tabular}{|ll} 
Multiple R & 0.70131 \\
R Square & 0.49183 \\
Adjusted R Square & 0.47352 \\
standard Error & 0.38840
\end{tabular}

Variable

B $\quad \underline{\text { SE B }}$

Beta

$\underline{\mathbf{T}}$

Sig T

G7

$-0.16753$

0.04549

$-0.29692$

$-3.683$

0.0004

FINTER

0.39987

0.09240

0.33350

4.327

0.0000

A 10

0.27780

0.07524

0.26377

3.692

0.0003

A6

01.0636

0.04769

0.15910

2.230

0.0277

Constant

0.58062

0.29390

1.976

0.0507

$F=26.85822$

Signif $F=0.0000$ 
- $\mathrm{R}$ square is 0.49183 which means that $49.183 \%$ of the variation in GSATISF could be explained by whether the candidate was put on the job just because it was vacant (G7), whether the interview was effective or not (FINTER), whether the candidate's major is related to his job (A10), and the candidate's experience (A6).

- The Coefficients of the independent variables ( $\beta$ values) :

- $\beta(G 7)$ is -0.16753 which means a negative correlation between G7 and GSATISF or Job satisfaction. Satisfaction decreases as the employee is put on his job just because it was vacant and someone was needed to fill it .

- $\beta$ (FINTER) is 0.39987 which means that for each added value in FINTER job satisfaction increases by 0.39987 and the correlation between FINTER and GSATISF is position.

- $\beta G(A 10)$ is 0.27780 which means a positive correlation between $A 10$ and GSATISF . As the employee's major is related to his job, his satisfaction increases.

- $\beta(\mathrm{A} 6)$ is 0.10636 which indicates also a positive correlation between A6 and GSATISF. The higher the experience of the newly hired employee the more he is satisfied on his job.

The resulting regression equation is :

$$
\begin{aligned}
\text { GSTATISF }= & 0.58062-0.16753 \mathrm{G} 7+0.39987 \text { FINTER }+0.27787 \text { A10 }+0.10636 \mathrm{~A} 6 \\
& (0.0507) \quad(0.0004) \quad(0.0000) \quad(0.0003)
\end{aligned}
$$

In testing the significance of the overall regression equation, significant $F$ was 0.0000 which is much less than the significance level (0.05). This indicates that the regression is significant and that the association between GSATISF and the independent variables is not by chance . 
Also, in testing the significance of the independent variables in the equation, it was found that the significant $T$ of each variable is less than the level of significance adopted in testing. The significant $\mathrm{T}$ for each independent variable is put in parentheses under the relevant independent variable in the equation.

\section{Interpretation of the equation:}

The above equation indicates that job satisfaction is dependent on four variables: G7, FINTER, A10 and A6.

As for Beta (G7) it is -0.16753 which means that for each added value in $G 7$, GSATISF (job satisfaction) decreases by 0.16753 . When the employee is put on his job just because someone was needed to fill it, his job satisfaction decreases. Hence, better placement on the Job i.e. effective selection is required to secure job satisfaction . Beta (FINTER) is 0.3987 meaning that for each added value in FINTER, (GSATISF) increases by 0.3987 . Effective interviews, then secure adequate placement on the Job ; hence leading to more satisfaction. Beta (A10) is 0.27780 which implies a positive correlation between (A10) and GSATISF and for each added value in A10, GSATISF increases by 0.27780 . As employees are put on jobs that matches their education and qualifications, their satisfaction increases. Therefore job satisfaction depends on effective placement and selection .

Beta (A6) is 0.10636 which also implies a positive correlation between GSATISF and A6 ; for each added value in A6, GSATISF increases by 0.1036 . The higher the experience of the new employee the higher is his satisfaction on the job. 
In summary, this regression equation indicates that satisfaction is dependent on selection(Whether the employee is placed on a job that matches his qualification and his education, and whether placement is effective or not). As selection improves the employee's satisfaction on the job increases.

\subsubsection{Regression equation with X9 being the dependent variable :}

To answer the third research question" Is employee turnover effected by the adequacy of recruiting and selection", an equation was build with X9 (turnover rate among new employees) dependent on a set of independent variables. These independent variables are :

Whether the bank is selective in recruiting specific university graduates (G1), whether placement is effective (G7), whether interviews are effective (FINTER), whether selection tests are used in selection (E0), whether test materials are related to the job (E1), Whether tests are held in a suitable place (E2), whether the various types of tests are used (E3) to (E6), the number of employees in the bank (A1), the number of branches of the bank(A2), the education of the employee (A3), his major (A4), the university from where he/she graduated (A5), his experience (A6), sex (A7), marital statues (A8), age (A9), whether his job is related to his education (A10), his position (A11), whether there is a personnel department in the bank (A12), whether there are personnel policies in the bank (A13), and whether these polices are known to all employees (A14).

The correlation matrix showing the correlation between the variables is shown in appendix (B). Table 61 shows the regression output at 0.05 level of statistical significance. Four variables have entered the equation and they are ranked in the table in order of the importance as potential predictors of $\mathrm{X} 9$. 


\section{Table 61}

\section{Regression Output with X9 being the}

Dependent Variable

\begin{tabular}{|ll}
\hline Multiple R & 0.63591 \\
R Square & 0.40438 \\
Adjusted R Square & 0.38292 \\
standard Error & 0.60875
\end{tabular}

$\begin{array}{cccccc}\text { Variable } & \underline{\text { B }} & \underline{\text { SE B }} & \underline{\text { Beta }} & \text { T } & \underline{\text { Sig T }} \\ \text { G1 } & -0.26220 & -0.06344 & -0.32705 & -4.133 & 0.0001 \\ \text { E0 } & 0.47937 & 0.11476 & 0.31046 & 4.177 & 0.0001 \\ \text { A1 } & 0.23223 & 0.07422 & 0.24484 & 3.129 & 0.0022 \\ \text { G7 } & -0.14027 & 0.06199 & -0.16876 & -2.263 & 0.0256 \\ \text { Constant } & 1.54006 & 0.30142 & & 5.109 & 0.0000\end{array}$

$$
\mathbf{F}=18.84044 \quad \text { Signif } \mathbf{F}=0.0000
$$

$R$ square is 0.40438 which means that $40.438 \%$ of the variation in $X 9$ could be explained or determined by G1 , E0, A1 and G7 .

The Beta values of the independent variables are shown in Table 61 and explained below:

$\mathrm{Beta}(\mathrm{G} 1)$ is -0.26220 indicating a negative correlation between $\mathrm{Gl}$ and $\mathrm{X} 9$. As banks are selective in their choice of universities from where the employee graduated, turnover increases. In recruiting, banks should attract candidates from various universities . 
Beta $(\mathrm{E} 0)$ is 0.47937 indicating a positive correlation between E0 and X9. As tests are used during selection, turnover improves since tests secure better placement .

Beta (A1) is 0.23223 meaning that as the number of employees in the bank increases, turnover rate increases.

Beta $(\mathrm{G} 7)$ is -0.14027 which means a negative correlation between $\mathrm{G} 7$ and $X 9$. As placement on the job is adequate turnover among new comers increases. This might be because the employee's satisfaction decreases if he was not adequately placed on his job as it was found in the previous regression equation.

The regression equation is :

$$
\begin{aligned}
& \mathrm{X} 9=1.54006-0.262020 \mathrm{G} 1+0.47937 \mathrm{E} 0+0.23223 \mathrm{~A} 1-0.14027 \mathrm{G} 7 \text {. } \\
& \begin{array}{lllll}
(0.0000) & (0.000) & (0.0001) & (0.0022) & (0.0256)
\end{array}
\end{aligned}
$$

In analyzing the significance of the regression equation, significant $F$ was 0.0000 which is much less than the level of significance adopted. Therefore, there does appear an association between $X 9$ and the independent variables ( $\mathrm{G} 1, \mathrm{E} 0 ., \mathrm{A} 1$, and $\mathrm{G} 7$ ) other than by random variation .

Also, in analyzing the significance of the independent variables in the equation, it was found that the significant $T$ of each variable was less than the significance level. Therefore, the relation between $X 9$ and each of the independent variable is significant and did not occur by mere chance . 


\section{Interpretation of the equation :}

worth mentioning here is that the wording of the questiosn G1 and G7 was negative; that was the reason why their coefficients were negative . this means that $\mathrm{X} 9$ increases as the answers of these questions are "Agree".

Question G1 is: "Most of the new employees are graduates of specific university (ies)".

Question G7 is: "I was placed on the job just because it was vacant and someone was needed to fill it" .

The obtained equation is self explanatory. As for Beta (G1) is -0.26220 , this means that for each added value in G1, X9 increases by 0.26220 . In other words, as recruiting policies (being selective and prefers some universities on others) are not adequate turnover rate among new comers increases. As for E0, Beta is 0.47937 meaning that $\mathrm{X} 9$ improves by 0.47937 for each added value in E0. Therefore, as tests are used in selection, turnover rates among new comers decreases. Hence, personnel managers are recommended to use selection tests when hiring new employees .Beta (A1) is 0.03233 which means that as the number of employees in the bank increases turnover rates increases also; this result is self-explanatory. As for (G7) its Beta is -0.14027 meaning that a negative correlation exists between $X 9$ and $\mathrm{G} 7$ and for each added value in $\mathrm{G} 7$, the turnover rate increases by 0.14027 . As employees are put on their job just because someone was needed to fill them (inadequate placement) turnover rates increase.

Therefore, turnover rate among new employees depend on effective recruiting policies as G1 indicates, on effective selection as E0 and G7 indicate, and on the number of employees in the bank (A1). 


\subsection{Crosstabulations and Chi-Square tests :}

Cross tabulations and Chi-square tests will be presented in this section to test the six hypotheses stated in chapter one.

The cross tabulation is one of the techniques used for describing sets of relationships. It is also called contingency table and it can be defined as a joint frequency distribution of observations on two or more sets of variables .

The Chi-square distribution is a means for testing the statistical significance of the contingency table. It allows us to test whether a difference exists across categories in two groups' distribution. The logic involved in the Chi- square test is the comparison of the observed frequencies (Oi) with the expected frequencies (Ei) . It tests whether a certain variable is dependent on or associated with another variable and whether this association is significant or it occurs by chance .

The hypotheses that will be tested in the following sections will test the difference across categories in two groups' distribution at 0.05 level of statistical significance meaning that the contingency table is said to be significant if its significance is less than the adopted level of statistical significance $(0.05)$.

The major cross tabulations and Chi-square tests of the hypotheses stated in chapter one are going to be presented in the following sections. 


\subsubsection{Crosstabulation and Chi-square test of E0 by $\mathrm{A} 6$.}

The hypothesis that is going to be tested is whether the use of selection tests (Eo) is dependent on the experience of the new employee (A6) .

$\mathrm{H}_{0}: \mathrm{E} 0$ is dependent on $\mathrm{A} 6$.

$\mathrm{H}_{1}: \mathrm{E} 0$ is independent of A 6 .

The following table represents the crosstabulation and the results of the Chi-square test. The percentages are put in parentheses .

Table 52

Crosstabulation of E0 by $\mathrm{A} 6$

\begin{tabular}{|c|c|c|c|c|}
\hline $\begin{array}{c}\text { Experience } \\
\text { Use tests }\end{array}$ & 0 years & 1 to10 years & above 10 years & Row total \\
\hline Yes & 33 & 18 & 9 & 60 \\
$(68.8 \%)$ & $(43.9 \%)$ & $(33.3 \%)$ & $(50.7 \%)$ \\
\hline No & 15 & 23 & 18 & 56 \\
$(31.3 \%)$ & $(56.1 \%)$ & $(66.7 \%)$ & $(48.3 \%)$ \\
\hline Column total & 48 & 41 & 27 & 116 \\
& $(41.4 \%)$ & $(35.3 \%)$ & $(23.3 \%)$ & $(100.0 \%)$ \\
\hline
\end{tabular}

Significance $=0.0060$

Minimum Expected Freq $=13.034$

Degrees of Freedom (D.F) $=2$ 
Table 52 indicates the following results :

- $\quad 68.8 \%$ of the employees with no experience at all were subject to tests as compared to $31.3 \%$ who were not tested when employed .

- $\quad 43.9 \%$ of the employees with medium experience (from 1 to 10 years) were tested while $56.1 \%$ of them were not tested during selection .

- $\quad 33.3 \%$ of the employees with high experience were tested while $66.7 \%$ were not tested.

As we go from left to right in the "yes" row, the percentage use of tests decreases while as we go from left to right in the "No" row, the percentage use of selection tests increases. Hence, one can conclude that the use of selection tests may be associated with the experience of the candidate. Since the significance of the contingency table is 0.0060 which is much less than the significance level $(0.05)$. Therefore $\mathrm{H}_{0}$ is adopted at 0.05 level of statistical significance .

The result of the test : The use of selection tests is dependent on the experience of the new employee. The higher the candidate's experience, the less is the probability that he will be subject to selection tests. This crosstabulation reassures the result of the first research question concerning the effectiveness of selection . Selection tests are needed at all levels especially for experienced employees in order to test their banking experience and what they have already learned on their previous job(s). A person with 10 years experience sometimes doesn't know as much as another person with 3 years experience.Therefore, the purpose of tests is to assess that experience and to determine whether the individual is able to work on his job and to perform his work successfully . 


\subsubsection{Cross abulation and Chi-square test of E0 by X9:}

The hypothesis to be tested in this section is whether turnover among new comers (X9) is dependent on the use of selection tests(Eo)

$$
\begin{aligned}
& \mathrm{H}_{0}: \mathrm{X}_{9} \text { is dependent on } \mathrm{E} 0 \\
& \mathrm{H}_{1}: \mathrm{X}_{9} \text { is independent of } \mathrm{E} 0 .
\end{aligned}
$$

Table 53 includes the crosstabulation and the results of the Chi-square test

\section{Table 53}

\section{Crosstabulation of E0 by X9}

\begin{tabular}{|c|c|c|c|}
\hline $\begin{array}{c}\text { Use tests } \\
\text { Turnover rate }\end{array}$ & Yes & No & Row Total \\
\hline 0 to $20 \%$ & 31 & $\mathbf{1 2}$ & 42 \\
& $(\mathbf{5 1 . 7 \% )}$ & $(\mathbf{2 1 . 4 \% )}$ & $(37.1 \%)$ \\
\hline 21 to $40 \%$ & $\mathbf{2 2}$ & $\mathbf{2 3}$ & 45 \\
$(\mathbf{3 6 . 7 \% )}$ & $\mathbf{( 4 1 . 1 \% )}$ & $(38.8 \%)$ \\
\hline $41 \%$ and above & $(\mathbf{1 1 . 7 \% )}$ & $(\mathbf{3 7 . 5} \%)$ & 28 \\
\hline Column Total & $\begin{array}{c}60 \\
(51.7 \%)\end{array}$ & $\begin{array}{c}56 \\
(48.3 \%)\end{array}$ & $\begin{array}{c}116 \\
(100.0 \%)\end{array}$ \\
\hline
\end{tabular}

significance $=0.0005$

Minimum Expected Freq. $=13.517$

Degrees of Freedom (D.F) $=2$. 
Table 53 indicates that $51.7 \%$ of the employees who were tested when selected are those of banks whose turnover rate among new comers is low ; this percentage decreases to $36.7 \%$ and then to $11.7 \%$ in banks of higher turnover rates .

This indicates that turnover rate among new comers might be associated with the use of selection tests. Since the significance of the contingency table is 0.0005 (much less than the significance level adopted); one can conclude that turnover rate is associated or dependent on the use of selection tests. As tests are used during selection, turnover rate among new comers decreases. Therefore $\mathrm{H}_{0}$ is adopted at 0.05 significance level .

The result of the test : Turnover rate among new comers is dependent on whether tests are used during selection. The higher the use of selection tests, the lower is the turnover rates among new employees. Therefore to reduce rotation and training costs that must be incurred on employees who would leave the bank, selection tests can be used to determine well in advance those who are not up to the standard required. 


\subsubsection{Crosstabulation and Chi-square test of F5 by $A 11$.}

The hypothesis that is going to be tested is whether the type of interview is dependent on the position to be filled .

$$
\begin{aligned}
& \mathrm{H}_{0}=\mathrm{F} 5 \text { is dependent on All } \\
& \mathrm{H}_{1}=\mathrm{F} 5 \text { is independent of All }
\end{aligned}
$$

Table 54 below includes the crosstabulation and the results of the

Chisquare test at 0.05 level of statistical significance.

Table 54

crosstabulation of F5 by A11

\begin{tabular}{|c|c|c|c|c|}
\hline $\begin{array}{c}\text { position } \\
\text { Interview }\end{array}$ & Low & Medium & High & Row Total \\
\hline One-to- one & $\begin{array}{c}53 \\
(\mathbf{9 4 . 6 \% )}\end{array}$ & $\begin{array}{c}25 \\
(\mathbf{6 7 . 6 \% )}\end{array}$ & $\begin{array}{c}17 \\
(\mathbf{7 3 . 9 \% )}\end{array}$ & $\begin{array}{c}95 \\
(81.9)\end{array}$ \\
\hline Panel & $\mathbf{2}$ & $\mathbf{1 2}$ & $\mathbf{6}$ & 20 \\
$(\mathbf{3 . 6 \% )}$ & $(\mathbf{3 2 . 4 \% )}$ & $(\mathbf{2 6 . 1 \% )}$ & $(17.2 \%)$ \\
\hline Group & $\mathbf{0}$ & $\mathbf{0}$ & $\begin{array}{c}1 \\
(\mathbf{0 . 0} \%)\end{array}$ \\
\hline Column Total & $\begin{array}{c}56 \\
(48.3 \%)\end{array}$ & $\begin{array}{c}37 \\
(31.9 \%)\end{array}$ & $\begin{array}{c}23 \\
(19.8 \%)\end{array}$ & $\begin{array}{c}116 \\
(100.0 \%)\end{array}$ \\
\hline
\end{tabular}

Significance $=0.0040 \quad \mathrm{DF}=4 \quad$ Min. Expected Freq. $=0.198$ 
The one-to-one interview is the interview type that is mostly used especially at lower level $(94.6 \%)$ This percentage however decreases at higher levels. While the panel interview is the type that is mostly used at medium and high managerial levels .

Table 54 indicates that as the position to be filled is at higher levels the use of panel interviews increases. One can then conclude that an association may exist between the type of the interview and the position to be filled. In testing the significance of the contingency table, it was found that its significance is 0.0040 which is less than the level of significance adopted. Hence $\mathrm{H}_{0}$ is accepted at 0.05 significance level.

The result of the test: The type of the interview depends on the position to be filled. The higher the position, the more is the use of the panel interview where a group of interviewers throw questions on a single candidate .

\subsubsection{Crosstabulation and Chi-square test of $\mathrm{F} 4$ by $\mathrm{A3}$.}

The hypothesis to be tested is whether the effectiveness of the interview is dependent on the education of the candidate .

$\mathrm{H}_{0}=\mathrm{F} 4$ is dependent on $\mathrm{A} 3$.

$\dot{\mathrm{H}_{1}}=\mathrm{F} 4$ is independent on $\mathrm{A} 3$.

The crosstabulation and the results of the Chi-square results are presented in the following Table 55. 


\section{Table 55}

crosstabulation of F4 by $\mathrm{A3}$

\begin{tabular}{|c|c|c|c|c|}
\hline $\begin{array}{l}\text { Education } \\
\text { Interview }\end{array}$ & High school & B.S. & $\begin{array}{c}\text { M.S } \\
\text { or higher }\end{array}$ & Row Total \\
\hline Not effective & $\begin{array}{c}20 \\
(66.7 \%) \\
\end{array}$ & $\begin{array}{c}29 \\
(40.3 \%) \\
\end{array}$ & $\begin{array}{c}4 \\
(28.6 \%) \\
\end{array}$ & $\begin{array}{c}53 \\
(45.7 \%) \\
\end{array}$ \\
\hline Undecided & $\begin{array}{c}3 \\
(10.0 \%)\end{array}$ & $\begin{array}{c}5 \\
(6.9 \%) \\
\end{array}$ & $\begin{array}{c}3 \\
(21.4 \%) \\
\end{array}$ & $\begin{array}{c}11 \\
(9.5 \%) \\
\end{array}$ \\
\hline Effective & $\begin{array}{c}7 \\
(23.3 \%)\end{array}$ & $\begin{array}{c}38 \\
(52.8 \%) \\
\end{array}$ & $\begin{array}{c}7 \\
(50.0 \%) \\
\end{array}$ & $\begin{array}{c}52 \\
(44.8 \%) \\
\end{array}$ \\
\hline Column Total & $\begin{array}{c}30 \\
(25.9 \%)\end{array}$ & $\begin{array}{c}72 \\
(62.1 \%)\end{array}$ & $\begin{array}{c}14 \\
(12.1 \%)\end{array}$ & $\begin{array}{c}116 \\
(100.0 \%)\end{array}$ \\
\hline
\end{tabular}

Significance $=0.0261 \quad$ D.F $=4 \quad$ Min. Expected Freq $=1.328$

Table 55 indicates the following results :

- $\quad 66.7 \%$ of employees who have High school education stated that the interview was subject to outside interruptions while this percentage decreased as the education of the employee is higher .

- Only $23.3 \%$ of employees with High school education answered that the interview was not subject to outside interruptions (effective) while this percentage increases as the interviewee's education is higher. 
Therefore, one can conclude that the effectiveness interview might be associated with the education of the interviewer. The higher the education of the candidate, the more and more important the interviewee becomes to the bank and the more and more effective and adequate interviewing techniques become .

The significance of the contingency table is 0.0261 which is less than the level of significance used; therefore, we can accept the $\mathrm{H}_{0}$ at 0.05 significance level.

The result of the test: The type of the interview depends on the education of the interviewee. The higher the interviewee's education, the more important he becomes to the interviewer and to the bank, and the better the ways that the interviewer seeks in interviewing the candidate.

\subsubsection{Crosstabulation and Chi-square test of G2 by A10.}

The hypothesis to be tested is whether satisfaction on the job (G2) is dependent on whether the employee's job is related to his major (A10)

$\mathrm{H}_{0}: \mathrm{G} 2$ is dependent on $\mathrm{A} 10$.

$\mathrm{H}_{1}: \mathrm{G} 2$ is independent of $\mathrm{A} 10$.

Table 56 summarizes the cross tabulation and the results of the Chi-square test . 


\section{Table 56}

Crosstabulation of $\mathbf{G} 2$ by $\mathbf{A 1 0}$

\begin{tabular}{|c|c|c|c|}
\hline $\begin{array}{l}\text { Major } \\
\text { Satisfied } \\
\end{array}$ & Related & Not Related & Row Total \\
\hline Yes & $\begin{array}{c}44 \\
(68.8 \%) \\
\end{array}$ & $\begin{array}{c}23 \\
(44.2 \%)\end{array}$ & $\begin{array}{c}67 \\
(57.8 \%) \\
\end{array}$ \\
\hline Undecided & $\begin{array}{c}10 \\
(15.6 \%)\end{array}$ & $\begin{array}{c}8 \\
(15.4 \%) \\
\end{array}$ & $\begin{array}{c}18 \\
(15.5 \%)\end{array}$ \\
\hline No & $\begin{array}{c}10 \\
(15.6 \%)\end{array}$ & $\begin{array}{c}21 \\
(40.4 \%) \\
\end{array}$ & $\begin{array}{c}31 \\
(26.7 \%) \\
\end{array}$ \\
\hline Column Total & $\begin{array}{c}64 \\
(55.2 \%)\end{array}$ & $\begin{array}{c}52 \\
(44.8 \%) \\
\end{array}$ & $\begin{array}{c}116 \\
(100.0 \%)\end{array}$ \\
\hline
\end{tabular}
Significance $=0.0084$
D.F $=2$
Min Exp Freq $=8.069$

The above table indicates that :

- $68.8 \%$ of employees whose major is related to the job are satisfied with their job and answered that their job is the best for them as compared to other jobs. However, just $15.6 \%$ of employees whose major is related to the job answered that they are not satisfied with their job .

- Only $15.6 \%$ of employees whose job is related to their education answered that they are not satisfied with their job. However, $40.4 \%$ of those whose job is not related to their education stated that they are not satisfied with their job. 
The results in Table 56 indicate that satisfaction on the job might be associated with whether the employee's job is related to his education. In testing the significance of the results, the significance of the contingency table is 0.0084 which is less then the level of significance adopted. This indicates that there is a difference across categories in the two groups $\mathrm{G} 2$ and $\mathrm{A} 10$; therefore, $\mathrm{H}_{0}$ is adopted at 0.05 significance level.

The result of the test : Job satisfaction or whether the employee considers that his job is the best for him is dependent on adequate placement. Therefore, as the employee is adequately placed on a job that matches his major, his job satisfaction increases.

\subsubsection{Crosstabulation and chi-square test of G7 by A11.}

The hypothesis is to be tested in this section is whether better placement at work is dependent on the position to be filled .

$$
\begin{aligned}
& \mathrm{H}_{0}=\mathrm{G} 7 \text { is dependent on } \mathrm{A} 11 . \\
& \mathrm{H}_{1}=\mathrm{G} 7 \text { is independent of } \mathrm{A} 11 .
\end{aligned}
$$

The crosstabulation and the Chi-square results are summarized in Table 57 
Table 57

Crosstabulation of G7 by A11

\begin{tabular}{|c|c|c|c|c|}
\hline $\begin{array}{l}\text { Position } \\
\text { Placement }\end{array}$ & Low & Medium & High & Row Total \\
\hline Bad & $\begin{array}{c}32 \\
(57.1 \%) \\
\end{array}$ & $\begin{array}{c}14 \\
(37.8 \%)\end{array}$ & $\begin{array}{c}5 \\
(21.7 \%)\end{array}$ & $\begin{array}{c}51 \\
(44.0 \%) \\
\end{array}$ \\
\hline Undecided & $\begin{array}{c}9 \\
(16.1 \%) \\
\end{array}$ & $\begin{array}{c}3 \\
(8.1 \%) \\
\end{array}$ & $\begin{array}{c}4 \\
(17.4 \%)\end{array}$ & $\begin{array}{c}16 \\
(13.8 \%) \\
\end{array}$ \\
\hline Good & $\begin{array}{c}15 \\
(26.8 \%) \\
\end{array}$ & $\begin{array}{c}20 \\
(54.1 \%)\end{array}$ & $\begin{array}{c}14 \\
(60.9 \%) \\
\end{array}$ & $\begin{array}{c}49 \\
(42.2 \%) \\
\end{array}$ \\
\hline $\begin{array}{c}\text { Column } \\
\text { Total }\end{array}$ & $\begin{array}{c}56 \\
(48.3 \%)\end{array}$ & $\begin{array}{c}37 \\
(31.9 \%)\end{array}$ & $\begin{array}{c}23 \\
(19.8 \%)\end{array}$ & $\begin{array}{c}116 \\
(100.0 \%)\end{array}$ \\
\hline
\end{tabular}

Significance $=0.0129 \quad$ D.F $=4 \quad$ Min Expected Freq $=3.172$.

Table 57 indicates that $57.1 \%$ of employees at low positions answered that they were placed at the job just because it was vacant and someone was needed to fill it ; while $26.8 \%$ answered that they were fairly placed on their job. However , at high managerial positions only $21.7 \%$ of the respondents answered that they were put on their job just because it was vacant and someone was needed to fill it while $60.9 \%$ of them answered that they were adequately placed .

As we go in the " Bad" row from low positions to high positions the percentage decreases while as we go in the "Good" row from low to high position, the percentage increases. This indicates that placement on the job might be associated with the position of the candidates. 
In testing the significance of the contingency table, the significance of the table was 0.0129 which is below the significance level $(0.05)$ adopted in the test; therefore, $\mathrm{H}_{0}$ is accepted at 0.05 significance level .

The result of the test: The adequacy of placement is dependent on the position to be filled. The higher the position to be filled, the more sensitive it becomes, and the more adequate and effective the placement becomes. However, adequate placement must be a rule for all positions from bookkeeper to manager since decisions at higher levels are based on the analysis and the work of employees at lower levels. 
This chapter includes the analysis of the findings of this research. It answered the research questions, the results are :

1. The recruiting process adopted by banks in Lebanon is adequate but it needs some improvements; while the selection process in most of the banks is below standard.

2. Job satisfaction is dependent on recruiting and selection.

3. Turnover rates among new comers decreases as adequate recruiting and selection processes are followed.

This Chapter also includes these major findings :

1. The use of selection tests decreases as the candidate's experience increases.

2. The turnover rate among new comers decreases as selection tests are used during employment.

3. The use of the panel interview increases at higher levels.

4. The interviewer seeks better ways in his interviews as the candidate's education increases.

5. Job satisfaction increases as the employee is placed on a job that matches his education (i.e. as placement is adequate).

6. The higher the position the more adequate is the placement .

The next Chapter includes a summary of the research findings and some recommendations to the personnel managers to secure adequate recruiting and selection. 


\section{CHAPTER V \\ SUMMARY AND RECOMMMENDATIONS}

\subsection{Introduction:}

This piece of research intends to assess the adequacy of recruiting and selection processes followed by banks operating in Lebanon. It also attempts to study the impact of recruiting and selection on employee satisfaction. Thirty five personnel managers or assistant personnel managers from thirty five banks have been contacted and asked to fill a questionnaire. Also, one hundred and sixteen newly hired employees at different positions of the thirty five banks selected were contacted and asked to fill a questionnaire which is approximately similar to that directed to personnel managers. To answer the research questions and to test the hypotheses stated in chapter one, descriptive analysis as well as statistical analysis such as crosstabulations and regressions have been used.

This chapter presents a summary of the results of the questions and the hypotheses tested in the previous chapter.

\subsection{Descriptive Analysis.}

" Do ' banks operating in Lebanon follow adequate recruiting and selection process?"

In order to answer the above question, the questions of several sections in the questionnaires have been analyzed. These sections are : recruiting policies, recruting sources, recruiting methods, selection interviews, and reference checks sections. 
As for the adequacy of recruiting policies, sources, and methods, the results as follows:

1- Effective assessment of human resources needs are followed by banks. Almost all banks anticipate human resources needs ahead of time and are ready to select new employees whenever a need arises.

2- Almost all banked depend on a variety of sources of recruits. This is a good sign since this brings a variety of ideas, thoughts and methods for carrying the job more efficiently.

3- However, two negative answers were found in analyzing the adequacy of the recruiting process. First, personnel managers showed their preference to select specific university graduates for new positions. Second, about $50 \%$ of the employees who answered the questionnaires answered that they were not subject to a screening interview before the selection process stated.

The above results indicate that the recruiting process can be considered effective except in two important points that need improvement.

As for the adequacy of the selections process, the results that will be presented below are based on employee's answers since wide differences appeared between their answers and those of the personnel managers. 


\section{A. Selection tests:}

only half of the employees contacted in this research answered that they were tested during selection. Of these employees $30 \%$ only answered that the tests were held in a suitable calm place and $68 \%$ answered that the tests materials were related to the job. As for the type of tests they were subject to, the results are presented below:

\section{Tests used}

Intelligence tests

Interest tests

Job knowledge tests

Skills tests

\section{Percentage (out of 60)}

$31.7 \%$

$55.0 \%$

$23.3 \%$

$66.7 \%$

The most important type of tests, "job knowledge test", is the least used one; this indicates that test materials are not related to the job to be filled. Also, interest tests should be included in every test since they assess the candidate's interest to work on the job vacancy.

\section{B. Selection interviews:}

As with selection tests, some unfavorable results were found in assessing their effectiveness of selection interviews :

About $50 \%$ of the newly hired employees stated that they were subject to an interview with their supervisor. However, this percentage should be higher since this interview is more important than that with the personnel manager because here, the position supervisor knows more than the personnel manager about the job, the qualifications needed and can judge better than the personnel manager whether the candidate is acceptable or not. 
- A summary of the results of the questions asked to assess whether interview techniques are adequate or not is presented below:

\section{Percentage}

The interview talks of the interview time .

$42.2 \%$

The interviewer did not ask job related questions.

$50.9 \%$

The interview was subject to outside interruptions.

The interviewer sticks to the application blank

during the interview.

The interviewer knows everything about the

candidate (education, experience, test scores, etc..).

The interviewer knows everything about the job

(its duties, requirements, responsibilities etc...

$55.2 \%$

The interviewer knows everything about the

bank (its size, rank, etc.....).

$80.2 \%$

Most of the above questions prove that interview techniques are not adequate. They indicate that most of the interviews are used to collect personal rather than job related information from the candidate. They Also show that during the interview, time is not allowed for the candidate to talk about his education, his experience, and knowledge about the job to permit the interviewer to give his opinion whether the candidate is qualified and able to handle the job successfully. 


\subsection{Regression Analysis:}

Multiple regression analysis was used to answer the second and the third questions.

The second research question was: "Does employee satisfaction increase with better recruiting and selection?"

A regression equation was built where job satisfaction (GSATISF) is the dependent variable.

Four variables entered the equation: The adequacy of placement (G7), the effectiveness of interview techniques (FINTER), whether the employee's job is related to his major (A10), and the employee's experience (A6).

The resulting regression equation is:

GSATISF $=0.58062-0.16753+0.39987$ FINTER +0.27787 A10 +0.10636 A6

The coefficients of the independent variables indicate that:

i- Employee satisfaction increases when the interview techniques are adequate, i.e when interviews are held to select the candidate that best suits the job. ii- Employee satisfaction increases when the employee is put on a job that is compatible with his education and his qualifications .

iii- Employee satisfaction decreases when placement on the job is inadequate or when the employee was put on the job just because somebody was needed to fill it. For example, when an employee whose major is accounting is put in the legal department just because someone is needed to fill the vacant place. iv- Satisfaction increases with the experience of the candidate. This may be because selection techniques are more effective when the employee's experience increases. This was shown in the crosstabulation performed 
between the experience of the candidate and the adequacy of interviews, the higher the candidate's experience, the more adequate the interview techniques are.

Therefore, the above equation shows that employee's satisfaction is dependent on the adequacy selection.

The third research question was : "Is employee turnover affected by the adequacy of recruiting and selection?"

A regression equation was built to answer this question. The dependent variable was turnover rate among new comers (X9).

The independent variable that entered the equation were: recruiting policies (G1), the adequacy of placement (G7), the use of selection tests (E0), and the number of employees in the bank (A1).

The resulting regression equation is:

$\mathrm{X} 9=1.54006-0.262020 \mathrm{G} 1+0.047937 \mathrm{E} 0+0.23223 \mathrm{~A} 1+0.14027 \mathrm{G} 7$

The coefficients of the independent variables indicate that turnover rate among new comers decreases when selection tests are used during selection. However, this rate increases when the banks is selective and chooses its new employees from specific universities, when placement on the job is not adequate and when the number of employees in the bank increases. Therefore, $X 9$ is dependent on the adequacy of recruiting and selection. 


\subsection{Crosstabulations and Chi-square tests:}

To test the six hypotheses stated in chapter one, crosstabulations and chi-square tests where performed to detect whether some variables were related to other variables or whether the relations were obtained by chance.

The results of the chi-square tests that were performed at 0.05 level of statistical significance are as follows:

1- The use of selection tests is dependent on the candidate's experience; the higher his experience, the lesser is the use of selection test.

2- Turnover among new employees is dependent on whether the employees was subject to selection tests. As the use of selection test increases, turnover rates among new comers decrease.

3- The type of the interview is dependent on the position to be filled; the higher the position, the more the use of panel interview.

4- The adequacy of interview techniques depends on the education of the candidate; the higher the candidate's education, the more adequate the interview techniques become. This indicate biase.

5- Employee's satisfaction or whether the employees considers his job the best for him is dependent on whether his job is related to his major. As the employee was put on a job that matches his education, his job satisfaction increases .

6- The adequacy of placement is dependent on the position to be filled. The higher the position the more sensitive it becomes and the more adequate the placement becomes. This is also a negative point. 


\subsection{Recommendations:}

Employees are the bank's most valuable assets; they are the mirror of the bank. The more they are well chosen, the more customers and business the bank will attract and the faster it will grow and prosper. "Well chosen" here does not mean physical appearance; however, it means honesty, experience, education, and good communication and interaction skills. Therefore, to secure the employment of the most adequate individuals, recruiting and selection processes must be improved as much as possible, especially nowadays where competition among banks has become very intense.

This research has shown that there are some deficiencies in the recruiting and selection techniques followed by banks' personnel managers. This section is therefore, concerned with the presentation of some recommendations which if carried out carefully may lead not only to the selection of the most suitable individuals but to the placement of the individual at the job that best matches his qualifications and interests:

1- The research results indicated that only $37.1 \%$ of the personnel managers have their education related to personnel. Therefore, the first and the most important recommendation is that the personnel manager should be personnel oriented; he should have both an experience and a background in the personnel domain. A Computer Science or a Finance graduate person for example, can not carry out the personnel work as effectively as another person who is specialized in the personnel field.

2- Nowadays, everything is changing ; what was new in the past is now considered obsolete. Personnel managers should always update their knowledge 
about personnel matters. They are then recommended to attend seminars and to read current issues in personnel whether in personnel magazines or books.

3- Planning is a basic step for every action to be taken. For every position to be filled, effective planning for the position requirements should be done . Also, planning should be done based on the mutual cooperation of both the personnel manager and the position supervisor. The position supervisor is in a better position to suggest the performance criteria and the qualifications required since he knows the job more than the personnel manager. This reduces the placement mistakes committed by banks where employees are put on jobs that are not compatible with their qualifications.

4- Personnel managers should always review their recruiting and selection processes and assess their adequacy. One way to do this is to call the new employee at the end of the training period and ask him whether he is satisfied on his job or whether he can find himself more productive on another job. Based on the employee's answer and on the review of these processes, the personnel manager can determine whether these processes were adequate or not and can then correct any deficiencies in them. This check should always be repeated to secure high satisfaction.

5- All employees at all levels should pass by same selection process. They should all be subject to selection test, to selection interviews with the personnel manager and with the position supervisor, they should all be treated equally in interviewing and testing, etc..... The selection process should never differ from one position to another or even from one person to another in the same position. However, this does not mean that a standard test should be used for all employees; for every position as well as for every job there should be a specific test . 
6- Personnel managers are also recommended to try to apply recruitment software applications that may facilitate a lot of their work and save the time that will be lost in the searsh for appropriate recruits .

There are other recommendation to correct the specific recruiting and selection mistakes found in this piece of research:

a- Job knowledge tests and interest tests should always be given for every employee . Also, test materials should be related to the job to be filled.

b- The candidate that succeeded in the selection tests and in the interview with the personnel manager should be subject to an interview with the position's manager.

c- During interviews, interruptions should be reduced to minimum .

d- Job related questions should be asked in the interviews.

e- The interviewer should always prepare himself for the interview. He should gather all information about the bank, the job, and the interviewee.

f- The interviewer should never stick to the application and require the information already found in it. This renders the interview boring and just an oral repetition of the application blank.

g- Personnel managers should attract recruits from various sources.

h- Every recruit should be subjest to a short screening interview before the selection process starts.

Finally, to secure the placement of the right person on the right job the above recommendations should be implemented carefully. Personnel managers should be personnel oriented, they should always update their knowledge, they should always review their recruiting and selection processes to correct any mistake in them, and they should treat all recruits equally. If all these recomendations are fully emplemented, most of the deficiencies found in the recruting and selection processes will disappear. 


\section{Implications for Future Research:}

First, it is recommended that others repeat the same study using a larger sample. Also, it is recommended that others assess, in addition to the adequacy of recruiting and selection, the personnel managers' attitude towards computerized recruiting tools. 
APPPENDIX A QUESTIONNAIRES 


\section{Dear respondent:}

This questionnaire is designed to be used for the fulfillment of a :Vaster Degree Research. The purpose of this research is to describe and study the effectiveness of recruitment and selection activities of banks operating in Lebanon.

I am pleased to inform you that you have been chosen to fill this questionnaire: your cooperation is of great imponance for my research. I assure you that your answers and ideas will not be used for other purposes except my Research Topic. You are kindly requested to fill all this questionnaire frankly and as soon as you car.

Thank you

Nada Hajj

School of Business - Lebanese American triversity (LAU)

Formerly, Beirut University College (BUC) 


\section{A - Demographic and business section:}

Answer the following questions:

The approximate number of employees in the bank (all branches)

The number of branches of the bank

Your education / last degree you major

University or school where you graduated

Number of years of experience before you were employed; if any

Sex

Marital status

Age

The department where you work

Your position in the bank

Choose the answer that best suits the bank where you work:

(Circle your answer)

- Is there a personnel department in the bank?

- Are there personnel policies in the bank?

- If yes, are they known to all employees?

- If yes, how?

$\begin{array}{ll}a \text {-Yes } & b-N_{0} \\ a \text {-Yes } & b \text {-No } \\ a \text {-Yes } & b \text {-No }\end{array}$

a - By using internal builetins.

b - On bulletin board.

$c$ - In meetings.

\section{B - Turnover analysis in the bank:}

State whether you agree, disagree or are undecided with these statements (put a $\sqrt{ }$ mark under your choice).
A-Agree
$B$ - Disagree
C - Undecided

- Turnover is higher among newcomers than old employees.

A $\quad \underline{C}$

- Turnover is higher among males than females.

- Tumover is higher nowadays than in the past. 


\section{C - Factors affecting emplovment:}

In your opinion do the following factors have a strong, medium or no effect on employment decisions: (put a $\sqrt{ }$ under your choice).
A - Strong effect
B - Medium effect
C - No effect

- The religion of the applicant.

$\underline{B} \quad \underline{C}$

- The age of the applicant.

- The marital status of the applicant.

- The sex of the applicant.

- The education of the applicant.

- The importance of the position to be filled.

- The organization where the applicant worked previously.

- The university from where the applicant graduated.

- The bank's customers (enforcing some candidates).

- Political interference.

\section{D - Recruiting methods:}

How were you informed that there was a job opening in the bank? (Circle your answer):

a - I read about it in an advertisement.

$b-I$ was applying in a private employment firm.

$c$ - I was applying in an executive search firm.

d - A university professor told me that there is a job opening.

e - An employee or a relative in the bank told me.

$f$ - I was an employee in a company providing the bank with its services (ex. audit firm...) and I was offered the job.

$g$ - I simply submitted the application without any notice.

e - Others, specify

Before you submitted the application, were you subject to a short screening interview?
a- Yes
$b-$ No 


\section{E - Selection tests:}

If you were tested when employed, please state whether you agree, disagree or you are undecided with these statements: (put $\sqrt{ }$ under your choice).
A-Agree
B - Disagree
$C$ - Undecided

$\underline{A} \quad \underline{B} \quad \underline{C}$

1 - Test materials are related to my current job.

2 - I was given the test in a suitable calm place.

3 - Tests included some questions to assess:

- Our knowledge about the job.

- Our intelligence.

- Our interest to work on the job vacancy.

- Our job skills such as case solving, typing...

\section{F - Selection Interviews:}

If you were interviewed during employment please answer the following questions:

- I was interviewed with the branch or department manager $a$ - Yes $b$ - No

- I was interviewed with the personnel manager

a- Yes $\quad b-$ No

- I was interviewed with an employee in the personnel department

- The interview was held in a suitable, calm place a- Yes $\quad b$ - ivo

a- Yes b- io

- What was the type of the interview you were subject to? (circle your answer)

a - One-to-one interview (you and the interviewer).

b - Panel interview (you and a group of interviewers).

c - Group interview (you and a group of applicant with one or more interviewers). 
- If you were subject to an interview during employment, state whether you agree. disagree, or are undecided with these statements: (put a $\sqrt{ }$ under your choice).
A - Agree
B - Disagree
C - Undecided

- The interviewer was talking most of the interview time.

- The interviewer asked job related quesions to assess our knowledge about the job.

- The interview was subject to some outside interruptions.

- During the interview, the interviewer has my application with him and was verifying the information I provided.

- The interviewer knows everything about the bank.

- The interviewer knows everything about the job.

- The interviewer knows my credentials before the interview begins: education, previous experience, tests scores...

- The interviewer had a prepared list of questions to be asked:

\section{G - General evaluation of the emplovment process:}

State your degree of agreement with these statements: (put a $\sqrt{ }$ under your choice).
A - Strongly Agree
B - Agree
$C$ - Undecided
$\mathrm{D}$ - Disagree
E - Strongly Disagree

$\underline{A} \quad \underline{\mathrm{B}} \quad \underline{\mathrm{C}} \quad \underline{\mathrm{D}} \quad \underline{\mathrm{E}}$

- The majority of new employees are graduates of specific university (ies).

- My job is the best for me as compared to other jobs.

- I am placed at a job that fits my interests and qualifications.

- I always desire to learn more and more about my job.

- If I was offered another job my productivity would be lower.

- My job is similar to what I expected it to be.

- I was placed on my job just because it was vacant and someone was needed to fill it.

- My performance is improving with time.

- I am more interested at work now than when I started. 


\section{Open Question:}

Do you think that there are other points related to this topic that have not been dealt with? Do you have any other comment?

Thank you for your kind cooperation 


\title{
Dear respondent:
}

This questionnaire is designed to be used for the fuilillment of a Master Degree Research. The purpose of this research is to describe and study the effectiveness of recruitment and selection activities of banks operating in Lejanon.

I am pleased to inform you that you have been chosen to fill this questionnaire: your cooperation is of great importance for my research. I assure you that your answers and ideas will not be used for other purposes except my Research Topic. You are kindly requested to fill all this questionnaire frankly and as soon as you can.

\author{
Thank you \\ Nada Hajj \\ School of Business - Lebanese American L'niversity (LAU) \\ Formerly, Beirut University College (BUC)
}




\section{A - Demographic and business section:}

Please answer the following questions:

- Position currently occupied

- Education / last degree

- Major

- Age

- Sex

- Marital Status

- Years of experience in your department

- Total number of emplovees in this bank

- Number of branches of this bank

Choose the answer that best fits the bank: (Circle your answer)

- Is there a personnel department in this bank? $a-$ Yes $\quad$ b- No

- If yes, when was it formed? In year

- Are there personnel policies in this bank? a - Yes $\quad b-N_{0}$

- Are personnel policies known to all employees?

a - Yes $\mathrm{b}-\mathrm{No}$

- If yes, how:
a - By using internal bulletins.
b - On builetin boards.
$c$ - In meetings.

Personnel policies such as hiring, promotion, salaries administration, and others are performed: (Circle the best answer).

a) In. the personnel department (centralized in that department under the control of the personnel manager).

b) In various departments such as salaries administration is performed by the financial manager, etc. (decentralized).

c) By a single individual whose responsibility is to carry ail personnel functions. 


\section{B - Turnover analysis:}

- What is the approximate number of employees hired every year

- What is the approximate number of newly hired employees voluntarily leaving the bank every year?

State whether you agree, disagree or are undecided with these statements:

(put a $\sqrt{ }$ mark under your choice)
A-Agree
$B$ - Disagree
C - Undecided

$\underline{\text { A }} \quad \underline{\mathrm{B}} \quad \underline{\mathrm{C}}$

- Employee turnover is higher among new comers than old ones.

- Employee turnover is higher among males than females.

- Employee turnover among new comers is higher nowadays than in the past.

- Turnover costs are not very high.

- Decision concerning the acquisition of new employees is not as important as the acquisition of a fixed asset.

\section{C - Factors affecting employment:}

State whether these factors have a strong, medium, or no effect on employment decisions in banks: (put a $\sqrt{ }$ under your choice)
A - Strong effect
$B$ - Medium effect
C - No effect

- The religion of the candidate.

- The age of the candidate.

- The marital status of the candidate.

- The sex of the candidate.

- The education of the candidate.

- The importance of the position to be filled.

- The organization where the applicant previously worked.

- The university from where the candidate graduated.

- The bank's customers (enforcing some candidates).

$\underline{A} \quad \underline{\mathrm{B}}$ 


\section{D - Recruitment:}

1 - State your degree of agreement with these statements:

$A$-Strongly Agree $\quad B$-Agree $\quad C$-Disagree $\quad D$-Strongly Disagree

$1 \quad \underline{B} \quad \underline{D}$

- Performance crieteria are identified for every position. $-\ldots+\ldots$

- There is a job description for all jobs.

- We are always ready with a pool of appropriate recruits from which to select employees.

- Human resources needs are anticipared ahead of time.

- Most of our new employees are graduates of a specific university(ies).

- Our reputation is a factor in attracting new recruits.

- Before appiying of a job a short screening interview is held with the candidate.

E - Sources of recruits:

2 - The recruits that the bank attracts to fill new vacant positions are:

$A$-All of them B-Most of them C-Some of them D-None of them (Put a $\sqrt{ }$ under your choice).

$\underline{B} \quad \underline{C} \quad \underline{D}$

- Current employees through transfers and promotions.

- Specific university graduates.

- Other banks employees.

- Relatives and friends of our employees.

- Employees of companies providing us with their services.

- Pass by candidates.

\section{F. - Methods of recruiting:}

To attract candidate to apply for the openings, the bank depends on:

(Put a $\sqrt{ }$ under your choice).
A- Always
$B$ - Most of the times
C - Sometimes
D - Never

- Advertisements.

- Private employment and executive search firms.

- Internships (students accepted as trainees).

- University professors who maintains close contact with personnel officers.

- Pass by candidares; the bank is well known.

- Current employees who suggest adequate recruits.

A $B \quad$ C

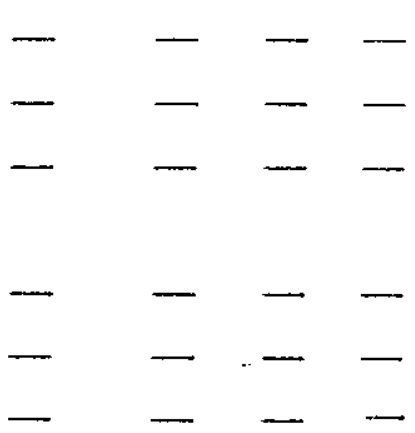




\section{$G$ - Selection tests:}

If you use tests as a selection tool please answer the following questions:
A-Always
B - Most of the times
C - Sometimes
$D$ - Never

- Tests are given under uniform conditions.

- Test results are compared to a standard score.

- Individuals who have high test scores are now good performers.

- Testsinclude questions to assess the candidate intelligence.

- Tests include questions to assess the individuals interest to work on a cerrain job.

- Tests include questions to assess the individual's knowledge of how to perform a job.

- We give tests that require the individual to demonstrate certain skills ex: soiving cases, ryping, ...

$\pm \underline{B} \quad \underline{D}$

H - Selection interviews:

If interviews are used in selection piease answer the following questions:

(Put a $\sqrt{ }$ under your choice).
A-Always
B - Most of the times
C - Sometimes
D - Never

- An interview is held with the personnel manager.

$\underline{A} \quad \underline{B} \quad \underline{D} \quad \underline{D}$

- An interview is held with the branch or department manager.

- An interview is held with a personnel department emplovee

- The interviewer knows everything about the bank: its s1ze, rank...

- The interviewer knows everything about the job: salaries, duties and responsibilities...

- The interview knows the applicant's credentials.

- The interviewer talks most of the interview time.

- Job related questions are not asked here; they can be uncovered through tests.

- Interuptions during the interview are allowed.

- Hll interview questions are prepared and listed in front of the interviewer.

- Only main interview questions are prepared.

- No interview questions are prepared betore the interview.

- During the interview the interviewer sticks to the application blank and verifies the information in it. 


\section{I - Reference check:}

If you check the information provided by candidates please answer the following questions: (put a $\checkmark$ under your choice).
$A$ - Always B - Most of the times
C - Sometimes
D - Never

1 - To confirm information the bank depends on:

$\underline{B} \quad \underline{C} \quad \underline{D}$

- Personnel references provided by the applicant.

- Recommendations of previous employers.

- Recommendations of universities and professors.

\section{J - Emplovment and emplovee performance:}

Please answer these questions taking into consideration that the new employee has already completed the training period: (on average).

(Circle your choice).

1 - The employee productivity is:
a - High
b- Acceptable or average
c - Below average

2. Employee cooperation with colleagues.

a - High cooperation b-Acceptable cooporation c-No cooperation.

3 - The employee degree of interest toward his job:
a - Very enthusiastic
$b$ - Enthusiastic
c- Not enthusiastic

4 - Employee desire to learn more about his job:
a - Strong desire
b - Average desire
c- No desire

\section{Open Question:}

Do you think that there are other points related to this topic that have not been dealt with? Do you have any other comment? 



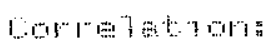

\begin{tabular}{|c|c|c|c|c|c|c|}
\hline FINTER & $F:$ & $\cdots$ & ei & 2 & 8 & 912 \\
\hline 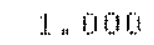 & .067 &.,- 420 & $-n_{4} 487$ & 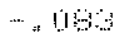 & $\cdots=8$ & $\cdots, y=$ \\
\hline .107 & 5.9100 & $=00$ & 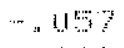 & $\cdots .17 \%$ & $\cdots, 05$ & $-1,3$ \\
\hline${ }^{\cdots}{ }_{n} 429$ & .020 & .t. $:=110$ & 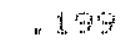 & .1176 & $=161$ & $=0$ \\
\hline$\cdots, y=17$ & 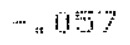 & $=13$ & 1.0100 & $.4 \%$ & . 39 & $=7 \mathrm{i}$ \\
\hline- „ & $\ldots .1 \%$ & $=07 \%$ & "1. 46 & $1=$ bint & " "म20 & $\cdots=0$ \\
\hline$\cdots,-104$ & $=: 140$ & .461 & .29 & $-M$ & 1. 100 & $=13$ \\
\hline$-\cdots+113$ & (.) , 19 & 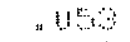 & 47 & 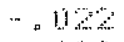 & $=16$ & 1 "yna \\
\hline 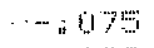 & 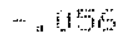 & $=111$ &, 102 & $=110 \mathrm{O}$ & 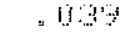 & -317 \\
\hline .16 & $\cdots=1114$ & $n 15$ & .143 & .16 & -06 & 20 \\
\hline-260 & „ & $=276$ & .15 & $=117$ & $\cdots, 496$ & $=051$ \\
\hline-114 & $\ldots .121$ & .044 & $.07 \%$ & " 164 & $=12$ & $=11$ \\
\hline , L &, 1.17 & " & $=120$ & 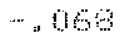 & $\cdots, 010$ & 40 \\
\hline${ }_{n} \mid 17$ &,-- 085 & $\cdots=17 \%$ & "066 & $=140$ & .09 & $=01$ \\
\hline " 0137 & $\cdots+11=4$ & 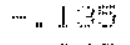 & 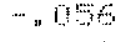 & $n 1511$ & $-7 \mathrm{~b}$ & $\cdots, 13$ \\
\hline$=14$ & " 06 & " & $\cdots, 116+$ & 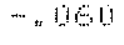 & $=4 !$ & 4 \\
\hline
\end{tabular}

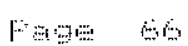

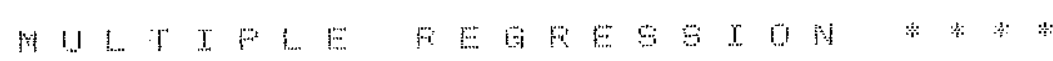

\begin{tabular}{|c|c|c|c|c|c|c|}
\hline A18 & 614 & 1 & \% & i & 4 & $6=$ \\
\hline .075 & $.19 \%$ & 90 & $\cdots=124$ & .130 & $\Rightarrow 7 \%$ & 437 \\
\hline 96 & $\cdots, 0104$ & $=080$ & $-{ }_{n} 120$ & .087 & $\cdots=010$ & $\cdots=10 \%$ \\
\hline 101 & r L & 27 & $=1144$ & 48 & $+\cdots$ & $\cdots, 13$ \\
\hline-1.12 & $=143$ & $.15 \mathrm{e}$ & .078 & 126 & $=168$ & $\cdots, \square$ \\
\hline .0190 & $=0$ & 4117 & .064 & $\cdots .06$ & $=14$ & , 1 \\
\hline-110 & 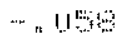 & $\cdots, 096$ & $=126$ & 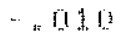 & $=045$ & $\cdots=0$ \\
\hline .337 & -205 & 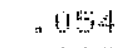 & +192 & 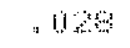 & " & ${ }^{-}$" 1,19 \\
\hline .000 & -240 & .116 & 120 & $=020$ & -.050 & -.16 \\
\hline a & $1=000$ & , 20\% & 169 & .194 & -.01 & $\cdots, 116$ \\
\hline+113 & $\pi 207$ & 1.000 & .058 & 204 & $\cdots=0118$ & $=01$ \\
\hline $.12 \%$ & .130 & $.0 \%$ & 1.0101 & $=107$ & $-7,14$ & -1604 \\
\hline 190 & -104 & $=204$ & .107 & $1=1100$ & $\cdots, A 7 \%$ & $-\quad-36$ \\
\hline .689 & $\cdots, 011$. & $\cdots .9142$ & ${ }^{n+}, \mid \leq 4$ & $\cdots, 47$ & 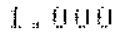 & .134 \\
\hline$=161$ & $\cdots=116$ & " r t & $\cdots, \quad 104$ & $-\cdots,-33$ & $=134$ & 1.600 \\
\hline .1019 & $\times 125$ & $\cdots, 0 \%$ & - 127 & 437 & .1167 & $=16$ \\
\hline
\end{tabular}

F⿻

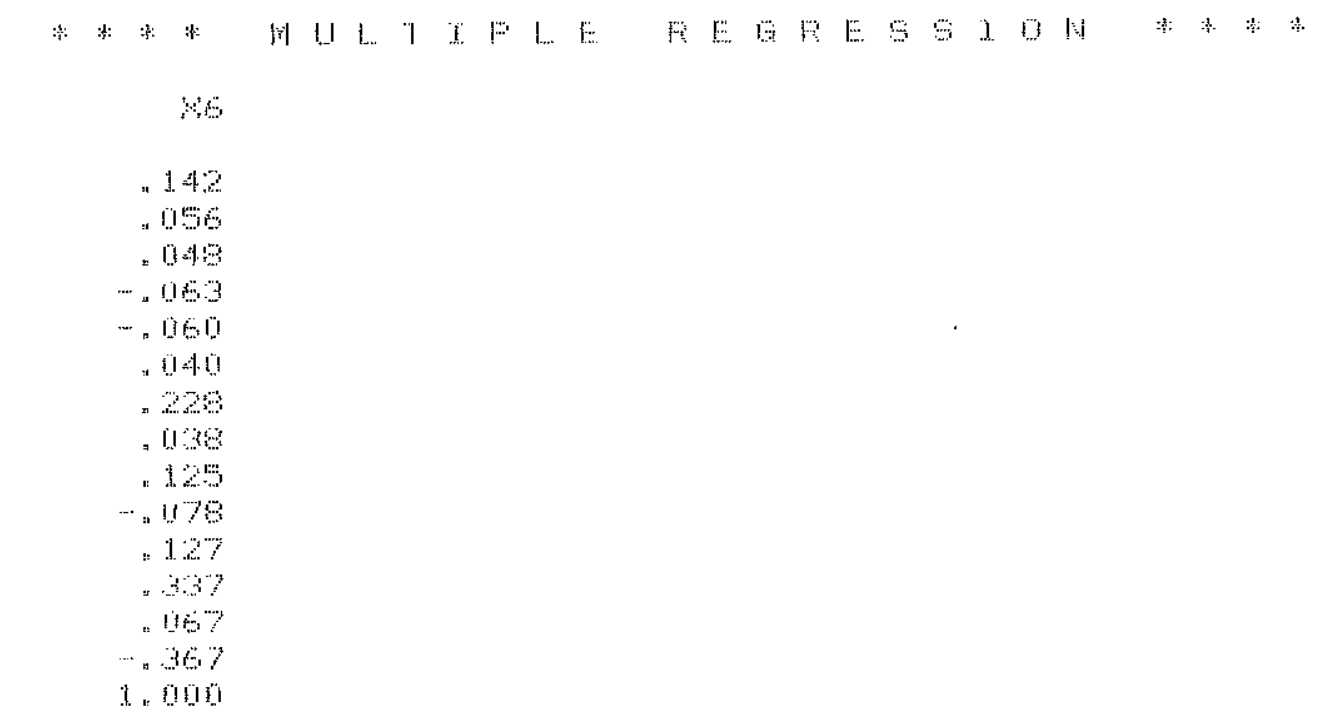




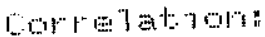

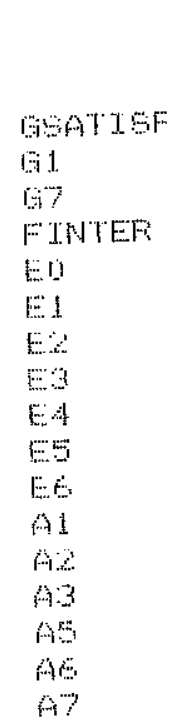

बलिए

bit.

G) FINTEF

Eis

E 1

E

\section{1000}

.... 217

-.. 45

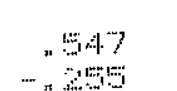
- 110
- 123
" $\mathrm{L} 6$
1.0100

"1)

.29

… 217

1. 100

1. 1100

- 4.6

110
-250

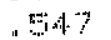

" 120

- . 1.23

.49

- 44

1. 0100

- 1199

. 19

:1174

-193

… +147

$-., 136$

" 629

- 19

- 119

. $42 \%$

$-\cdots$
$\cdots \rightarrow$

" 01

. 070

- 191

$\cdots+1.40$

ㄱ.. 196

$-x+9$

$-7,9$

$-364$

...

$-\cdots$

- .

. 016

-...

-32
.06

-... 343

$\cdots, 094$

-...

. 11

-..., 606

$\ldots .147$

$\cdots+113$

-. . 10

...

1. .800

.196

- 74

" 30

. 71

-70
-700

$+75$

+70
$+\cdots, 8$

.1165

... 26

- 102

$-4.97$

$.7 \%$
-179

$\cdots+197$

$=16$

$\begin{array}{rr}-206 & -109 \\ -137 & -.169\end{array}$

- 106

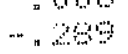

. 16

$+21$

ㄷ. 11 1 114

132

744

1. 010

.720

.65

.795

:760

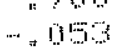

… 042

... 15

.... "120

औसी

$\ldots, 010$

$5 \mathrm{se} / \mathrm{pt}$

Bag 78

$\begin{array}{lrrrrrrrrr} & & & & & \end{array}$

pos

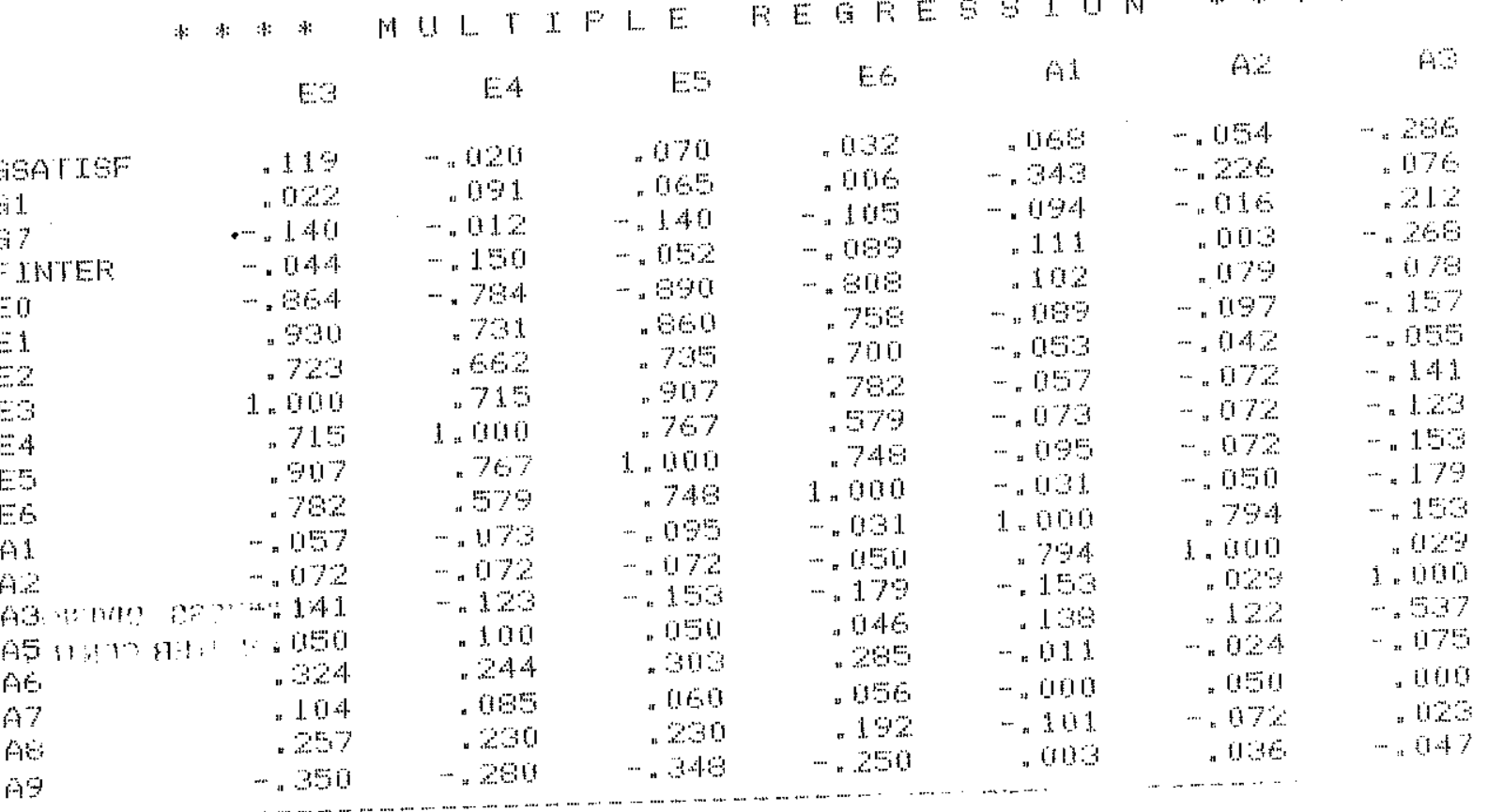




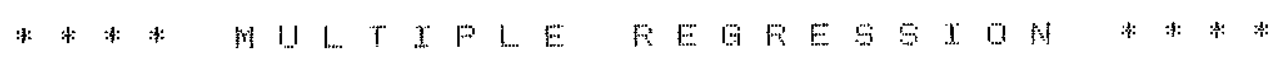

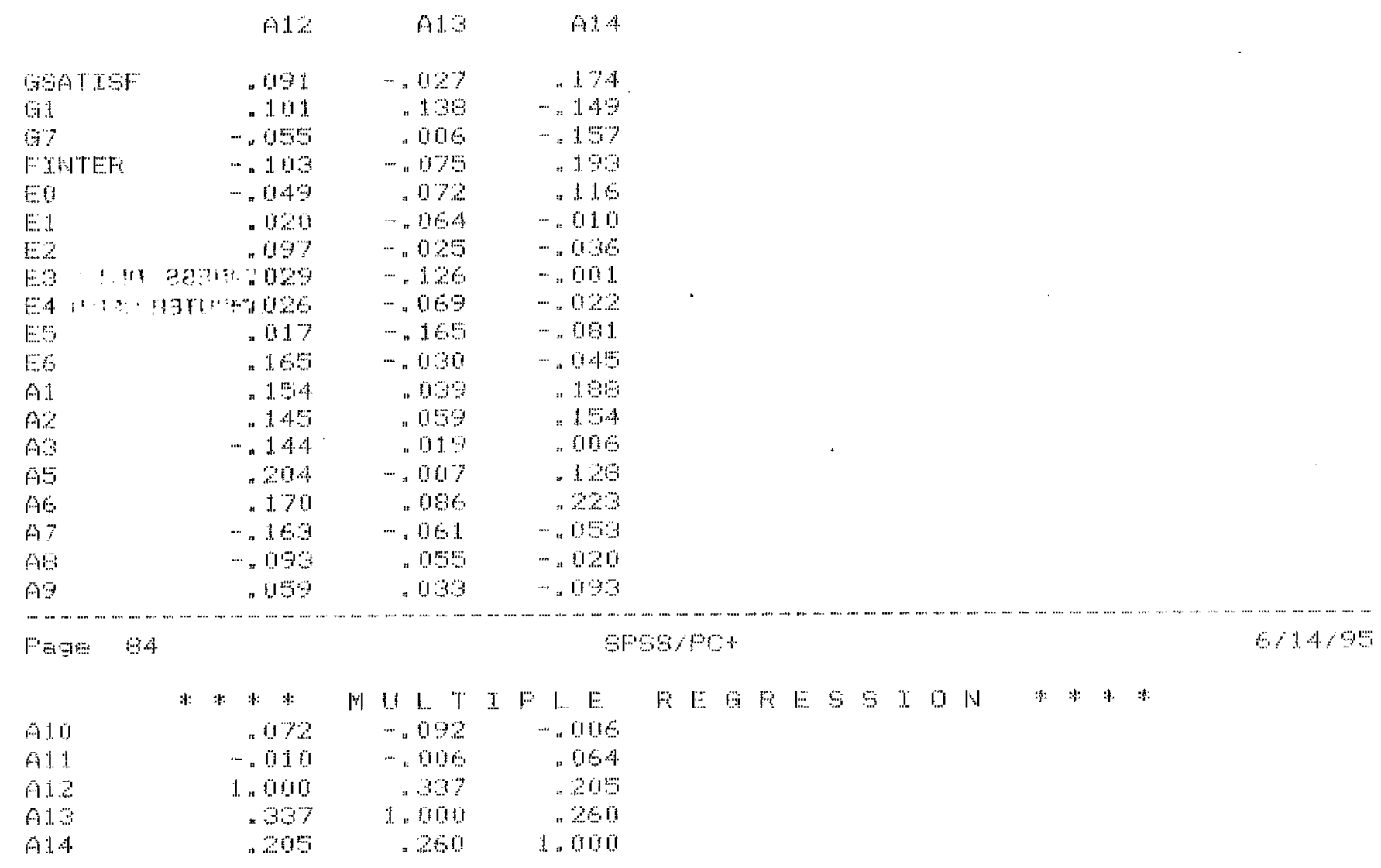




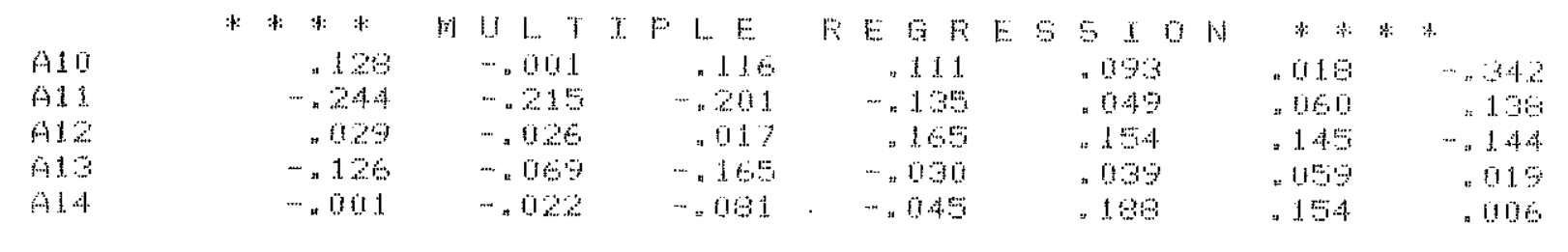
*: $:$ :

\begin{tabular}{|c|c|c|c|c|c|c|c|}
\hline & 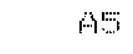 & $A B$ & 97 & $A B$ & 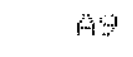 & AB & A $\perp 1$ \\
\hline nSATSF & .013 & $=36$ & . 115 & $n 20$ & $\cdots, 26$ & $=9$ & 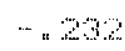 \\
\hline i. & -.139 & .060 & $-{ }^{2}, 106$ & "1) & " 01 & -245 & $\cdots, 019$ \\
\hline 80 & -20 & $-\cdots, 20$ & , 037 & $\cdots+23$ & n 300 & $\cdots, 24{ }_{n}$ & - 305 \\
\hline FWMEF & .165 & .09 & $\cdots, 163$ & : 015 & ... 20 & . 20 & ". $13 \%$ \\
\hline$E$ & .0106 & -29 & $\cdots=\mid 104$ & - . 28 & , s17 & $-03+$ & " and \\
\hline$E 1$ & - 69 & "271 & .132 & - & -.334 & +16 & $-\pi 06$ \\
\hline$E$ & 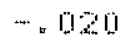 & .290 & $-\cdots, 010$ & $=310$ & -296 & $-{ }^{2}$ & -194 \\
\hline$E 3$ & . 013 & 324 & $\because 104$ & .287 & 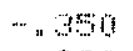 & $-12 \theta$ & $-z_{4}$ \\
\hline$E 4$ & $=100$ & , 24 & .06 & 230 & -200 & $-\cdots, 01$ & -21 \\
\hline$E 5$ & .050 & $x 300$ & $\Rightarrow 60$ & $=230$ & $-\cdots,-34$ & -116 & $-\cdots \cdot 201$ \\
\hline$E 6$ & $=116$ & - 20 & $" 1=6$ & $" 1 \%$ & I & "111 & 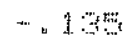 \\
\hline 1 & .138 & - . . & $\cdots, 400$ & $\cdots=101$ & .003 & -193 & -140 \\
\hline m & -12 & $-\Rightarrow$ 1 & $=410$ & $-\ldots 72$ & .136 & . 13 & "विध \\
\hline $\mathrm{AB}^{3}$ & 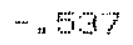 & $-07 \%$ & "1000 & .023 & $\cdots+4$ & -342 & $=13$ \\
\hline $\mathrm{A}^{\mathrm{s}}$ & 1.010 & -203 & . & -24 & -2010 & $=2+4$ & .... \\
\hline$m$ & $-\cdots 13$ & 1.981 & 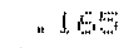 & nes & $-\cdots .7 .6$ & $\cdots \cdots$ & $\ldots{ }^{\prime}+40$ \\
\hline a? & * 1010 & $n \perp 6$ & 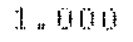 & - ЗОE & -40 & $=0.3$ & $\cdots, 167$ \\
\hline 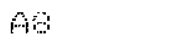 & 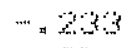 & - & -23 & 1.000 & $\cdots \cdots$ & $\cdots, 135$ & $-\cdots, 4$ \\
\hline 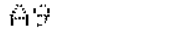 & 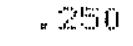 & $-\cdots 716$ & -420 & ${ }{ }_{1} \theta 46$ & 1. 040 & "66 & : \\
\hline
\end{tabular}

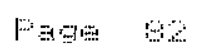

$\operatorname{sps} / \mathrm{FH}$

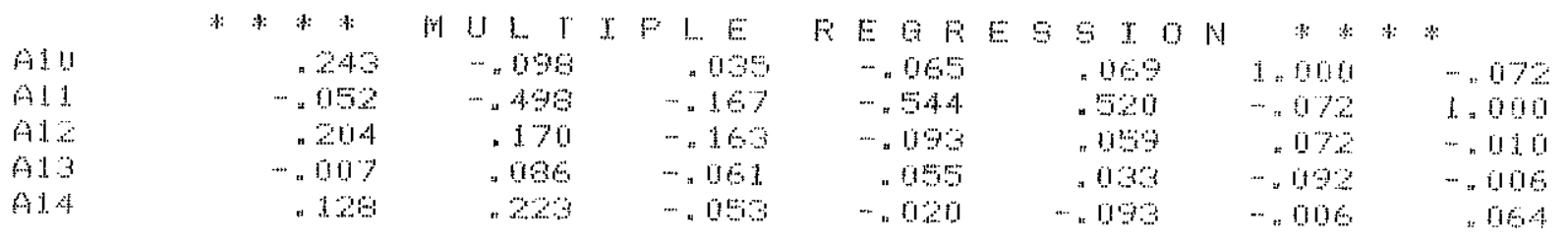




\begin{tabular}{|c|c|c|c|c|c|}
\hline 17.2 & 1 & 1 & 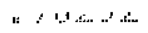 & 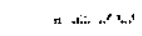 & 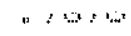 \\
\hline 2 & $-{ }^{\prime} 06067$ & $-\cdots, 0606$ & $\because 70137$ & -.96 & $=37 \%$ \\
\hline $\mathrm{AB}$ & - - & - „ 04876 & $=704 \mathrm{~L}$ & $-=5$ & ${ }_{n} 6097$ \\
\hline A & $\cdots, 07 \times 4 \times 7$ & ‥ 0964 & 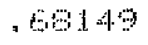 & - 1. & 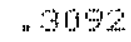 \\
\hline 47 & " 9725 & . 0922 & .70381 & $1,0,35$ & - 19 \\
\hline A & --.90640 & ${ }^{-}$" 09795 & $-8,49$ & -1.01 & $n-3147$ \\
\hline
\end{tabular}

Figan 100

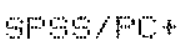

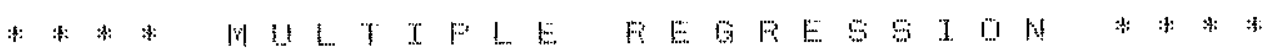

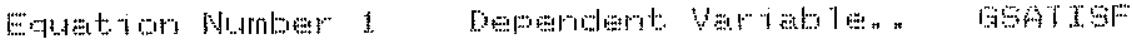

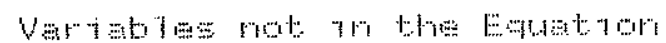

ver atol

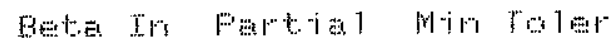

\% $59 T^{4}$

9

$4.6653-13$

$=010460$

$.44,497$

68597

$-046$

" 1616

A.1.

$3.9606-13$

$\operatorname{mos} \%$

7020

, i 1010

.09115

" 15

.9604

113

- 0110.15

"11.45

.7090

- 90 . 390

A 14

"1 4204

$.710 \% 47$

.153

- 67

. 4010.696

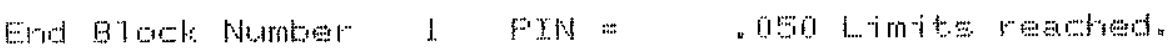

Page 101

$\mathrm{FFOH} / \mathrm{Fi}+\mathrm{H}$

s. 14.95

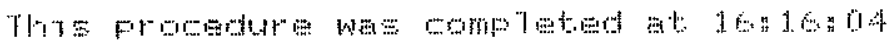

regres.

dewrowat =

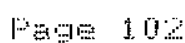

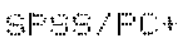

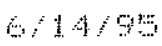

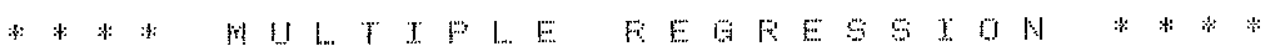

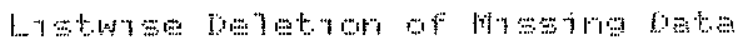

N 


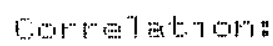

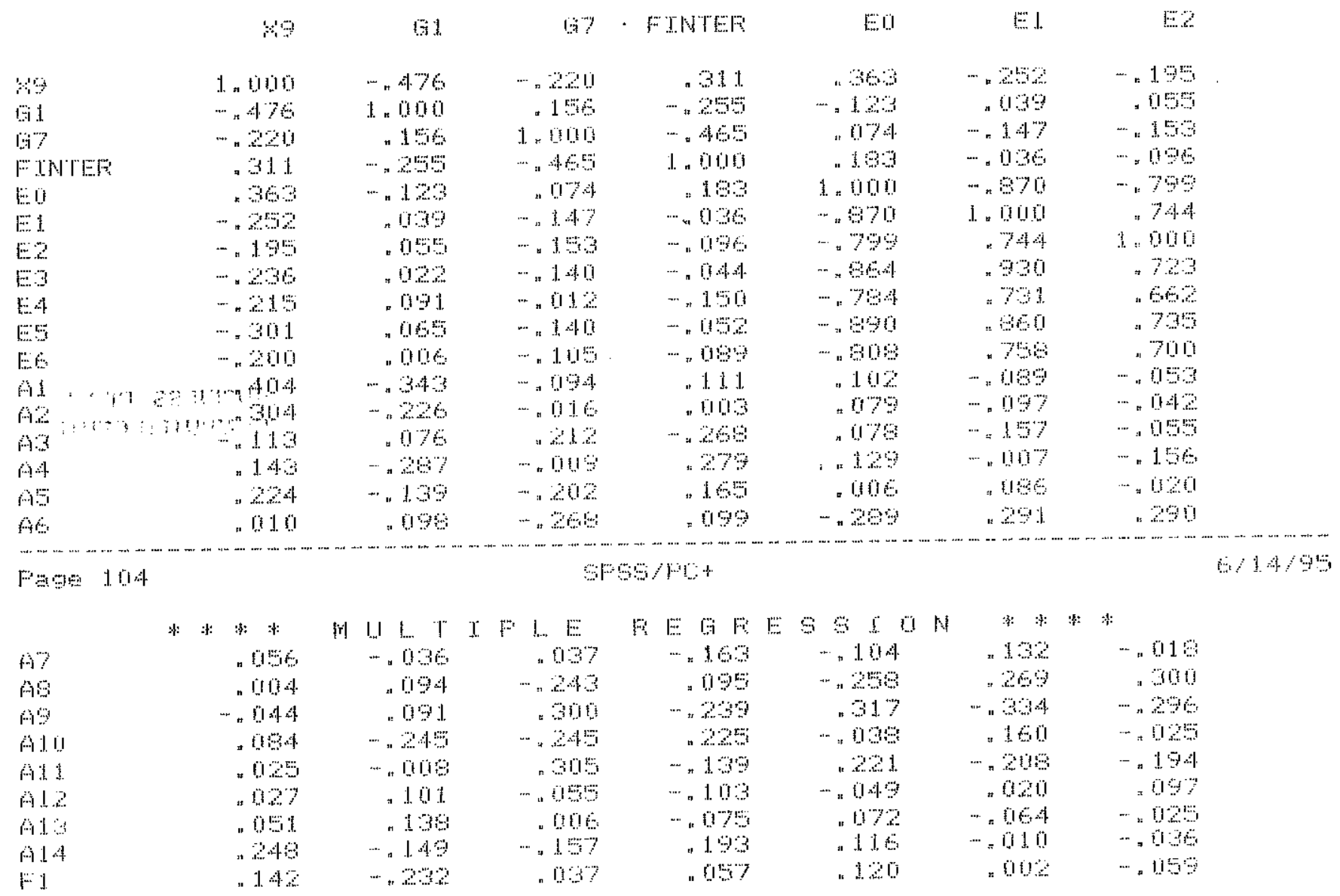


M L L I I

E3 E4 E⿺

\begin{tabular}{|c|c|c|c|c|c|c|c|}
\hline w & . & $-\cdots+2=$ & $-\cdots, 301$ & $\cdots$ & .414 & $=301$ & $\cdots=113$ \\
\hline 81 & $\Rightarrow 2$ & : 091 & " 76 & +006 & $-\cdots, 34$ & $-\quad 22$ & $=17 \%$ \\
\hline 17 & $\therefore 140$ & $-4,112$ & $\cdots, 1.40$ & $\cdots, 105$ & $\cdots, 194$ & 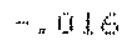 & 212 \\
\hline FINTEF & $\Rightarrow, 044$ & $\cdots=150$ & $\cdots, 0$ & -.. " & . II I I & - 0103 & -266 \\
\hline$E 0$ & $\cdots, 64$ & $\cdots 79$ & $\cdots$ & $\cdots, 60 \%$ & $=10 \%$ & $.07 \%$ & 1178 \\
\hline$E: L$ & .96 & n 73 & +6! & $\times 78$ & -.016 & ... . 1197 & $\rightarrow=1,57$ \\
\hline 2 & 473 & 162 & .7 & .700 & -013 & $\cdots, n$ & - “ \\
\hline$E 3$ & 1,8100 & .71. & .917 & $=70$ & $\cdots, \quad B$ & $\cdots+0 \%$ & $\cdots=14$ \\
\hline$E 4$ & $\times 715$ & 1.01010 & .767 & 579 & $-\cdots, 173$ & $\cdots=27$ & $\cdots=1,3$ \\
\hline 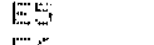 & .907 & $" 767$ & 1.0100 & -740 & 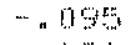 & 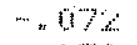 & $\cdots$. 19 \\
\hline 6 & .752 & 479 & $\div 740$ & 1.010 & $\Rightarrow$ - 31 & $\cdots,-151$ & $\cdots, 179$ \\
\hline 1 & -0.07 & $-.07 \%$ & 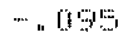 & $\cdots+131$ & $1:$ allin & .74 & $-\cdots, \quad 15$ \\
\hline 92 & $\cdots, 072$ & 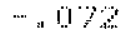 & $\cdots .0772$ & - & $=7$ & 1,0100 & $=112$ \\
\hline ब & $-" 14 L$ & $\cdots, 123$ & $\cdots, n, 1 \mathrm{t}$ & $-{ }^{2}, 17 \%$ & $\cdots, 15$ & " & $1=010$ \\
\hline 4 & 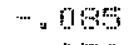 & $\cdots \cdots \ldots 1.4$ & $-\cdots .13$ &,- 040 & $=135$ & .672 & a 4 \\
\hline & $=0$ & "110 & * $01=0$ & $=04 \%$ & "136 & " 11 & 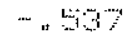 \\
\hline & -34 & 244 & .803 & .295 & $\cdots, \pi 11$ & 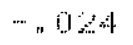 & $\cdots, 07=$ \\
\hline & $=104$ & " & - 100 & $=06$ & -... & “ $0 \mathrm{~s}^{-1}$ & ๑ 1001 \\
\hline & , 27 & -230 & .230 & $.19 \%$ & -.101 & 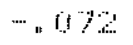 & .02 \\
\hline
\end{tabular}

Fing 106

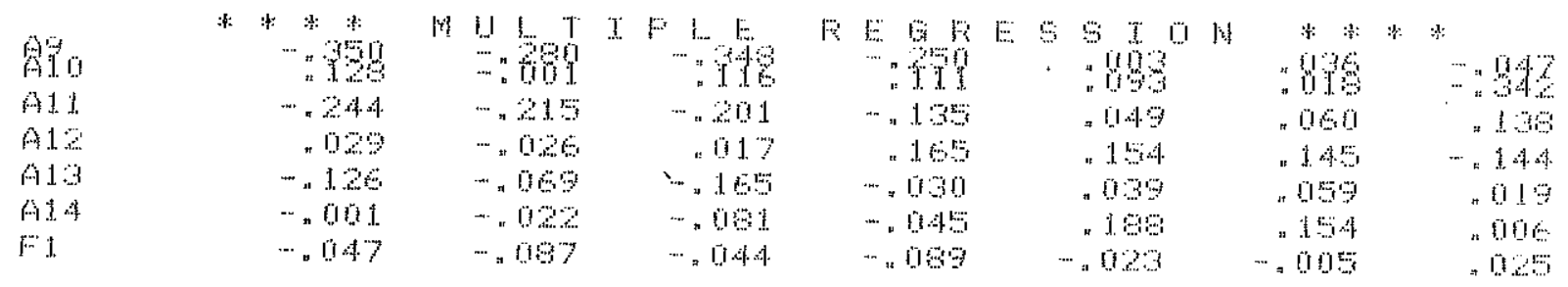

$F=107$

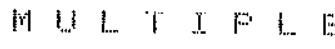

FEFE

$\therefore 24$

$-\cdots, 159$

$-2.212$

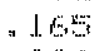

ㅁ. 10

.086

- . 020

" 050

$-100$

. 050

"046)

.13

" 12

-.. , 53

- 240

1,000

1 tim

- 240

$-166$

- Otis

$\cdots, \mathrm{I} 4 \mathrm{4}$

" 000

... 23
97

लि

\section{. 010}

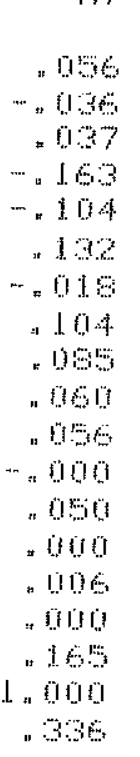

$A 9$

A I 0

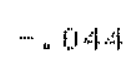

: $11,-1 ;$

$-269$

. 10

$-289$

a 201

$=200$

$+34$

- 24

.3013

-

$\cdots, 011$

… 024

$\cdots, 075$

-...

$-\cdots, 203$

1.

"1.6\%

. 66

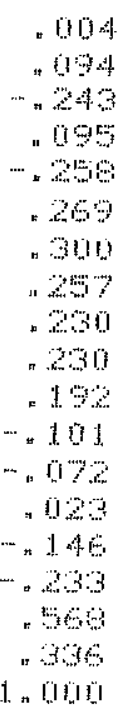

. 101

. 500

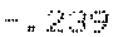

.317

... +34

$-., 256$

…, 350

$-.290$

.... 3 - 3

… 2

.003

. 036

$-0.04 \%$

$-189$

210

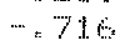

- 920

.... 64 


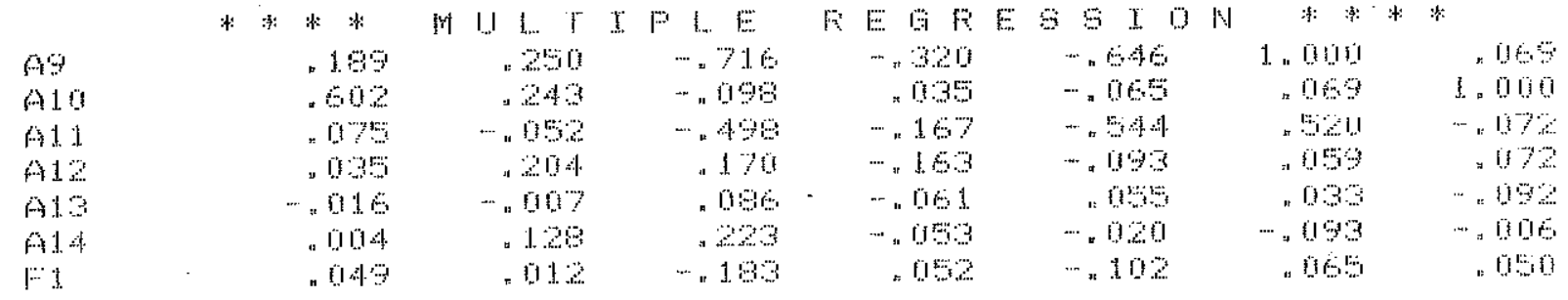

*** \#ULT

\begin{tabular}{|c|c|c|c|c|c|}
\hline & $A 1 \mathrm{I}$ & $A 2$ & A.13 & i. 14 & $F 1$ \\
\hline 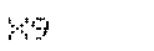 & .0 & .1127 & . & a 46 & -14 \\
\hline 81 & ${ }^{-\cdots}$. 106 & * 101 & " $1 \mathrm{se}$ & 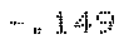 & $-29 \%$ \\
\hline 17 & $=305$ & $-\cdots, 5$ & - B16 & $\cdots, 157$ & .07 \\
\hline F INTEE & ${ }_{n} 13 \%$ & 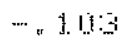 & $-{ }_{n} 0175$ & : & .057 \\
\hline Eit & $=21$ & 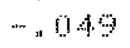 & .972 & .11. & 120 \\
\hline$E 1$ & ${ }^{2}+213$ & .620 & $\cdots, 01 \%$ & $-\cdots$ & $=010$ \\
\hline 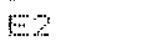 & $-1,34$ & .097 & 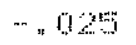 & $\cdots .830$ & 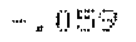 \\
\hline 5 & 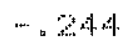 & " & $\ldots=1 \%$ & ... . & $\ldots, 0147$ \\
\hline 64 & -215 & 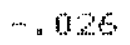 & 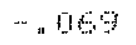 & . & $\ldots=$, is 7 \\
\hline$E 5$ & -.. n & .0117 & $\ldots, 16$ & $-{ }_{n}, 01$ & $\therefore .944$ \\
\hline 6 & $\cdots+1.5$ & 1,65 & $\cdots, 030$ & $\cdots, 045$ & ... . 189 \\
\hline A.1. & .043 & .154 & .030 & " 196 & 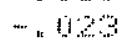 \\
\hline$a^{2}$ & .860 & .1 .45 & .05 & $=154$ &,+ 100 \\
\hline 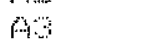 & $=130$ & -144 & " 619 & .006 & .025 \\
\hline A & .07 & . & $\cdots \cdot 018$ & .1914 & "134 \\
\hline $4=$ & 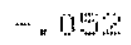 & 201 & $\cdots, .107$ & "129 & " \\
\hline$\omega$ & $\ldots .496$ & .1 .70 & $=0 \Leftrightarrow$ & $=23$ & $\cdots=183$ \\
\hline$A 7$ & -.167 & $\cdots=13$ & $\cdots, 0,0,1$ & $\cdots, 0$ & " \\
\hline $\mathrm{mo}$ & $-5,4$ & .... , & .95 & " & $\cdots \quad 102$ \\
\hline
\end{tabular}

Fiage 1.0

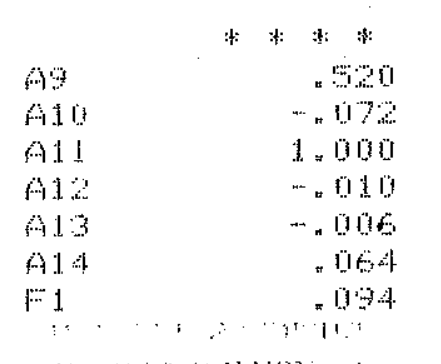

Fats 1.1.
$65 / \mathrm{Fot}$

$6 / 14 \%$
$M \quad I . . \quad$ L... T I
FE木EE
*) * :

\begin{tabular}{|c|c|}
\hline$\cdots, 093$ & ${ }_{n} 016$ \\
\hline$-n 00$ & " 050 \\
\hline$=0,4$ & - إ. \\
\hline 205 & $-\cdots$ \\
\hline$n 20$ & 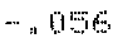 \\
\hline 1000101 & $\cdots=001$ \\
\hline t & 1.070 \\
\hline
\end{tabular}
$\begin{array}{lll}1.15 & I\end{array}$

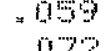
$-, 092$
$=010$
…, 1016
1. 0100
.397
43
1. 100
200

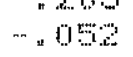

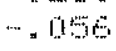
… 6104
1, gाओ

Pe 